\title{
MONey OUt of ThIN AiR: The NationWIDE NARROWBAND PCS AUCTION
}

\author{
PETER C. CRAMTON \\ University of Maryland 20742
}

The Federal Communications Commission held its first auction of radio spectrum at the Nationwide Narrowband PCS Auction in July 1994. The simultaneous multiple-round auction, which lasted five days, was an ascending bid auction in which all licenses were offered simultaneously. This paper describes the auction rules and how bidders prepared for the auction. The full history of bidding is presented. Several questions for auction theory are discussed. In the end, the government collected $\$ 617$ million for ten licenses. The auction was viewed by all as a huge success-an excellent example of bringing economic theory to bear on practical problems of allocating scarce resources.

\section{INTRODUCTION}

"By combining cutting-edge economic theory and auction procedures, the Federal Communications Commission (FCC) wrung top prices out of bidders for the next generation of paging services." So read the Wall Street Journal on August 1, 1994 (p. A4) at the conclusion of the FCC's historic auction. During five days in late July 1994, the FCC held the first of a series of auctions for radio spectrum to be used for personal communication services (PCS) - spectrum needed for tomorrow's portable phones, pagers, and other wireless communication devices. The spectrum promises to revolutionize communications over the next decade. The method of allocation promises to revolutionize the way the government allocates scarce public resources.

In August 1993, the U.S. Congress passed legislation that required the FCC to begin auctioning the spectrum. After months of debate among auction experts and industry representatives, the FCC decided in March 1994 that an innovative auction form, the simultaneous multiple-round auction, would best serve the FCC's objective of efficiency. This auction form was proposed by auction experts Paul Milgrom and Robert Wilson of Stanford University and Preston McAfee at the University of Texas. A simultaneous multiple-round auction is similar to a traditional ascending-bid "English" auction, except that, rather than selling each license in sequence, a large set of related licenses is auctioned simultaneously. In every round, a bidder can bid on any of the licenses being offered. The auction does not close until bidding has ceased on all licenses that is, until a round goes by in which there are no new bids on any of the licenses. There are three critical features of this method. First, the ascending-bid aspect allows the bidders to react to information revealed in prior rounds. This reduces the winner's curse, enabling the bidders to bid more aggressively. Second, by auctioning a large set of related licenses simultaneously, bidders are able to condition on relative prices across licenses. Since bidder valuations depend on the combination of licenses held, providing this price information on related licenses is essential to the formation of efficient aggregations of licenses. Some licenses are complements, whereas others are substitutes. The simultaneous sale of related licenses in an ascending-bid auction gives the bidders the flexibility they need to express these value interdependencies. In addition, it assures that similar licenses will sell for similar prices. Third, keeping the bidding on all licenses open until there are no new bids gives the bidders the most flexibility in switching among license aggregations as prices change. ${ }^{1}$

I am grateful to Paging Network, Inc. for supporting the research that led to this paper and to MCI Communications Corporation for initiating my involvement in the PCS auctions. The views expressed are my own, and not those of either PageNet or MCI I thank Evan Kwerel, John McMillan, David Sappington, and especially Robert Wilson for helpful comments.

${ }^{1}$ See McMillan (1994a) and Chakravorti et al. (1995) for a discussion of the FCC's auction design decision. It should be emphasized that the FCC's objective in designing the auction was not revenue maximization. Rather, the FCC seeks to maximize social welfare by allocating the spectrum in the most efficient way possible. If revenue maximization were the goal, the FCC would auction just a single license in each region, which would be inconsistent with the public interest. 
The FCC decided to begin with the simplest of the auctions, the auctioning of ten nationwide narrowband licenses. ${ }^{2}$ The ten licenses not only are small in number, but since they are nationwide licenses, the aggregation issues are much simpler. Unlike the other licenses, geographic aggregation is not an issue with nationwide licenses. The sole aggregation issue comes from the fact that a bidder can acquire up to three nationwide licenses. However, despite the small number of licenses the auction is an important one. The ten licenses amount to over $40 \%$ of the total narrowband PCS spectrum to be auctioned. From a consumer viewpoint, it made sense to allocate these high-value licenses first to hasten the development of narrowband PCS services.

This first auction was viewed by everyone as an experiment. The stakes were enormous. If the auction failed, it would mean that the FCC would have to rethink its entire auction strategy. Firms and consumers would have to tolerate further delays and more uncertainty. Fortunately, the auction was a huge success. Not only did the U.S. Treasury collect $\$ 617$ million, ten times more than preliminary estimates, ${ }^{3}$ but the licenses went to the bidders that valued them the most - the bidders most apt to make the best use of the spectrum. The time required to conduct the auction was just five days.

In the past, licenses were awarded by "comparative hearings," an FCC administrative proceeding, conducted by an administrative law judge. Comparative hearings could take years to award a license. Often the selection among similar applications was based on arbitrary factors. In 1982 Congress granted the FCC the authority to use lotteries, and in 1984 the Commission switched to lotteries to award cellular licenses. As with comparative hearings, rent seeking was common in the lottery process. The FCC received nearly 400,000 applications for cellular licenses. This onslaught of applications reduced the one apparent advantage of lotteries: speed. Moreover, in terms of awarding licenses to the firms that are best able to develop the spectrum, lotteries may be even worse than comparative hearings, since selection is random. Even when resale is allowed, lotteries are inefficient because a lottery winner has a strong incentive to misrepresent its private value of the license in negotiations with potential buyers (Cramton et al., 1987). In the cellular industry, it took ten years for efficient license aggregations to form through resale.

Economists have been arguing for auctions for decades. ${ }^{4}$ This July they finally got their way. Perhaps more surprising is that firms also lobbied for auctions. One might think that the firms would prefer being "given" the spectrum. The problem is that neither comparative hearings nor lotteries would necessarily award spectrum to firms with legitimate spectrum needs. These firms had to buy the spectrum from the lucky few that were given spectrum. With comparative hearings or lotteries, the firms still pay for the spectrum, but in a process fraught with rent seeking and delay. Firms, consumers, and taxpayers all benefit from the allocation of spectrum by auction (see MacMillan, 1994b).

The goals of this paper are modest. I begin by describing the auction rules and discussing some design issues (Section 2). Then in Section 3, I describe how firms prepared for the auction. In Section 4 , I present a detailed history of the bidding in the nationwide narrowband auction. The bidding history raises many theoretical questions, which are discussed in Section 5. I do not offer a full theoretical analysis of the simultaneous multiple-round auction, nor do I review basic auction theory. ${ }^{5}$ There are no new theorems here. Rather my intent is to present some of the issues and provide all of the data in the hope that this will stimulate future theoretical and empirical work based on these auctions.

\footnotetext{
${ }^{2}$ Narrowband refers to the relatively narrow slice of spectrum (about $50 \mathrm{kHz}$ ) associated with each of these licenses in contrast to broadband licenses, which have a bandwidth of as much as $30 \mathrm{MHz}$ (almost 1,000 times that of the narrowband licenses). Narrowband is ideal for advanced paging services, voice messaging, and e-mail. The wider bandwidth of broadband is necessary for real-time voice communication.

${ }^{3}$ It should be emphasized that the preliminary estimates made by the Congressional Budget Office and the Office of Management and Budget were based on uninformed speculation. The estimates do not reflect any analysis of either the supply or demand for PCS services. In contrast, the firms' bids are based on detailed demand studies and substantial research and development in PCS services and technologies.

${ }^{4}$ See Coase (1959), Kwerel and Felker (1985), and Kwerel and Williams (1993).

${ }^{5}$ However, I can direct the reader to several excellent surveys of auction theory: McAfee and McMillan (1987), Milgrom (1987,1989), Wilson (1992b), and Rothkopf and Harstad (1994). The reader should also consult the seminal work of Milgrom and Weber (1982).
} 


\section{Auction Rules}

The auction rules for the nationwide narrowband auction were detailed in the FCC's Third Report and Order (1994). Ambiguities were then resolved in subsequent public notices. In what follows, I summarize the rules that were used in the nationwide auction.

\subsection{What is BEING Auctioned?}

There are eleven nationwide narrowband licenses. The licenses come in three different types: $50 / 50 \mathrm{kHz}$ paired licenses, $50 / 12.5 \mathrm{kHz}$ paired licenses, and $50 \mathrm{kHz}$ unpaired licenses. With the "paired" licenses, the first number denotes the amount of outbound capacity (from transmitter to consumer unit), and the second number denotes the amount of inbound capacity (from consumer unit to transmitter). An unpaired license consists of only outbound capacity. Inbound spectrum is not the same as outbound spectrum. The inbound spectrum, which is in a very quiet (low interference) part of the spectrum $(900 \mathrm{MHz})$, can only be used for low-power transmissions. This makes it ideal for transmission from small consumer devices but ill-suited for transmission from network transmitters, which must use greater power to reach the low-power consumer devices. Hence, one $50 / 50 \mathrm{kHz}$ paired license is not the same as two $50 \mathrm{kHz}$ unpaired licenses. There are five $50 / 50 \mathrm{kHz}$ licenses (lot numbers 1 to 5), three $50 / 12.5 \mathrm{kHz}$ licenses (lot numbers 6 to 8), and three $50 \mathrm{kHz}$ licenses (lot numbers 9 to 11). License 9, one of the $50 \mathrm{kHz}$ licenses, was not up for auction because it had been set aside for Mtel as a Pioneer's Preference award. ${ }^{6}$

An auction winner gains the exclusive right to use the spectrum in accordance with FCC rules for a period of ten years. Licenses typically are renewed without charge provided the licensee has adhered to FCC rules and met build-out requirements. A bidder can win up to three licenses.

The licenses are auctioned simultaneously. In any round, a bidder can bid on any subset of the licenses for which it has applied, such that the number of bids in any round is no more than the bidder's current eligibility.

\subsection{Designated Entities}

To encourage broad participation in PCS markets, firms controlled by women or minorities (so called "designated entities" or DEs) are given a $25 \%$ bidding credit on licenses 5,8 , and 11 . This discount is designed to offset any discrimination these firms may face in raising capital and offering PCS services.

\subsection{Payment Rules}

Payments are received by the FCC at three times: (1) An upfront payment before the bidding begins assures that the bidder is serious. Any withdrawal penalties are taken from the bidder's upfront payment. (2) A down payment of $20 \%$ is paid within five business days after the close of the auction. (3) A final payment of the remaining $80 \%$ is paid within five business days of the award of the license. $^{7}$

The upfront payment, due two weeks before the auction begins, defines the bidder's maximum eligibility in any round of bidding. ${ }^{8}$ Each bidder must make an upfront payment of $\$ 350,000$ per license for the maximum number of licenses the bidder intends to bid on in any round. An upfront payment of $\$ 1,050,000$ gives a firm the ability to bid on three licenses-the maximum number a firm

\footnotetext{
${ }^{6}$ Pioneer's Preference awards were intended to be rewards to innovative firms for their "pioneering" technology. In practice, the Pioneer's Preference process suffers from the same rent-seeking problems as "comparative hearings." Under pressure from Congress, it has since been abandoned. See footnote 31.

${ }^{7}$ Licenses are awarded one to three months after the auction. The time until award depends on whether a party files a "petition to deny" the award of the license, in which case an additional review process must be carried out.

${ }^{8}$ Significant upfront payments are important to assure that the applicant is a serious bidder. The Interactive Video Data Services (IVDS) auction, held on July 27-28, was marred by several defaults by winning bidders (Washington Post, August 31,1994 , p. F1). The defaults were apparently the result of bidders not fully understanding the auction rules before the auction. A large upfront payment, which can serve as a penalty in the event of default, provides an incentive for bidders to be well prepared.
} 
can win. An upfront payment of $\$ 3,500,000$ gives the firm maximum bidding flexibility-the ability to bid on any number of licenses in any round.

\subsection{MINIMUM BID INCREMENTS}

To assure that the auction concludes in a reasonable amount of time, the FCC specifies minimum bid increments between rounds. In the early rounds, a new bid must exceed the high bid from the prior round by $5 \%$ or the fixed amounts given in Table I, whichever is greater. Opening bids must exceed the minimum initial bid given in Table I.

The FCC reserved the right to adjust the bid increments in response to bidder behavior. In the early rounds, when bidder activity is high, the FCC is likely to set larger bid increments; in the later rounds, when bidder activity is low, the FCC is likely to set smaller bid increments. ${ }^{9}$

\subsection{ACtIVITY RuLE}

The activity rule is a further device for controlling the pace of the auction. There are two stages. In the initial stage each bidder must be active on at least one license in every round. In the final stage, each bidder must be active on the maximum number of licenses he desires. The final stage begins by announcement any time after round 15 . Each bidder is allowed five waivers of the activity rule. A waiver prevents a reduction in maximum eligibility in the prior round. Waivers are applied automatically. In stage one, if a bidder fails to bid in a round, then an automatic waiver is used to maintain the bidder's eligibility. In stage two, an automatic waiver is used whenever a bidder's eligibility would otherwise fall as a result of its reduced bid activity. A bidder that does not wish to maintain its eligibility from the prior round may override the automatic waiver.

\subsection{Stopping RULE}

A simultaneous stopping rule is used to give the bidders maximum flexibility in pursuing backup strategies. All markets close if a single round passes in which no new bids are submitted on any license.

Any time after round 20, the FCC may announce that the next or any future round is the last round of bidding. A "declared final round" is a last-ditch device that would only be used after other steps are taken to hasten the pace of the auction: shortening the time between rounds, extending the hours of the auction, increasing the bid increments, and moving to stage two. Automatic waivers do not keep the auction open. However, a bidder can submit a proactive waiver to keep the auction open. As a warning to bidders, the auctioneer will announce when the auction is about to close. For example, with ten minutes left, the auctioneer announces, "There have been no new bids or proactive waivers. The auction will close in ten minutes if no new bids are received."

\footnotetext{
${ }^{9}$ The FCC established a panel of three experts to control the pace of the auction by setting the bid increment between rounds in addition to using other devices. The panel consisted of two economists, John McMillan and Charles Plott, and one professional auctioneer, William Stevenson.
} 
TABLE I.

MINIMUM BID INCREMENTS AND MINIMUM INITIAL BIDS

\begin{tabular}{ccccc}
\hline $\begin{array}{c}\text { License } \\
\text { Number }\end{array}$ & $\begin{array}{c}\text { License } \\
\text { Type }\end{array}$ & $\begin{array}{c}25 \% \text { Credit } \\
\text { for DE }\end{array}$ & $\begin{array}{c}\text { Minimum Bid } \\
\text { Increment }\end{array}$ & $\begin{array}{c}\text { Minimum } \\
\text { Initial Bid }\end{array}$ \\
\hline 1 & $50 / 50 \mathrm{kHz}$ & No & $\$ 250,000$ & $\$ 500,000$ \\
2 & $50 / 50 \mathrm{kHz}$ & No & $\$ 250,000$ & $\$ 500,000$ \\
3 & $50 / 50 \mathrm{kHz}$ & No & $\$ 250,000$ & $\$ 500,000$ \\
4 & $50 / 50 \mathrm{kHz}$ & No & $\$ 250,000$ & $\$ 500,000$ \\
5 & $50 / 50 \mathrm{kHz}$ & Yes & $\$ 250,000$ & $\$ 500,000$ \\
6 & $50 / 12.5 \mathrm{kHz}$ & No & $\$ 150,000$ & $\$ 300,000$ \\
7 & $50 / 12.5 \mathrm{kHz}$ & No & $\$ 150,000$ & $\$ 300,000$ \\
8 & $50 / 12.5 \mathrm{kHz}$ & Yes & $\$ 150,000$ & $\$ 300,000$ \\
10 & $50 \mathrm{kHz}$ & No & $\$ 125,000$ & $\$ 250,000$ \\
11 & $50 \mathrm{kHz}$ & Yes & $\$ 125,000$ & $\$ 250,000$ \\
\hline
\end{tabular}

Notes: DE = designated entity. License 9 not up for auction since awarded to Mtel as a Pioneer's Preference award.

\subsection{BID INFORMATION}

Each bidder is given a confidential bidder number at registration. Results are displayed using the bidder number, rather than the bidder's name, to preserve privacy and limit opportunities for collusion or predatory bidding. High bids and bidder numbers are posted after each round. In addition, all valid bids and bidder numbers for each license are displayed at the conclusion of each bidding round.

\subsection{Bid Withdrawal Penalty}

To discourage insincere bidding, there are penalties for withdrawing a high bid. If a high bid is withdrawn before the auction closes, the penalty is the difference between the high bid and the eventual selling price, unless the eventual selling price exceeds the withdrawn bid in which case the penalty is 0 . If the bid is withdrawn after the close of the auction, there is an additional penalty of $3 \%$ of the minimum of the winning bid and the defaulting bid. After the close of each round, there is a ten-minute withdrawal period in which the prior high bidders can withdraw their bids. If a bidder withdraws its high bid, the bidder number for the withdrawn license is listed as "FCC," and the minimum bid is the prior high bid for that license.

\subsection{Time Between Rounds}

The length of a round is initially one hour with a withdrawal period of ten minutes. At this pace, given that five days were scheduled for bidding from 9 AM to $6 \mathrm{PM}$, the total number of rounds available is 30 (if one assumes the FCC needs 20 minutes to post results and instructions for each succeeding round). The number of rounds may be increased by extending the hours or shortening the time between rounds.

\section{Bidder Preparation and Bidding Strategy}

Bidder preparation began months, if not years, before the auction. The initial task was to develop plans for narrowband PCS applications. This task involves substantial research and development, both within the firm and in joint efforts with equipment vendors, to determine the technological and cost attributes of the services. ${ }^{10}$ Marketing studies, including focus groups and demand analysis, are needed to assess demand for the services.

\footnotetext{
${ }^{10}$ A good example is the development of PageNet's VoiceNow service, which offers voice messaging with a device no bigger than a standard pager. The idea was initially conceived in-house, but then the voice pager was developed in a joint R\&D venture with Motorola.
} 
The next task that must be completed well in advance of the auction is acquiring the required capital. For most of the bidders, the auction prices are likely to be large relative to their liquid assets. Hence, the firms had to issue debt or sell equity. For example, "In January, [PageNet] began amassing a war chest with a $\$ 300$ million debt offering to supplement a $\$ 100$ million cash hoard and a $\$ 450$ million line of credit." In the words of PageNet's President Terry L. Scott, "We came loaded for bear" (Business Week, August 15, 1994, p. 34). Budget constraints undoubtedly played a role in the bidding. The most successful firms raised sufficient funds so that the budget constraints would not get in the way.

Meanwhile, the regulatory groups within the firms were busy lobbying the FCC in an effort to develop sensible auction rules that would respect their firms' interests. Most firms came before the FCC armed with an auction expert or two. In sharp contrast to the days of comparative hearings, the lobbying process was remarkably free of rent seeking. One of the great advantages of allocating the licenses by auction is that it removes most rent-seeking opportunities. Instead, the firms and the FCC focused on making the auction rules as efficient as possible. ${ }^{11}$ Given the complexity of designing and implementing efficient auction procedures, the Commission chose to hire a leading game theorist John McMillan) to advise it, and consulted extensively throughout the policy development and implementation process with outside experts.

The above tasks represented the backbone of the preparations. The next step was to develop a bidding strategy.

\subsection{VALUATION MOdEL}

The most important element in a bidding strategy is the valuation model. The better the information about values, the more successful the bidding is likely to be. In the nationwide narrowband auction, there are three types of licenses $(50 / 50 \mathrm{kHz}, 50 / 12.5 \mathrm{kHz}$, and $50 \mathrm{kHz})$. Each firm is eligible to hold up to three licenses in any geographic area. Hence, a complete valuation model should specify a value estimate for each possible auction outcome, that is, each combination of licenses. The valuation model should recognize that there are advantages to holding adjacent licenses. To reduce interference, adjacent licenses are separated with a "guard band" that cannot be used. However, if a single firm owns adjacent licenses, then it can use the guard band for transmissions, thereby making better use of the spectrum. This means that there is a premium to owning adjacent licenses. Since there are only two $50 \mathrm{kHz}$ licenses and three $50 / 12.5 \mathrm{kHz}$ licenses, there are a total of 36 possible outcomes, if one recognizes a premium for adjacency or the option of adjacency in the case of licenses that are adjacent to licenses that will be sold at a later narrowband auction. This is assuming that licenses of the same type are perfect substitutes ignoring the adjacency issue-a good assumption in the narrowband auction. Table II presents a table of the 36 different license combinations that need to be valued.

\footnotetext{
${ }^{11}$ The auction experts played a central role in this debate. As a testament to the state of auction theory, the final rules represented a near consensus among auction experts. There was disagreement on a few issues such as the degree of simultaneity but on most issues there was a consensus among the auction experts.
} 
TABLE II.

Possible License Combinations to be Valued Recognizing Value of Adjacency

\begin{tabular}{|c|c|c|c|c|c|c|c|c|c|c|c|}
\hline \multirow[b]{3}{*}{ Case } & \multirow[b]{3}{*}{$50 / 50 \mathrm{~s}$} & umber & \multirow{3}{*}{$\begin{array}{l}\text { No. } \\
50 \mathrm{~s}\end{array}$} & \multicolumn{2}{|c|}{ Adjcent } & \multicolumn{3}{|c|}{ Number } & \multicolumn{3}{|c|}{ Adjcent } \\
\hline & & & & \multicolumn{2}{|c|}{ Adjacen } & \multirow[b]{2}{*}{ Case } & \multirow[b]{2}{*}{$50 / 50 \mathrm{~s}$} & \multirow[b]{2}{*}{$50 / 12 \mathrm{~s}$} & \multicolumn{3}{|c|}{ Adjacen } \\
\hline & & $50 / 12 \mathrm{~s}$ & & $\mathrm{t}$ & Option & & & & $50 \mathrm{~s}$ & $\mathrm{t}$ & Option \\
\hline 1 & 3 & 0 & 0 & 2 & 0 & 19 & 2 & 0 & 0 & 0 & 0 \\
\hline 2 & 3 & 0 & 0 & 1 & 0 & 20 & 1 & 1 & 0 & 0 & 1 \\
\hline 3 & 3 & 0 & 0 & 0 & 0 & 21 & 1 & 1 & 0 & 0 & 0 \\
\hline 4 & 2 & 1 & 0 & 1 & 0 & 22 & 1 & 0 & 1 & 0 & 1 \\
\hline 5 & 2 & 1 & 0 & 0 & 0 & 23 & 1 & 0 & 1 & 0 & 0 \\
\hline 6 & 2 & 0 & 1 & 1 & 0 & 24 & 0 & 2 & 0 & 1 & 1 \\
\hline 7 & 2 & 0 & 1 & 0 & 0 & 25 & 0 & 2 & 0 & 1 & 0 \\
\hline 8 & 1 & 2 & 0 & 1 & 0 & 26 & 0 & 2 & 0 & 0 & 1 \\
\hline 9 & 1 & 2 & 0 & 0 & 0 & 27 & 0 & 1 & 1 & 0 & 1 \\
\hline 10 & 1 & 1 & 1 & 0 & 0 & 28 & 0 & 1 & 1 & 0 & 0 \\
\hline 11 & 1 & 0 & 2 & 1 & 0 & 29 & 0 & 0 & 2 & 1 & 1 \\
\hline 12 & 0 & 3 & 0 & 2 & 0 & 30 & 1 & 0 & 0 & 0 & 1 \\
\hline 13 & 0 & 2 & 1 & 1 & 0 & 31 & 1 & 0 & 0 & 0 & 0 \\
\hline 14 & 0 & 2 & 1 & 0 & 0 & 32 & 0 & 1 & 0 & 0 & 1 \\
\hline 15 & 0 & 1 & 2 & 1 & 0 & 33 & 0 & 1 & 0 & 0 & 0 \\
\hline 16 & 2 & 0 & 0 & 1 & 1 & 34 & 0 & 0 & 1 & 0 & 1 \\
\hline 17 & 2 & 0 & 0 & 1 & 0 & 35 & 0 & 0 & 1 & 0 & 0 \\
\hline 18 & 2 & 0 & 0 & 0 & 1 & 36 & 0 & 0 & 0 & 0 & 0 \\
\hline
\end{tabular}

Notes: $\#$ adjacent $=$ number of pairs of licenses that are adjacent. adjacent option = case has less than three licenses and includes a license that is adjacent to a license that will be sold at a later auction.

The incremental value of spectrum typically declines with the number of licenses owned. For example, suppose that a single $50 / 50 \mathrm{kHz}$ license has enough capacity to satisfy demand estimates over the next three years. The value of a second $50 / 50 \mathrm{kHz}$ license is then reduced, because its capacity will be underutilized until several years after the award. However, if two $50 / 50 \mathrm{kHz}$ licenses are essential in providing a viable service, then the value of the second $50 / 50 \mathrm{kHz}$ license may well exceed the value of the first.

In determining values, it is important not only to make point estimates of value but to gauge the extent and source of uncertainty in the estimates. This is an essential input in determining the bidding discount factor described in the next subsection.

The valuation estimates should reflect the fact that there are alternatives to winning in the nationwide auction. The most obvious alternatives are the regional, major trading area (MTA), and basic trading area (BTA) auctions. ${ }^{12}$ Indeed, only a minority of all narrowband spectrum is auctioned on a nationwide basis, as can be seen in Table III.

\footnotetext{
${ }^{12}$ Each BTA is a collection of counties, each MTA is a collection of BTAs, and each region is a collection of MTAs. In the United States, there are 3,142 counties, 493 BTAs, 51 MTAs, and 5 regions.
} 
TABLE III. SUPPLY OF NARROWBAND PCS SPECTRUM BY AUCTION

\begin{tabular}{|c|c|c|c|c|c|c|}
\hline \multirow[b]{2}{*}{ License Type } & \multicolumn{4}{|c|}{ Number of Licenses in Area } & \multicolumn{2}{|c|}{$\begin{array}{c}\text { Response } \\
\text { Channel }\end{array}$} \\
\hline & Nationwide & Regional & MTA & BTA & MTA & BTA \\
\hline $50 / 50 \mathrm{kHz}$ & 5 & 2 & 2 & & & \\
\hline $50 / 12.5 \mathrm{kHz}$ & 3 & 4 & 3 & 2 & & \\
\hline 50 kHz (outbound) & 2 & & 2 & & & \\
\hline $12.5 \mathrm{kHz}$ (inbound) & & & & & 4 & 4 \\
\hline Number per area & 10 & 6 & 7 & 2 & 4 & 4 \\
\hline Number of areas & 1 & 5 & 51 & 493 & 51 & 493 \\
\hline Outbound (kHz) & 500 & 300 & 350 & 100 & & \\
\hline Inbound (kHz) & 287.5 & 150 & 137.5 & 25 & 50 & 50 \\
\hline Total (kHz) & 787.5 & 450 & 487.5 & 125 & 50 & 50 \\
\hline Outbound (\%) & 40.0 & 24.0 & 28.0 & 8.0 & & \\
\hline Inbound (\%) & 41.1 & 21.4 & 19.6 & 3.6 & 7.1 & 7.1 \\
\hline Total $(\%)$ & 40.4 & 23.1 & 25.0 & 6.4 & 2.6 & 2.6 \\
\hline
\end{tabular}

Notes: MTA = Metropolitan Trading Area; BTA = Basic Trading Area; MTAs and BTAs are based on the Rand McNally 1992 Commercial Atlas and Marketing Guide, 123rd Edition, pp. 38-39.

A nationwide aggregation of regional, MTA, or BTA licenses is roughly equivalent to a nationwide license of the same type. Bidders must assess the demand for regional, MTA, and BTA licenses in determining values for the nationwide auction. If the bidder anticipates that the demand for regional and MTA licenses is likely to be quite strong, then it may be that the option of waiting for the regional or MTA auctions is of little value. However, if there is a reasonable possibility that the demand for regional or MTA licenses is weak, then the bidder may wish to reduce the valuations because of the regional or MTA option. Some information about regional or MTA demand may be revealed during the nationwide auction. For example, if bidders observe one or more firms known to have a nationwide strategy drop out of the nationwide auction, then it may be that they are switching to a regional or MTA backup strategy, which will increase the demand (and prices) in these auctions.

The regional, MTA, and BTA licenses may also be used to supplement nationwide licenses. For example, suppose a single nationwide $50 / 50 \mathrm{kHz}$ offers enough capacity in most MTAs. Then the bidder could bid on only those MTAs where it has a shortage of capacity. Of course, these are likely to be the most sought after MTAs. Also, for some applications it may not be technically feasible to use an MTA specific channel to supplement a nationwide service.

The response channel licenses are another alternative to a nationwide license. When used with a bidder's existing licenses, a nationwide aggregation of response channel licenses would be equivalent to a nationwide $50 / 12.5 \mathrm{kHz}$ license. Because only incumbent firms are eligible for response channels, competition in the response channel auction may be more limited, and prices may be low. However, under the proposed rules for the response channel auction, it will be nearly impossible to acquire a nationwide aggregation at auction. ${ }^{13}$ The aggregation becomes even more unlikely if it is necessary to have the same channel across MTAs or BTAs. Finally, most incumbent bidders are not eligible to bid on all MTAs (a problem that may be resolved by subsequent FCC action). Unless the rules are changed, the response channels would have to be viewed as a supplement to a nationwide service and not as a means of forming a nationwide aggregation.

The final option is acquiring needed spectrum through postauction trade or acquisition. This option may prove attractive if the bidding gets overheated, especially if some of the high bidders appear to be in a poor position to utilize the spectrum they acquire in the auction. It may be better to

${ }^{13}$ However, the FCC has decided to rethink the rules for the response channel auction as soon as more experience is gained with the simultaneous multiple-round auction. The FCC's preliminary rules were made in great haste under the assumption that the response channel licenses would have a low value-an assumption that appears false if one judges from the prices in the nationwide auction. 
purchase additional licenses after the auction. It is not uncommon for postauction prices to be below auction prices. A recent example is wine auctions in France. Throughout the 1980s, wine futures have sold at a substantial premium at wine auctions (Ashenfelter, 1989). However, since postauction purchase of spectrum may involve considerable delay, this is a better strategy for additional capacity, not essential capacity. The essential capacity for a nationwide service most likely should be acquired in the nationwide auction.

Although estimating sales prices in the regional, MTA, BTA, and postauction markets is an uncertain business, it nonetheless is important to include these options in the analysis.

Despite all this complexity, it is important that the valuation model be simple enough to be understood easily by top management. In the final analysis, valuations will be set by top management. Hence, it is important that the valuation model not only be understandable by managers, but also be flexible enough to incorporate their judgments. Otherwise, the model will be cast aside in favor of intuition and rules of thumb.

In what follows, I sketch a simple and yet flexible valuation model. This valuation model is the basis of the simulation discussed in the next section. The valuation model depends on three essential parameters:

- $r$ = ratio of the value of inbound spectrum to outbound spectrum

- $\alpha=$ the extent of diminishing returns for inbound spectrum

- $\beta=$ the extent of diminishing returns for outbound spectrum

It is assumed that values can be stated in terms of the value of the best possible outcome (case 1: three adjacent $50 / 50 \mathrm{kHz}$ licenses). Specifically, the value of any license combination as a fraction of the value of the best outcome is:

$V_{i}=\frac{T_{i}}{\max _{j} T_{j}}$

where

$T i=r \cdot A_{i}^{\alpha}+B_{i}^{\beta}$

and $A_{i}$ is the fraction of inbound spectrum in case $i$ relative to case 1 , and $B_{i}$ is the fraction of outbound spectrum in case $i$ relative to case 1, by recognizing a premium for adjacency. Table IV gives a sample value table by assuming an adjacency premium of 5\% and a premium for the option of adjacency of $2.5 \%$. The premium associated with an option of adjacency is reduced by the probability that the firm will be successful in acquiring the adjacent band in the subsequent auction.

\subsection{BIDDING Discount}

A natural bidding strategy would be to estimate values for the various license combinations, bid on the licenses that represent the best values, and then stop bidding when the high bids exceed your value estimates. Unfortunately, bidding strategy is not so intuitive. In most auction environments, this strategy leads to the winner's curse: The winner of the auction ends up paying more than what the item is worth.

To see why this happens consider the following situation: Suppose I am auctioning off a jar of quarters. You are one of 24 bidders in the room. Each bidder looks at the jar, estimates the number of quarters, and then bids up to this estimated value. Suppose that each estimate is unbiased in the sense that the expected value of the jar is equal to the estimate-some estimates are low, some are high, but the average is about right. Now suppose that you find that you have won the auction. Should you feel glad that you were able to acquire the quarters for less than your estimate? No-at least not upon reflection. You won the auction because you had the highest estimate among the 24 bidders. Winning 
means that you overestimated the value the most. Although your estimate is initially unbiased, when you find that you won the auction your estimate is biased. The true value, in all likelihood, is substantially less than your estimate.

TABLE IV.

VALUE FOR EACH LICENSE COMBINATION $(R=1.35, \alpha=0.85, \beta=0.8)$

\begin{tabular}{|c|c|c|c|c|c|c|c|c|}
\hline \multirow[b]{2}{*}{$\begin{array}{c}\text { Case } \\
i \\
\end{array}$} & \multicolumn{3}{|c|}{ Number } & \multirow[b]{2}{*}{$\begin{array}{c}\text { No. } \\
\text { Adjacent }\end{array}$} & \multirow[b]{2}{*}{$\begin{array}{c}\text { Adjacent } \\
\text { Option }\end{array}$} & \multirow{2}{*}{$\begin{array}{c}\text { Inbound } \\
\text { Spectrum } \\
A_{i}(\mathrm{kHz})\end{array}$} & \multirow{2}{*}{$\begin{array}{c}\text { Outbound } \\
\text { Spectrum } \\
B_{i}(\mathrm{kHz})\end{array}$} & \multirow{2}{*}{$\begin{array}{c}\text { Value } \\
\text { Relative to } \\
\text { Case } 1 V_{i}(\%)\end{array}$} \\
\hline & $\begin{array}{c}50 / 50 \\
\text { licenses }\end{array}$ & $\begin{array}{c}50 / 12 \\
\text { licenses }\end{array}$ & $\begin{array}{c}50 \\
\text { licenses }\end{array}$ & & & & & \\
\hline 1 & 3 & 0 & 0 & 2 & 0 & 160 & 160 & 100 \\
\hline 2 & 3 & 0 & 0 & 1 & 0 & 155 & 155 & 97 \\
\hline 3 & 3 & 0 & 0 & 0 & 0 & 150 & 150 & 95 \\
\hline 4 & 2 & 1 & 0 & 1 & 0 & 118 & 155 & 86 \\
\hline 5 & 2 & 1 & 0 & 0 & 0 & 113 & 150 & 83 \\
\hline 6 & 2 & 0 & 1 & 1 & 0 & 105 & 155 & 82 \\
\hline 7 & 2 & 0 & 1 & 0 & 0 & 100 & 150 & 79 \\
\hline 8 & 1 & 2 & 0 & 1 & 0 & 76 & 155 & 72 \\
\hline 9 & 1 & 2 & 0 & 0 & 0 & 75 & 150 & 71 \\
\hline 10 & 1 & 1 & 1 & 0 & 0 & 63 & 150 & 66 \\
\hline 11 & 1 & 0 & 2 & 1 & 0 & 50 & 155 & 63 \\
\hline 12 & 0 & 3 & 0 & 2 & 0 & 40 & 160 & 60 \\
\hline 13 & 0 & 2 & 1 & 1 & 0 & 26 & 155 & 54 \\
\hline 14 & 0 & 2 & 1 & 0 & 0 & 25 & 150 & 52 \\
\hline 15 & 0 & 1 & 2 & 1 & 0 & 13 & 155 & 48 \\
\hline 16 & 2 & 0 & 0 & 1 & 1 & 105 & 106 & 71 \\
\hline 17 & 2 & 0 & 0 & 1 & 0 & 105 & 105 & 71 \\
\hline 18 & 2 & 0 & 0 & 0 & 1 & 101 & 101 & 68 \\
\hline 19 & 2 & 0 & 0 & 0 & 0 & 100 & 100 & 68 \\
\hline 20 & 1 & 1 & 0 & 0 & 1 & 63 & 101 & 55 \\
\hline 21 & 1 & 1 & 0 & 0 & 0 & 63 & 100 & 55 \\
\hline 22 & 1 & 0 & 1 & 0 & 1 & 50 & 101 & 51 \\
\hline 23 & 1 & 0 & 1 & 0 & 0 & 50 & 100 & 51 \\
\hline 24 & 0 & 2 & 0 & 1 & 1 & 26 & 106 & 43 \\
\hline 25 & 0 & 2 & 0 & 1 & 0 & 26 & 105 & 43 \\
\hline 26 & 0 & 2 & 0 & 0 & 1 & 25 & 101 & 41 \\
\hline 27 & 0 & 1 & 1 & 0 & 1 & 13 & 101 & 36 \\
\hline 28 & 0 & 1 & 1 & 0 & 0 & 13 & 100 & 36 \\
\hline 29 & 0 & 0 & 2 & 1 & 1 & 0 & 106 & 31 \\
\hline 30 & 1 & 0 & 0 & 0 & 1 & 51 & 51 & 39 \\
\hline 31 & 1 & 0 & 0 & 0 & 0 & 50 & 50 & 38 \\
\hline 32 & 0 & 1 & 0 & 0 & 1 & 13 & 51 & 24 \\
\hline 33 & 0 & 1 & 0 & 0 & 0 & 13 & 50 & 23 \\
\hline 34 & 0 & 0 & 1 & 0 & 1 & 0 & 51 & 17 \\
\hline 35 & 0 & 0 & 1 & 0 & 0 & 0 & 50 & 17 \\
\hline 36 & 0 & 0 & 0 & 0 & 0 & 0 & 0 & 0 \\
\hline
\end{tabular}

Notes: \# adjacent $=$ number of pairs of licenses that are adjacent. adjacent option = case has less than three licenses and includes a license that is adjacent to a license that will be sold at a later auction. I have chosen the parameter values $r, \alpha$, and $\beta$ to fit the auction outcome; they are not the values used by PageNet.

The winner's curse is commonly observed. ${ }^{14}$ I have conducted the jar of quarters experiment dozens of times with students and business executives. Every time, I make money. Usually $\$ 8$ in

\footnotetext{
14 The winner's curse was originally studied in Wilson (1969) and then Ortega-Reichert (1968) and Rothkopf (1969). See Capen et al. (1971) for a discussion of the winner's curve in bidding for oil leases and Hendricks et al. (1987) for empirical
} 
quarters sells for between $\$ 10$ and $\$ 20$. During a demonstration of the simultaneous multiple-round auction in January $1994,{ }^{15}$ winning bidders lost hundreds of fictitious dollars bidding on licenses worth hundreds of dollars. The bidders were FCC staff and representatives from several telecommunications companies.

Sophisticated bidders avoid the winner's curse by discounting the value estimates to reflect the negative information that winning conveys. The fact that you won means that no one else was willing to pay as much. The relevant estimate is the value conditional on winning, that is, the expected value conditional on the fact that your estimate is the highest of the 24 estimates. You can safely bid up to this conditional value without fear of losing money.

In understanding the winner's curse, it is helpful to think of two extreme types of auctions: a common value auction and a private value auction. The jar of quarters example is stark in that it is a pure common value auction. The item being auctioned is worth the same to everyone, and each bidder makes independent estimates of this uncertain value. The winner's curse is greatest in this extreme case. At the other extreme is a private value auction in which the item is worth different amounts to each bidder, and each bidder knows what it is worth to him, but not what it is worth to the others. In a pure private values auction, the strategy of bidding up to your private value is the best strategy. The winner's curse is not an issue, because winning does not convey any negative information about value. Winning simply means that the item is worth more to you than to the others.

Bidding on oil leases is a common value auction. The oil is worth the same to all bidders. Each bidder makes an estimate of this value, but no one knows what the true value is. It depends on how much oil is in the ground, how costly it is to extract, the future price of oil, etc. An example of a private value auction would be an art auction, where the art is purchased for private consumption rather than resale. A bidder's value of the art depends solely on the bidder's particular preferences.

The broadband PCS auction is a hybrid of these two auction forms. There are both private value and common value components. Some bidding discount is necessary, but the discount is not as large as in a pure common value auction. The discount depends on the extent of common value uncertainty. The key question is, To what extend do firms' value estimates differ because firms make different assumptions about factors that affect the value of the licenses to all bidders?

3.2.1 Sources of Common Value Uncertainty. There are several potential sources for common value uncertainty. All relate either to the cost of alternative sources of spectrum or to the profitability of future narrowband PCS markets.

- The FCC has reserved a third megahertz of narrowband PCS spectrum for future use. When will the FCC auction the third megahertz? Who will be eligible to bid?

- What will the sale prices be in the regional, MTA, BTA, response channel, and postauction markets?

- How competitive will the narrowband PCS markets be? What rates will the market support? How fast will costs decline with technological improvements?

- How fast will the narrowband PCS market grow? What market share will the firm be able to sustain?

The answer to each of these questions will affect estimates of value to all bidders. To the extent that firms draw different conclusions, estimates of common value will differ. These potential differences imply that winning will convey negative information. Value estimates should be discounted to avoid the winner's curse.

evidence. For experimental evidence on the winner's curse, see Bazerman and Samuelson (1983), Dyer et al. (1989), Giliberto and Varaiya (1989), Kagel and Levin (1986), Kagel et al. (1987, 1989), Levin et al. (1994), Thaler (1988), and Thiel (1988).

${ }^{15}$ The demonstration was part of a conference, "Spectrum Allocation: Auction Designs and Their Potential Impacts" at the Annenberg Washington Program in Washington, DC, organized by Barry Nalebuff and sponsored by the Sloan Foundation and the Yale School of Organization and Management. 
3.2.2 Setting the Discount. Determining an appropriate bid discount is part art and part science. First, the science: In an ascending-bid auction, the optimal bidding rule is to bid up to the estimate of value conditional on winning. In a common value auction, this conditional valuation can be determined once a distribution of uncertainty is specified.

Suppose there are $n$ bidders $(i=1, \ldots, n)$, and each bidder has an estimate $x_{i}=v+\varepsilon_{i}$, where $v$ is the true value and $\varepsilon_{i}$ (the error in the estimate) is normally distributed with mean 0 and standard deviation $\sigma$. This means that each bidder's estimate is unbiased (since the mean error is 0 ). However, the maximum of the $n$ estimates is biased according to the normal bias factors in Table V. For example, with 16 bidders and a standard deviation of $\$ 10$ million, the maximum of the 16 estimates is biased by $\$ 17.7$ million. Therefore, each bidder should reduce its estimate of value by $\$ 17.7$ million. The size of the reduction depends on the number of bidders and the amount of uncertainty. This is true in general. A larger discount is needed the more uncertainty there is and the greater the number of bidders.

\section{TABLE V.}

NORMAL AND LOGNORMAL BIAS FACTORS IN SYMMETRIC Common VALUe Auction

\begin{tabular}{c|cccccc}
\hline & \multicolumn{5}{c}{ Number of Bidders } \\
\cline { 2 - 6 } & \multicolumn{7}{c}{ Form of Uncertainty } & 2 & 4 & 8 & 16 & 32 \\
\hline Normal & .56 & 1.03 & 1.42 & 1.77 & 2.07 \\
Lognormal with $\sigma=.5$ & 1.27 & 1.57 & 1.89 & 2.22 & 2.56 \\
Lognormal with $\sigma=1$ & 1.52 & 2.21 & 3.08 & 4.17 & 5.48 \\
\hline
\end{tabular}

Notes: Both models assume that the marginal distribution of the common value has an infinite variance. $\sigma$ is the standard deviation of the conditional distribution of the log of the value in the lognormal model. With normal uncertainty, the bias factor is the number of standard deviations of bias (e.g., with 2 bidders the highest estimate is biased by .56 standard deviations; with lognormal uncertainty, the bias factor is the factor by which the highest estimate is biased (e.g., with 2 bidders and $\sigma=.5$ the highest estimate would be unbiased if it was discounted by 1/1.27). Source: Wilson (1992a, p. 25).

Alternatively, suppose that the estimates have an unbiased lognormal distribution, as is the case in the oil industry. ${ }^{16}$ Then, winning among $n$ bidders tells you that the estimate is biased by the lognormal bias factors in Table V. For example, with $\sigma=.5$ (this means that the log of the estimates has a standard deviation of .5) and 16 bidders, then the maximum of the 16 estimates is biased by a factor of 2.22. Therefore, a bidder with an unconditional estimate of \$20 million should stop bidding when the bidding reaches $20 / 2.22=\$ 9$ million.

An important difference between the above settings and the nationwide auction is that in the nationwide auction, there are several equivalent items for sale. Suppose that there are 20 bidders, 10 equivalent items for sale, and each bidder has a demand for one item. In this case, the bidders will want to condition their valuation on the fact that they have the tenth highest of the 20 estimates. But the tenth highest estimate is unbiased. No correction is needed! In the nationwide auction, the number of bidders will be revealed before the auction, but the number of licenses each firm demands will range from one to three and will not be known. In this setting, it is not straightforward to determine how much estimates should be discounted to avoid the winner's curse. However, the bias factors in Table V greatly overstate the bias of the estimate of a winning bidder in the nationwide PCS auction. A practical approach to determine the bias in estimates is to keep track of bidder activity. The sooner bidders drop out and the greater the number that drops out, the more biased is the estimate.

A second important difference between the settings above and the nationwide auction is that the bidders are not identical. Each firm has particular capabilities and has different plans for using the spectrum. If bidders drop out of the auction because of differences in private values, then nothing is learned from their exit. The bidding discount must be reduced to the extent that differences in private values are important. Private values depend on the unique attributes of the firms. Ideally, each firm

\footnotetext{
${ }^{16}$ Lognorrnal uncertainty arises when the estimate is the product of a number of independent random events.
} 
should determine its competitive advantage (costs, technology, marketing, etc.) and those of its competitors. When a competitor drops out of the auction, the firm should ask, Why? Was its estimate of value low because of a low private value or a low estimate of common value? Unfortunately, answering this question is difficult since bidder identities are not revealed. The bidders know that someone dropped out, but they do not know who.

One way to get a rough idea of how biased winning estimates are is to simulate the nationwide narrowband auction. This approach is discussed later in this section.

\subsection{WhICH LICENSES TO BID ON?}

An obvious strategy is simply to bid on the set of licenses that represents the best value given the current prices. Indeed, this is probably the best strategy much of the time. However, several complications need to be addressed. The first stems from the fact that bidders can acquire multiple licenses. As a result, a bidder must recognize that its demand for an additional license will raise prices. For example, a bidder that prefers two $50 / 50 \mathrm{kHz}$ licenses to one $50 / 50 \mathrm{kHz}$ and one $50 \mathrm{kHz}$ license at the current prices may be better off dropping down to one 50/50 and one 50, because holding out for two 50/50s will raise the price on all 50/50s. Hence, the decisions about what to go for and when to drop down to less desirable licenses are complex. The correct action requires a good sense of the demand for the various types of licenses.

A second complication related to the first is signaling. Since decisions of when to drop down depend on one's beliefs about demand, bidders may attempt to influence those beliefs through their bidding.

A bidder can signal a high value, thereby warning rivals to look elsewhere, by jump biddingbidding well in excess of the minimum bid.

Another form of jump bidding is bidding on more licenses than one is eligible to win (i.e., more than three). Doing so exposes the bidder to substantial bidding penalties if the bids turn out to be winners. However, if the bids are placed at a time when bidding activity is still strong, then the move can signal strength and hasten the auction along.

It is important to be cognizant of the activity rules when one is deciding on which licenses to bid. During the first stage of the auction, each bidder must be "active" in every round. A bidder is active if it is the current high bidder or it submits at least one bid in the round. In the first stage, activity on a single license is sufficient to maintain full eligibility. Hence, it is possible in stage one to "hide in the grass," bidding the minimum bid on the cheapest license. In the final stage (to be announced by the FCC after round 15), a bidder must remain active on the number of licenses it wishes to remain eligible for. A bidder active on only a single license would only be eligible to bid on one license in future rounds. Stage two, then, forces a strong bidder desiring multiple licenses to come out of the grass. However, each bidder has five waivers to the activity rules, so that withdrawals can be faked at little cost. (This is one of the costs of allowing waivers and concealing their use: The bidders get less accurate information about when others drop out, which aggravates the winner's curse.) A waiver must be used in any round in which the activity rule it not satisfied to prevent a reduction in eligibility.

Satisfying the activity rules is not a problem in the first stage. The bidder always has the option of bidding the minimum bid on the most underpriced license. In the final stage, satisfying the activity rule can be an issue. For example, in a particular round the most profitable bid may be for a single $50 / 50 \mathrm{kHz}$ license, with a pair of $50 / 12.5 \mathrm{kHz}$ licenses being the second most profitable set of licenses on which to bid. In subsequent rounds, the price of the 50/50s may increase to the point where the pair of 50/12.5s is more desirable. Under the final-stage rules, eligibility for the pair of $50 / 12.5$ s would be lost. I view a situation like this as unlikely. Typically, bidders will want to reduce activity as prices rise, rather than the reverse. Moreover, a bidder can determine at any point in the bidding whether there is a possibility that the bidder will want to increase its activity in later rounds. In this case (which is unlikely), the opportunity cost of reducing its activity must be included in the decision to bid on fewer licenses. The availability of waivers plays a role in determining this opportunity cost. If all five waivers are available, then the opportunity cost may be low; if only a 
single waiver is available, then the opportunity cost may be substantial. In my mind, this is one of the main uses of waivers.

\subsection{Simulation of the Auction}

To better understand these strategy issues and the implications of various auction rules, I constructed a simulation of the nationwide narrowband auction. By conducting thousands of computer simulations, one is able to get an empirical sense for how the auction rules affect the auction outcome. From the FCC's point of view, it is especially important to understand how to control the pace of the auction so that the auction concludes in a timely fashion. Simulations are also useful in testing and improving bidding strategies. Although existing auction theory is enormously helpful in understanding issues of auction design and bidding strategy, the spectrum auctions are too complex for the theory to offer definitive answers. The theory needs to be supplemented with analysis from auction simulations as well as judgment.

The simulation is based on the valuation model described earlier. However, for the simulation it is necessary to introduce uncertainty. I use a simple yet widely applicable model that is a hybrid of common and private value models. ${ }^{17}$ The model has five sources of uncertainty. The first is the common value factor $f_{c}$, which is normally distributed with mean one. Each firm observes an independent estimate $e=v \cdot f_{c}$ of the common value $v$, the average industry value of three adjacent $50 / 50 \mathrm{kHz}$ licenses (case 1). Since $f_{c}$ has a mean of one, the estimates are unbiased. The next source of uncertainty is the private factor $f_{p}$, which also is normally distributed with a mean of one. This independent factor determines a firm's value of three adjacent $50 / 50 \mathrm{kHz}$ licenses (case 1). The firm's estimated value of case 1 is $v \cdot f_{c} \cdot f_{p}$, and the true value is $v \cdot f_{p}$. The estimated value of all other cases is a fraction of the case 1 value, where the fraction is determined from the function $V_{i}(r, \alpha, \beta)$, as described earlier. Each of the variables, $r, \alpha$, and $\beta$ is an independent firm-specific normal random variable with mean and standard deviation given in Table VI. To get an empirical sense of how the bargaining outcome depends on the various parameters, it is necessary to vary the parameters across simulations. In any simulation, these parameters are the same for all firms and are common knowledge. For each simulation, the parameters are drawn from independent uniform distributions with lower and upper bounds given in Table VI. These distributions are roughly consistent with the outcome of the actual auction. The number of bidders $n$ is chosen so that all integers from 10 to 20 are equally likely. $n$ should be viewed as the number of serious bidders-bidders that have a reasonable chance of winning one or more licenses.

17 Wilson $(1981,1992 b)$ analyzes a related model in which the value estimate is the product of a common and private factor. 
TABLE VI.

VALUE Estimate Of LiCEnSE Combination

$i=v_{i}=v \cdot f_{c} \cdot f_{p} \cdot V_{i}(r, \alpha, \beta)$

\begin{tabular}{|c|c|c|c|c|c|}
\hline \multicolumn{3}{|c|}{$\begin{array}{l}\text { Sources of Uncertainty Within Simulation } \\
\text { (independent normal distributions) }\end{array}$} & \multicolumn{3}{|c|}{$\begin{array}{c}\text { Sources of Variation Across } \\
\text { Simulations (independent uniform } \\
\text { distributions) }\end{array}$} \\
\hline Variable & Mean & $\begin{array}{c}\text { Standard } \\
\text { Deviation }\end{array}$ & Parameter & $\begin{array}{l}\text { Lower } \\
\text { Bound }\end{array}$ & $\begin{array}{l}\text { Upper } \\
\text { Bound }\end{array}$ \\
\hline Common value factor, $f_{c}$ & 1 & $\sigma_{c}$ & $\sigma_{c}$ & .1 & .3 \\
\hline Private value factor, $f_{p}$ & 1 & $\sigma_{p}$ & $\sigma_{p}$ & .1 & .3 \\
\hline Inbound to outbound value, $r$ & $\mu_{r}$ & $\sigma_{r}$ & $\mu_{r}$ & 1 & 1.7 \\
\hline Returns to inbound spectrum, $\alpha$ & $\mu_{\alpha}$ & $\sigma_{\alpha}$ & $\mu_{\alpha}$ & .75 & .95 \\
\hline Returns to outbound spectrum, $\beta$ & $\mu_{\beta}$ & $\sigma_{\beta}$ & $\begin{array}{r}\mu_{\beta} \\
\text { Common value } \\
(\$ \mathrm{M}), v\end{array}$ & $\begin{array}{l}.7 \\
150\end{array}$ & $\begin{array}{c}.9 \\
250\end{array}$ \\
\hline
\end{tabular}

Notes: The common value $v$ is the average industry value of case 1 (three adjacent $50 / 50 \mathrm{kHz}$ licenses). The parameters $\sigma_{r}, \sigma_{\alpha}$, and $\sigma_{\beta}$ all equal .2; they do not vary across simulations.

The final element of the simulation is the bidding. In this preliminary simulation, I ignore issues of signaling, asymmetric bidders, and strategic issues of acquiring multiple licenses. Instead, I assume that bidders adopt a conservative and sincere strategy. In any round, the bidders place bids on the licenses that represent the best value given the current high bids and their valuation estimates. The bid on any license is equal to the minimum bid plus a small random term. The random term avoids ties. More importantly, the random term reduces the chance that all the bids for a particular license type will fall on the cheapest license, when the differences in prices are small. Each random term is drawn independently from a uniform distribution on $[0, h]$. For each simulation, the parameter $h$ is drawn from the uniform distribution from $\$ 1 \mathrm{k}$ to $\$ 1 \mathrm{M}$.

The bidders continue to bid so long as prices are below values. This strategy mimics the symmetric equilibrium in a standard English auction. The bids maximize the firm's profit given the current information, if one assumes these bids turn out to be winning bids. In calculating profit, the bidders adjust their valuation estimates to reflect any negative information conveyed by wining.

\subsection{How Biased are Winning Estimates?}

For the above bidding strategy to be an equilibrium, the bidders must correctly discount their estimates to avoid the winner's curse. I calculate the bias of winning estimates using an iterative process. I begin by "guessing" that the winning bias is $\sigma_{c}$, so that bidders discount their estimates by the factor $1 /\left(1+\sigma_{c}\right)$. I then run 1,000 simulations and estimate the bias as a function of the model parameters, using linear regression. I then run 1,000 more simulations, discounting value estimates according to the estimate of bias from the regression. These simulations are then used to re-estimate the bias. I continue this process until the regression coefficients have converged. The stable model of bias is then used to determine the bidding discount in all subsequent simulations.

Based on the simulations, I estimate the bias to depend on the model parameters as follows: ${ }^{18}$

Bias $=.002 n+.78 \sigma_{c}-.13 \sigma_{p}-.05$

The simulation confirms that the bias of the winning estimates is largely a function of the amount of common value uncertainty. Bias increases with the number of bidders and decreases with private value uncertainty. Hence, if there are 20 bidders and the common and private value factors have standard deviations of $20 \%$, then I would estimate the bias to be $12 \%$. In this setting, sometimes the

\footnotetext{
${ }^{18}$ Given the multiplicative valuation model, I also estimated bias with a log-linear model. Both models explain about a third of the variance. Including other parameters, such as mur, mualfa, and mubeta, add little.
} 
bias is greater than $12 \%$ and sometimes it is less than $12 \%$, but on average the bias of the winning estimates is $12 \%$.

The bias of an estimate is also likely to depend on the size of one's private value factor. If one has a small private value factor for a license and yet still wins, it is more likely that the estimate of common value is biased. Similarly, if one's private value factor is large, one's estimate of common value is probably less biased. Thus far, I have not included a bidder's private value factor in the estimate of bias.

Conducting mock auctions is essential to developing a good bidding strategy. It is the best way for top management to become familiar with the auction process and test strategy ideas. Every time I run a mock auction new insights come to light-insights that would not be discovered by simply thinking or brainstorming about strategy. Most of the large bidders conducted some form of mock auction as part of their preparations. In my work for PageNet, I created and ran two mock auctions. In the first, the bidders were given a value table and instructed to bid so as to maximize their profit. In the second mock auction, each bidder was given a value table as well as a computer that ran the bidding model. In this way, every member of the bidding team had experience with the bidding model. In each round, the model would suggest a bidding strategy given the bidders' valuations and the current prices. The bidders then used this information as a guide in deciding how to bid. There was not a problem with the bidders blindly following the advice of the computer. Experimentation was common.

The simulation was useful in running the mock auctions. We anticipated that there would be about twenty serious bidders in the real auction. Since we did not have twenty people on the bidding team, we ran the mock auctions with five real bidders and 15 computer simulated bidders. This combination of real and simulated bidders worked very well.

\section{BIDDING BEHAVIOR}

"A collective gasp swept the ballroom as the first round of results was announced: Bidding had started at \$20 million each for two licenses and \$10 million for five others." (Washington Post, July 26,1994, p. D1. ) With the FCC's minimum initial bid set at $\$ 250,000$ to $\$ 500,000$, few anticipated such high opening bids. This was an immediate indication that bidders would not bid the minimum. Jump bids would be common throughout the bidding. Indeed, the bid increments, which led to so much discussion before the auction, turned out not to play an important role in the bidding. The large bids in the opening round led many to speculate that the auction would conclude on Tuesday after only two days of bidding. ${ }^{19}$ Like so many predictions this turned out to be far from true. ${ }^{20}$ The auction would continue until Friday, only five hours before the bidding room (the Blue Room at Washington's Omni Shoreham Hotel) had to be cleared to begin preparations for a Saturday wedding.

In this section, I present the full history of bidding in the auction. The auction is of special interest because it is the first time the FCC used an auction to allocate spectrum. Moreover, the auction represents the first use of the simultaneous multiple-round auction, the auction form to be used in the broadband PCS auctions. Hence, this experience provides the best data available on bidding behavior in a simultaneous multiple-round auction. Much can be learned about the broadband auctions from a careful study of this bidding history.

\subsection{SUMMARY OF THE BIDDING}

The auction began on Monday morning, July 25, and concluded shortly before noon on Friday, July 29. The auction closed after 46 rounds. Figure 1 displays the total of the high bids and a measure of bidding activity, the number of new bids in each round. The total of the high bids increased rapidly

\footnotetext{
19 "Many speculated, however, that the winning bidders would establish themselves by midday on Tuesday." New York Times, July 26, 1994, p. D1.

${ }^{20}$ By Thursday, participants were more cautious in their predictions: "But few people were willing to make firm predictions because almost nothing had gone as expected since the bidding opened on Monday." New York Times, July 29 , 1994.
} 
early in the auction when bidder activity was high. As prices increased, bid activity declined as did the rate of increase in the total of the high bids.

Figure 2 displays the bid activity by license type. ${ }^{21}$ Through the first 18 rounds, bidding was primarily on the 50/50s and 50/12.5s. After round 19, bidding stopped for six rounds on the 50/50s, but then resumed again in round 26, before concluding in round 37. Bidding on the 50/12.5s was heavy throughout the first half of the auction, but concluded in round 25, 21 rounds before the end of the auction. Bidding on the 50s was light and steady throughout the auction. The last nine rounds of the auction involved new bids on only the 50s. In the final eight rounds, there was just a single new bid in each round-three bidders were competing for two licenses.

Figure 3 shows the demand curves revealed by the bidding for each license type. Price is stated in $\$ / \mathrm{MHz}$-pop (i.e., the cost of the license in dollars divided by the product of the size of the license in megahertz and the population covered, which is 250 million for a nationwide license) to make the prices among license types comparable. Indeed, one remarkable aspect of the bidding is that the final prices for all the licenses are nearly equal at about $\$ 3.00$ per MHz-pop. Since there is no reason that firms should value inbound and outbound spectrum equally, the equality of prices across license types stems from the FCC's making the right choice about the supply of inbound spectrum relative to outbound spectrum.

${ }^{21} \mathrm{Bid}$ activity in round one is not shown to make the figure more readable. In round one, there were 61 new bids: 30 on the $50 / 50 \mathrm{~s}, 18$ on the $50 / 12.5 \mathrm{~s}$, and 13 on the $50 \mathrm{~s}$. 


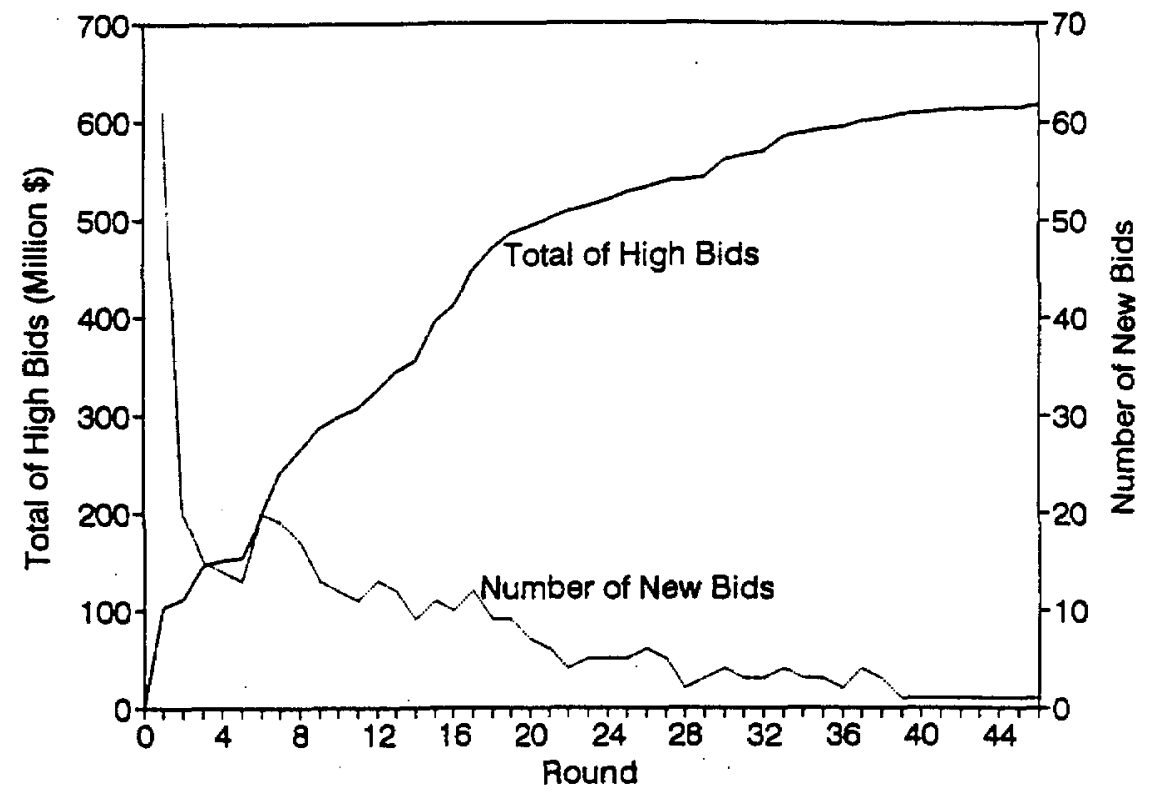

FIGURE 1. TOTAL SPENT AND BID ACTIVITY.

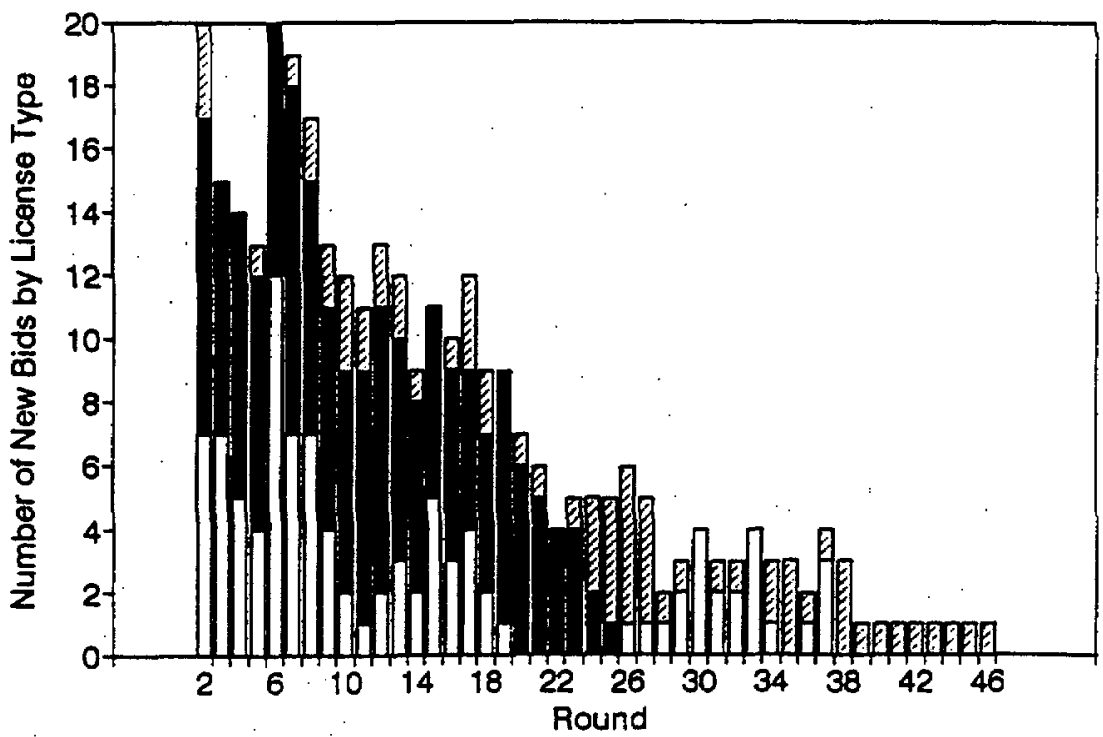

Bids on $50 / 50$ s Bids on $50 / 12 s$ Bids on 50 s

FIGURE 2. BID ACTIVITY BY LICENSE TYPE. 


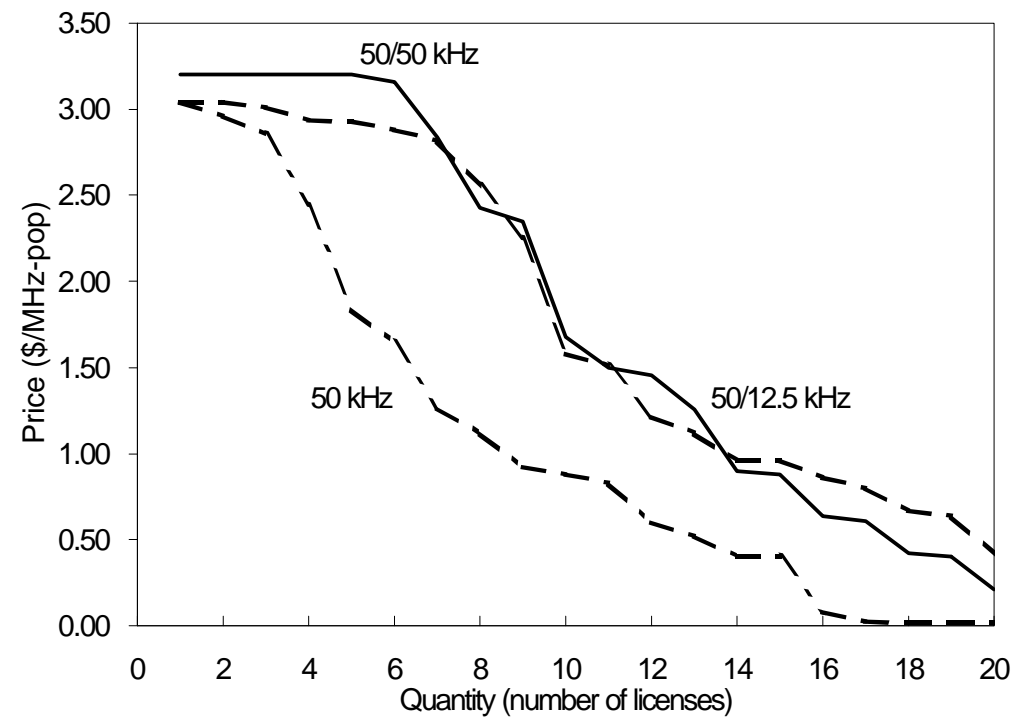

FIGURE 3. DEMAND BY LICENSE TYPE

Each of the demand curves is approximate. Because of the prevalence of jump bidding, it is impossible to know the exact price at which a bidder reduces its demand. Likewise, at the top of the demand curve, it is not known what the reservation prices of the high bidders are. It is only known that their walk-away prices were not reached. Finally, because of strategic bidding, the bids need not reflect the bidders' true valuations. A good example of strategic bidding was PageMart's bids of \$71 million each on licenses 2 and 3 in round 29. These bids bumped both PageNet (the high bidder on license 2) and $\mathrm{McCaw}$ (the high bidder on license 3). At these prices, PageMart had an interest in a single 50/50 license, not two, but it knew that either PageNet or McCaw would surely respond to the challenge, and probably both. By bidding on both 2 and 3, PageMart was able to test both PageNet and McCaw in one round. This strategic bidding throws off the demand curve slightly, since PageMart is credited as having a demand for two 50/50s at a price of $\$ 71$ million each. Another example of strategic bidding is the insincere low-bidding by several firms early in the auction (those hiding in the grass). For this reason, I have cut off the bottom of the demand curves.

Figure 4 shows the revealed demand for nationwide narrowband spectrum. The demand curve is constructed by calculating each firm's aggregate demand for spectrum from the firm's bids (weighing inbound and outbound spectrum equally), and then summing these individual bidder demands. The FCC's supply curve is shown as the vertical line at a quantity of $.7875 \mathrm{MHz}$. Like the demand curves in Figure 3, the market demand for spectrum derived from the bids is approximate. Nonetheless, it is possible to make at least a crude evaluation of the FCC's decision to withhold an additional third megahertz of narrowband spectrum from the narrowband auctions. If this third megahertz were divided like the first two megahertz, this would represent a $50 \%$ increase in the quantity supplied. From the demand curve, this increase in supply from .7875 to $1.181 \mathrm{MHz}$ would result in the average price falling from $\$ 3.13$ to $\$ 2.40$ per MHz-pop. Hence, the FCC would collect $2.40 \times 1.181 \times 250=$ $\$ 708$ million, rather than $3.13 \times .7875 \times 250=\$ 617$ million. The $50 \%$ increase in supply would result in a $15 \%$ increase in revenues. Given the relatively modest increase in revenues associated with a $50 \%$ increase in supply, a revenue maximizing FCC is probably better off waiting to sell the third megahertz. This is especially the case, since the $\$ 708$ million may be an overestimate of revenue. The demand curve on which the calculation is based relies on the assumption that supply is fixed at .7875 $\mathrm{MHz}$ until the FCC auctions the third megahertz. If supply is increased immediately, then scarce spectrum is less of a constraint on competition, hence competition is likely to be more intense, which reduces bidders' values, shifting the demand curve to the left. On the other hand, the FCC's objective 
is not to maximize revenues. The FCC's decision included the welfare of consumers, who would benefit through lower prices if more spectrum were allocated initially.

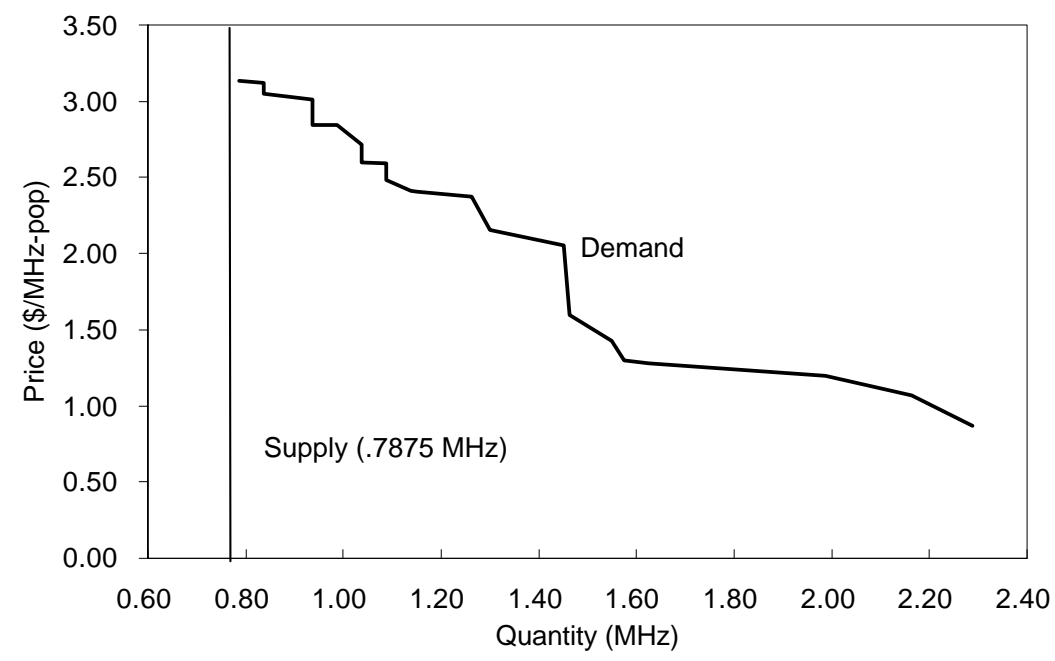

FIGURE 4. DEMAND FOR SPECTRUM.

Tables VIIa-VIId present the bid increments, the high bids, the confidential bidder numbers, and the bidding activity in each round. Each round in the table is separated by a line. The first 5 rows in a round correspond to the five $50 / 50 \mathrm{kHz}$ licenses (licenses 1 to 5); the next three rows are for the three $50 / 12.5 \mathrm{kHz}$ licenses (licenses 6 to 8 ); and the next two rows are for the $50 \mathrm{kHz}$ unpaired licenses (licenses 10 and 11). Each row gives the minimum bid increment, stated in both percentage and absolute terms, the minimum bid, the current high bid, the bidder number, and the number of new bids on the particular license (a blank cell means that there were no new bids).

Through round 21, the FCC roughly stuck to their 5\% bid increment rule. Then in round 22, after three rounds of inactivity on the 50/50s, the FCC sharply dropped the bid increments on the 50/50s. Bidding on these licenses, however, continued to be independent of the bid increments. Activity on the 50/50s did not renew until the prices on the 50/12.5s increased to the point where one of the bidders was enticed to switch back to the 50/50s. The FCC continued to adjust bid increments in response to activity in the prior round, but always keeping the bid increment below 5\%. In the last four rounds, the bid increments on the 50/50s and the 50/12.5s were all below .5\%. Despite this low increment, there was no activity on these licenses. Clearly, the failure to attract further bids was an indication that the market clearing price had been reached; it was not the case that significant bid increments were keeping bidders from bidding. Even on the 50s, the last set of licenses to close, the FCC was able to drop the bid increment to less than $1.4 \%$.

\subsection{BIDDING HISTORY}

Tables VIIIa-VIIIg display all the bids of all the bidders for each round of the auction. This table is most useful in tracking the firms' bidding strategies. Indeed, during the auction, PageNet used these tables to track bidder behavior. The tables were stored in a spreadsheet that displayed one round per screen. Hence, by flipping through the screens, one saw a "movie" of the bidding behavior, much like the flip books children have to see animation by flipping quickly through the pages. This format was very useful in getting a sense for firms' budget constraints and valuations by observing when firms would drop down to less valuable licenses or reduce their demands from three to two to one.

As before, each round in the table is separated by a line. Each row gives the bids placed by the bidders on a particular license. The first five rows are for the five 50/50s (licenses 1-5), the next three rows are for the three 50/12.5s (licenses 6-8), and the final two rows are for the two 50s (licenses 10-11). The high bid for a particular license appears in bold.

Although not shown in the tables, the spreadsheet also tracked bidder eligibility and the use of automatic waivers. The number of licenses a firm is eligible to bid on depends on the size of the 
upfront payment the bidder made. Most bidders made an upfront payment of $\$ 1,050,000$, which makes them eligible for 3 licenses. Four bidders (McCaw, Mtel, PageNet, and Mobile Media) made an upfront payment of $\$ 3,500,000$, which makes them eligible to bid on 10 licenses in any round. However, regardless of the upfront payment, no bidder is eligible to win more than three licenses.

There are two column headings. The first is the firm's abbreviated name for the top ten bidders, and the second heading is the bidder's confidential bidder number. For the top ten bidders, PageNet and other observant bidders were able to determine the bidders' identities by the end of the auction based on their bidding behavior. Bidder identities were uncovered by: (1) knowing the firms in the industry and their interests, (2) knowing how many licenses each firm was eligible to bid on, (3) observing whether a bid was placed and the time of the bid, ${ }^{22}$ (4) observing whether a bidder "placing" a bid received a written confirmation of the bid, ${ }^{23}$ and (5) observing who must have placed a fake bid when the FCC announces that no new bids or proactive waivers have yet been made in the round (i.e., all bids before the announcement had to be fake).

22 The FCC inadvertently listed the bid entry times of all bids in two rounds.

${ }^{23}$ It was common for a bidder that did not need to bid, because it was the current high bidder, to pretend to place a bid, so as to conceal its identity. These pretend bids were not always successful before round 18, because a bidder could not ask for written confirmation of the pretend bid. Almost all bidders asked for written confirmation of their bids. To get a written confirmation, the bid assistant would have to walk across the room in public view. In round 18, the FCC announced, "Beginning with this round, you may go into the bidding booth and request from the bidding assistant a confirmation of your actions regardless of whether you bid, exercise a proactive waiver, or do not submit a bid." Even this met with limited success, since the sheet on which the written confirmation was printed was folded differently depending on whether it was a real bid or a fake bid. 


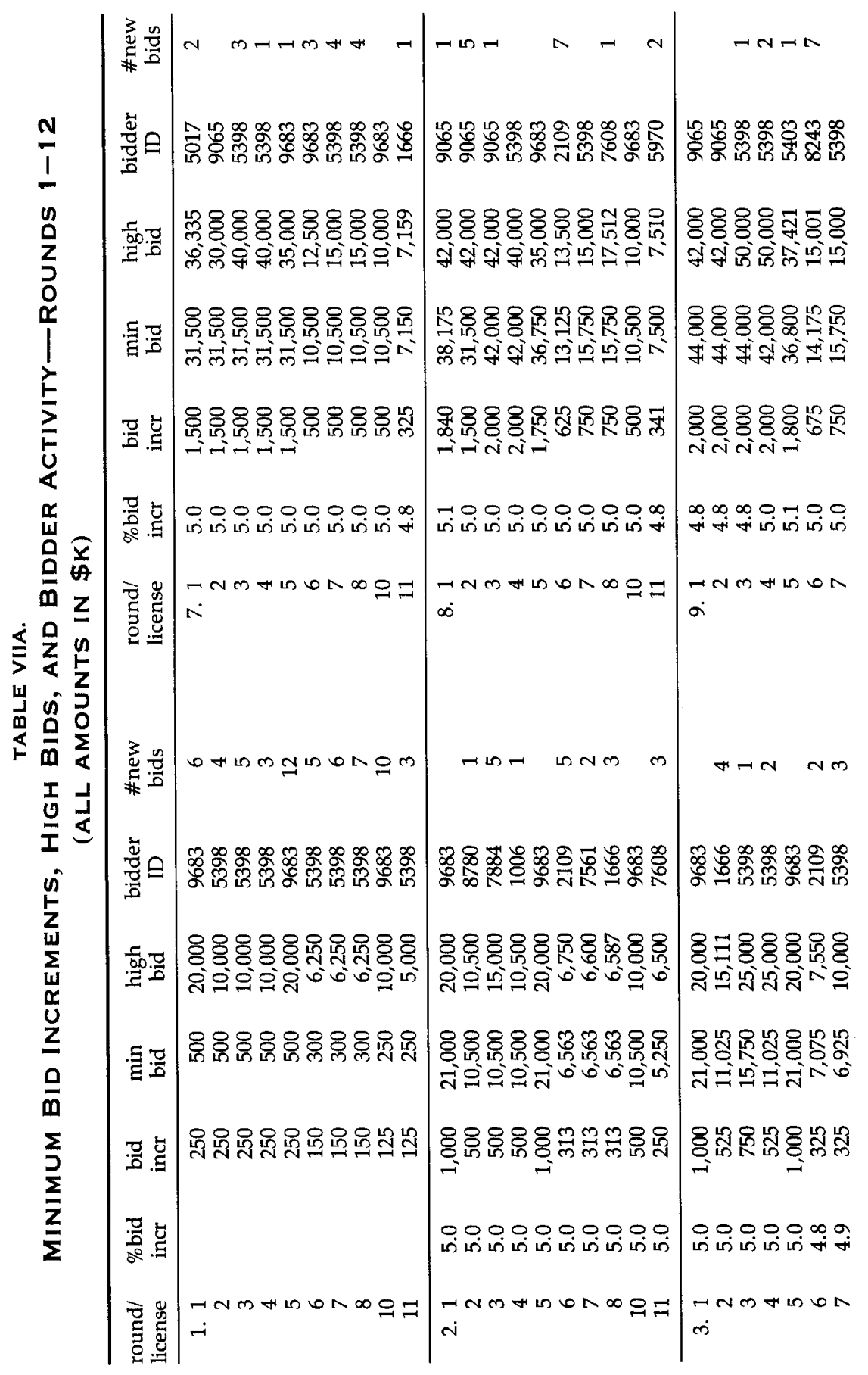




\begin{tabular}{|c|c|c|c|}
\hline$N$ & $N \operatorname{Ln} N$ & No & mo $N$ \\
\hline 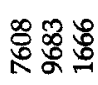 & 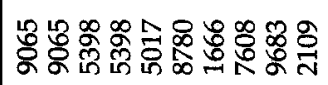 & 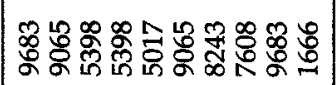 & 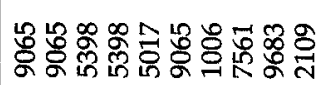 \\
\hline 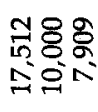 & 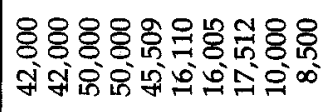 & 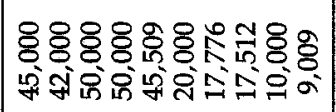 & 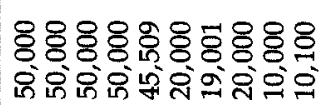 \\
\hline 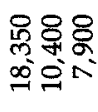 & 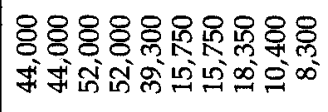 & 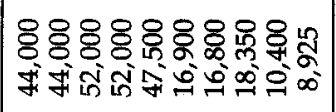 & 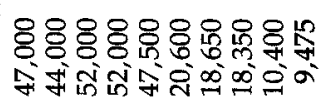 \\
\hline 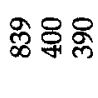 & 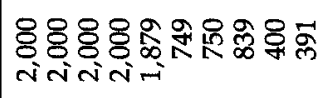 & 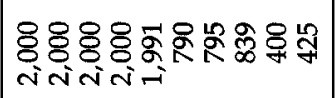 & 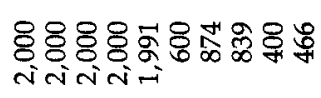 \\
\hline $\begin{array}{l}\infty \\
\text { Fi fi }\end{array}$ & 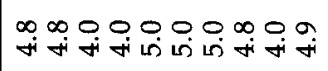 & 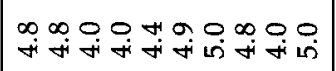 & 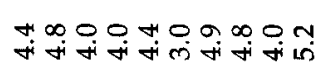 \\
\hline & $\begin{array}{l}\because N m+n \infty n \infty O= \\
\therefore\end{array}$ & $\begin{array}{l}-N m \operatorname{tin} 0 N \infty O F \\
\Rightarrow\end{array}$ & 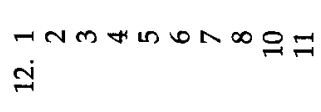 \\
\hline m & $\Rightarrow$ in & $\begin{array}{lll}- & \wedge & -\end{array}$ & MISATNN \\
\hline 광 : & 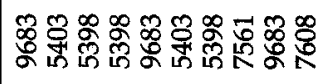 & 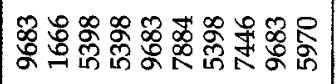 & 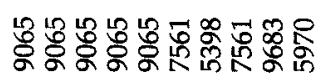 \\
\hline 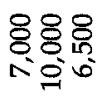 & 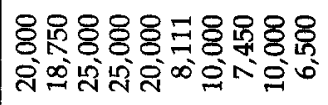 & 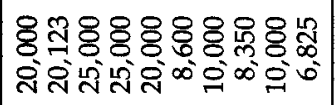 & 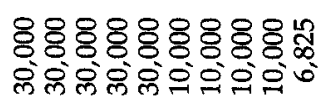 \\
\hline 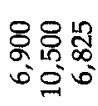 & 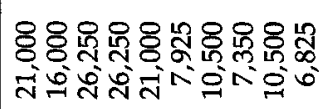 & 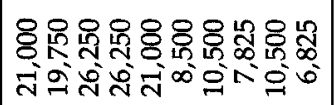 & 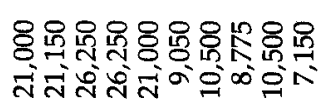 \\
\hline ్ㅜㅇㅠㅠ & $\underset{-1}{8}$ & 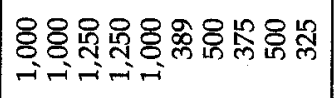 & 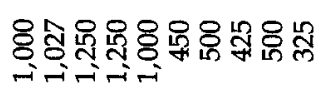 \\
\hline 궁요 & 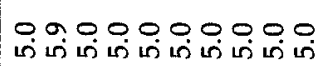 & 官 mo & 웁 \\
\hline & 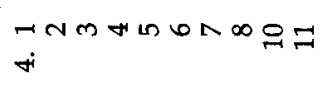 & $\begin{array}{l}\ln \\
-\operatorname{nin} m \ln \infty\end{array}$ & 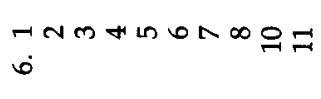 \\
\hline
\end{tabular}




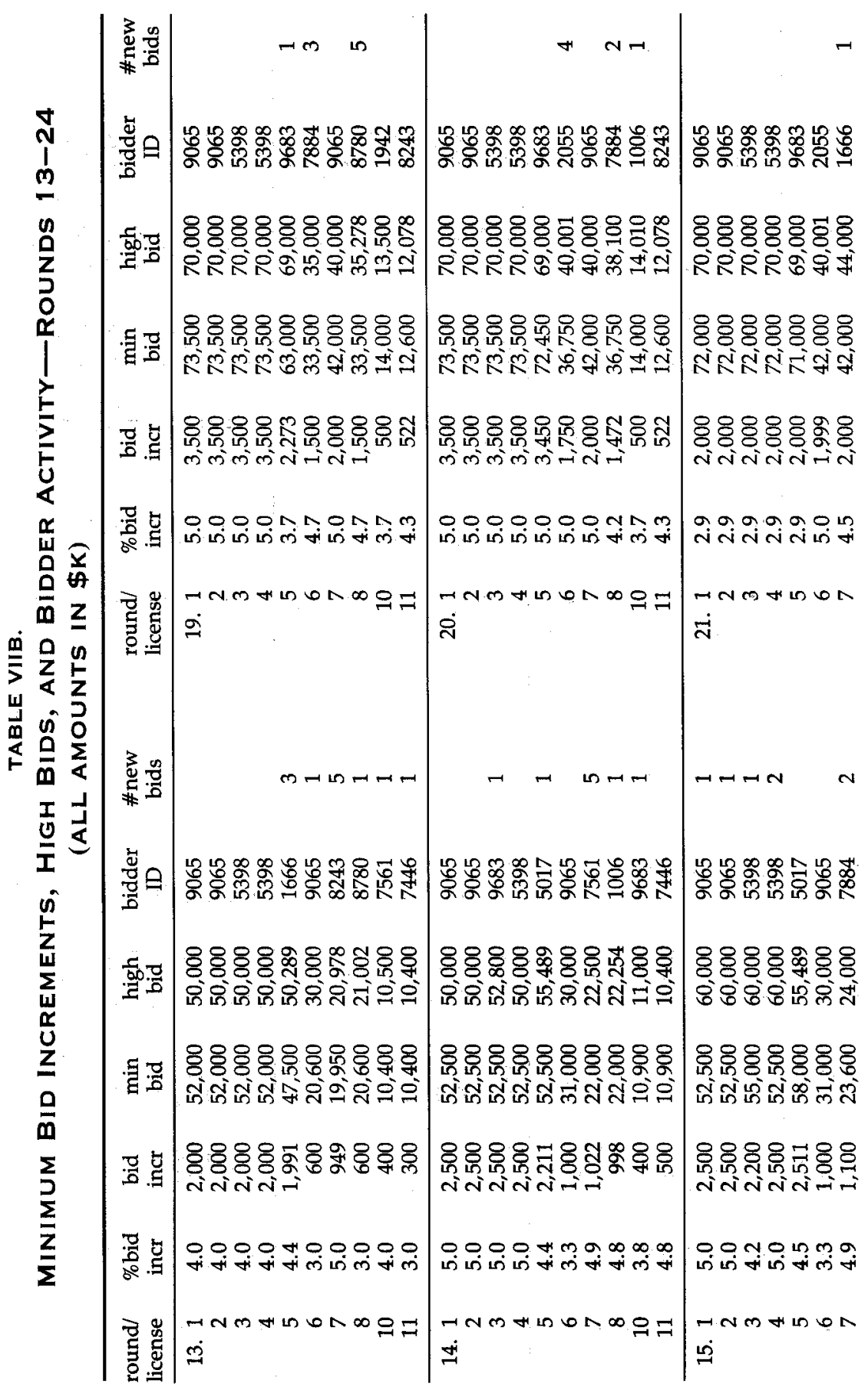




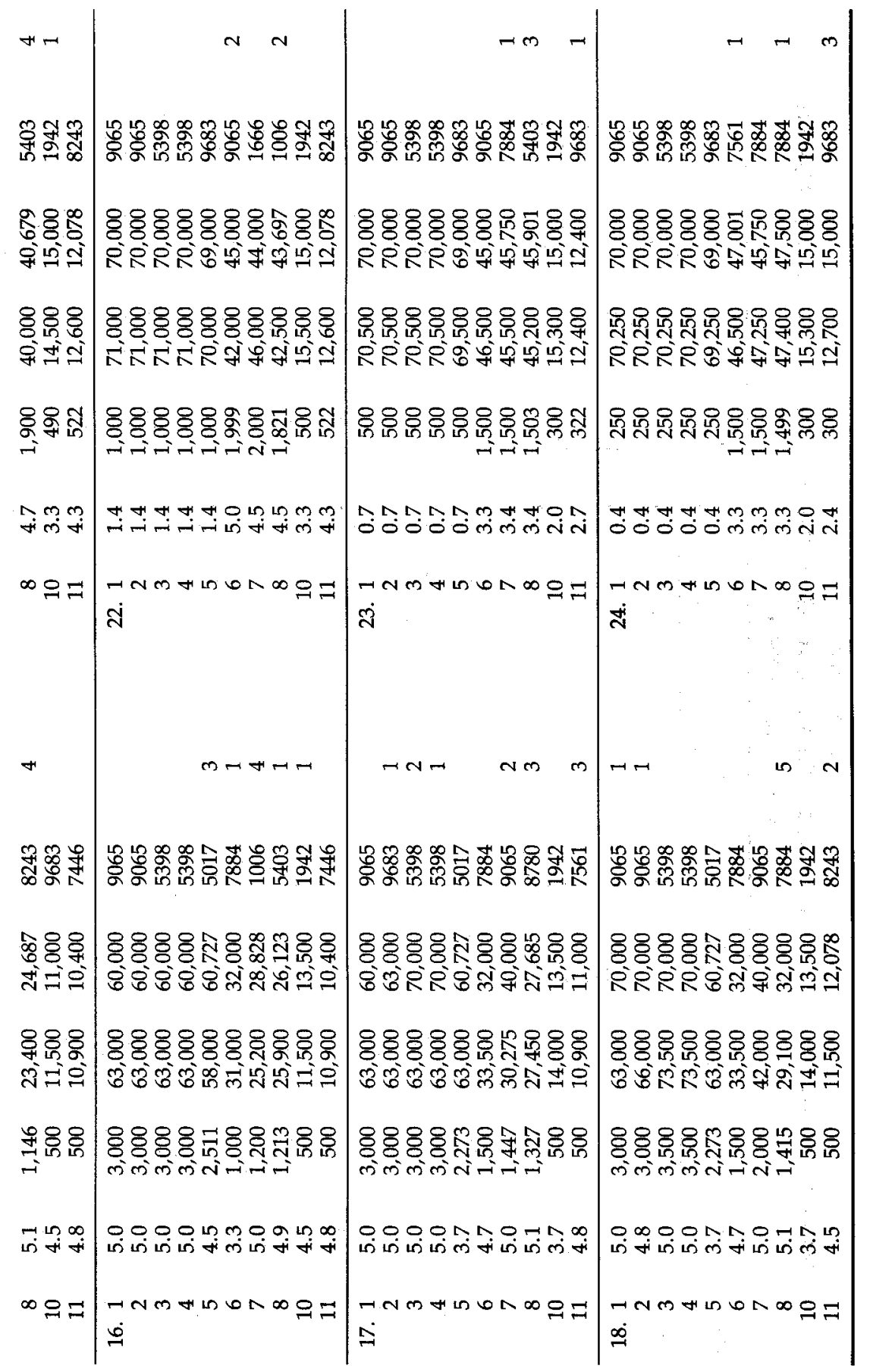




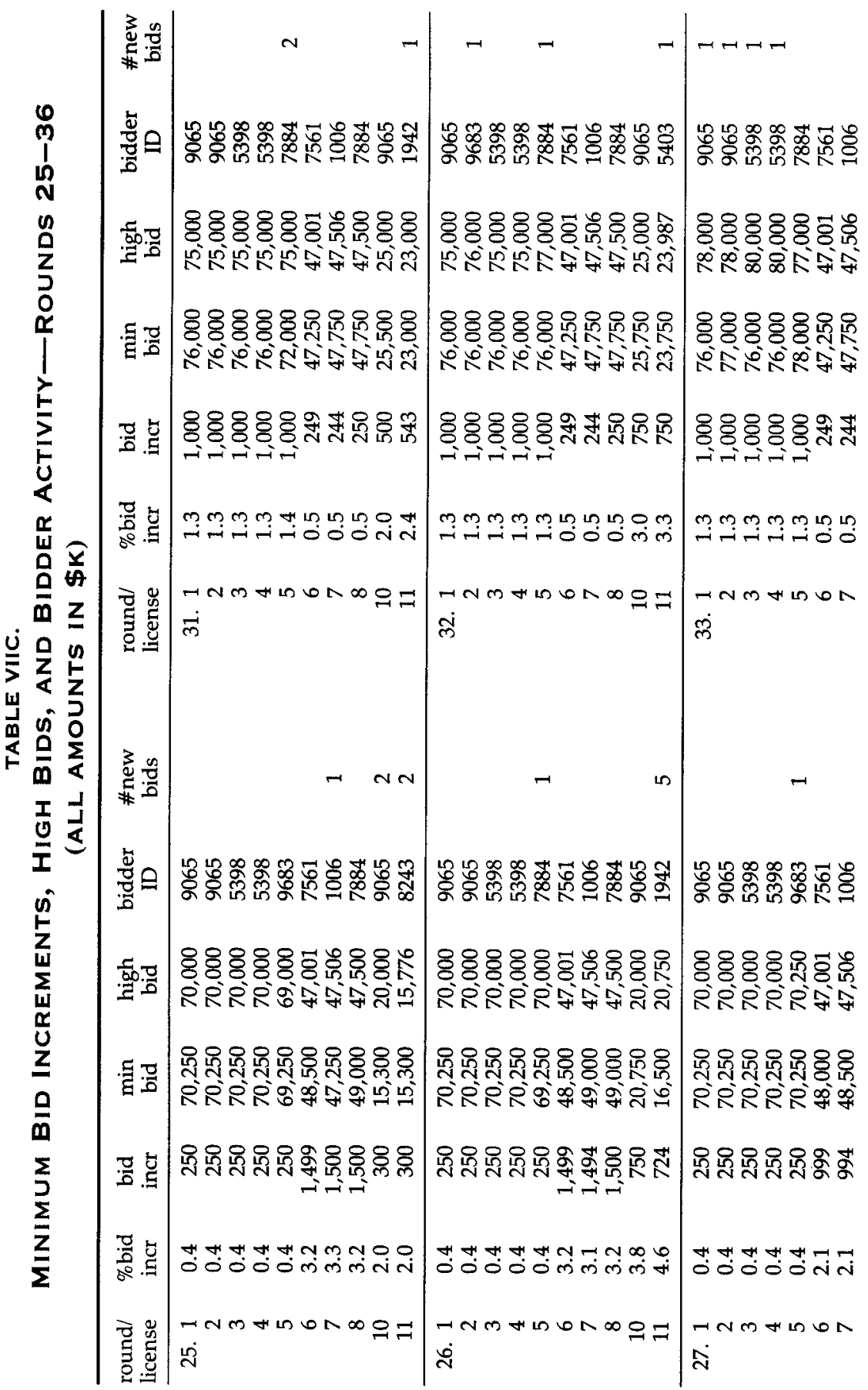




\begin{tabular}{|c|c|c|c|}
\hline & - & $N \rightarrow$ & - \\
\hline 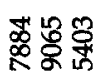 & 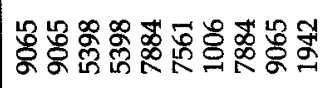 & 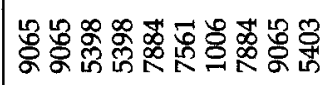 & 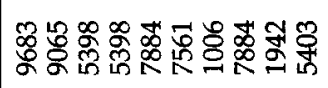 \\
\hline 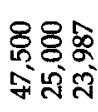 & 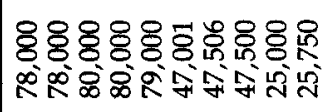 & 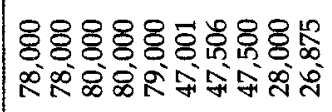 & 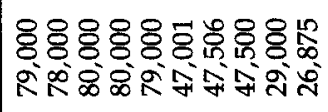 \\
\hline 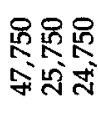 & 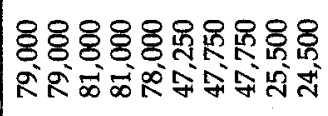 & 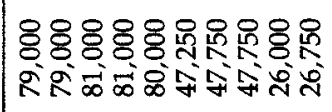 & 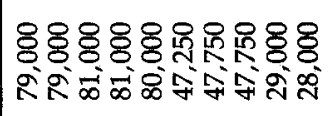 \\
\hline 影员悉 & 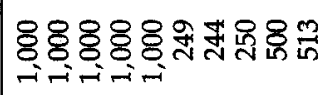 & 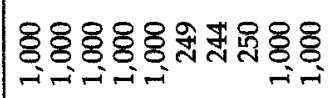 & రి: \\
\hline 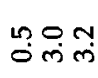 & 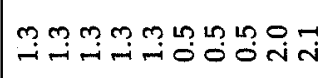 & 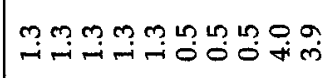 & 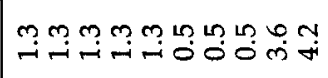 \\
\hline$\infty \Omega=$ & 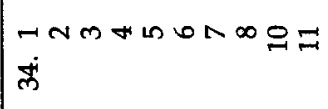 & 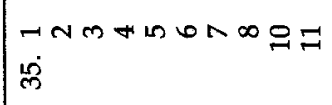 & 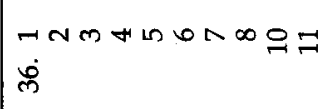 \\
\hline - & - & $\rightarrow \rightarrow$ & 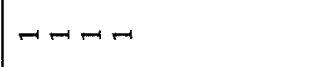 \\
\hline 营总㝵 & 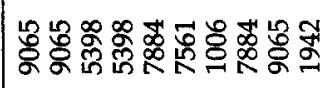 & 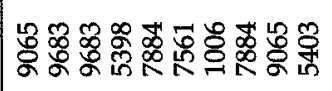 & 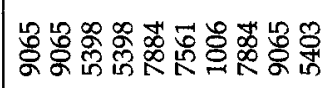 \\
\hline 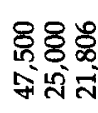 & 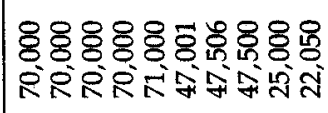 & 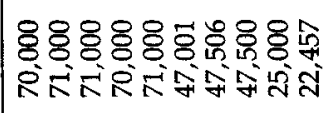 & 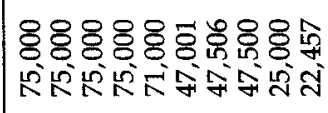 \\
\hline 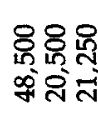 & 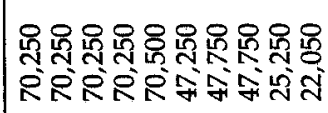 & 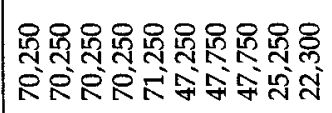 & 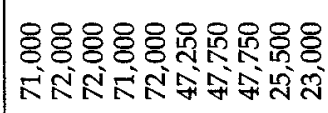 \\
\hline 8 & 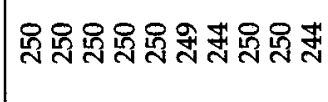 & 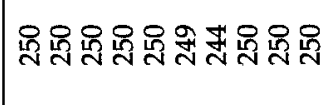 & 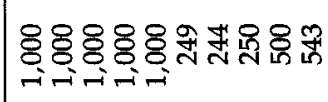 \\
\hline $\overrightarrow{\mathrm{N}} \mathrm{i} \sim$ & 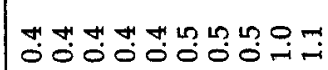 & 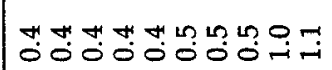 & نَّ \\
\hline & TNm then $=$ & 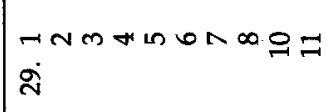 & 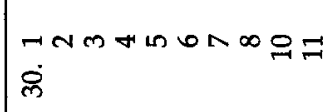 \\
\hline
\end{tabular}




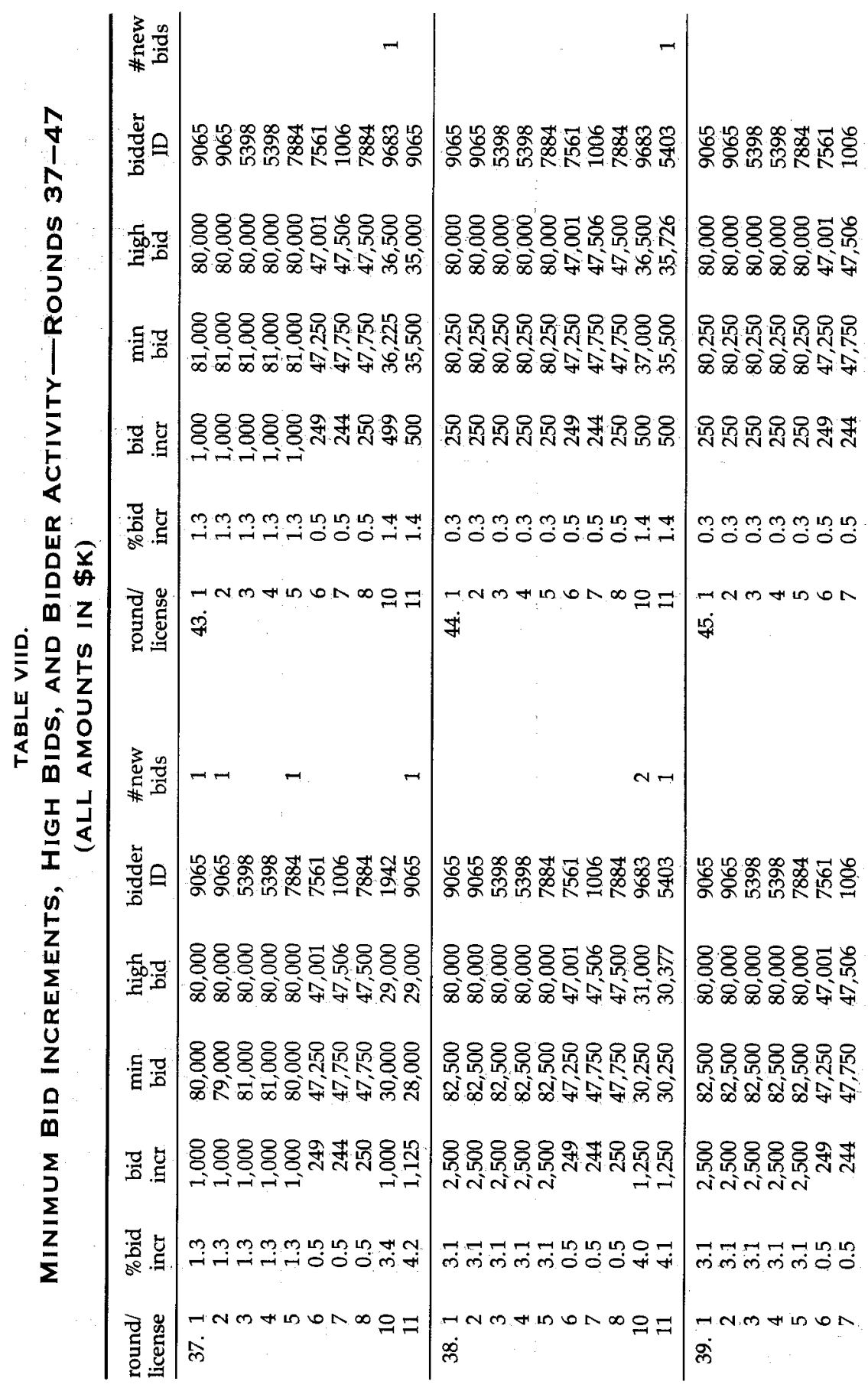




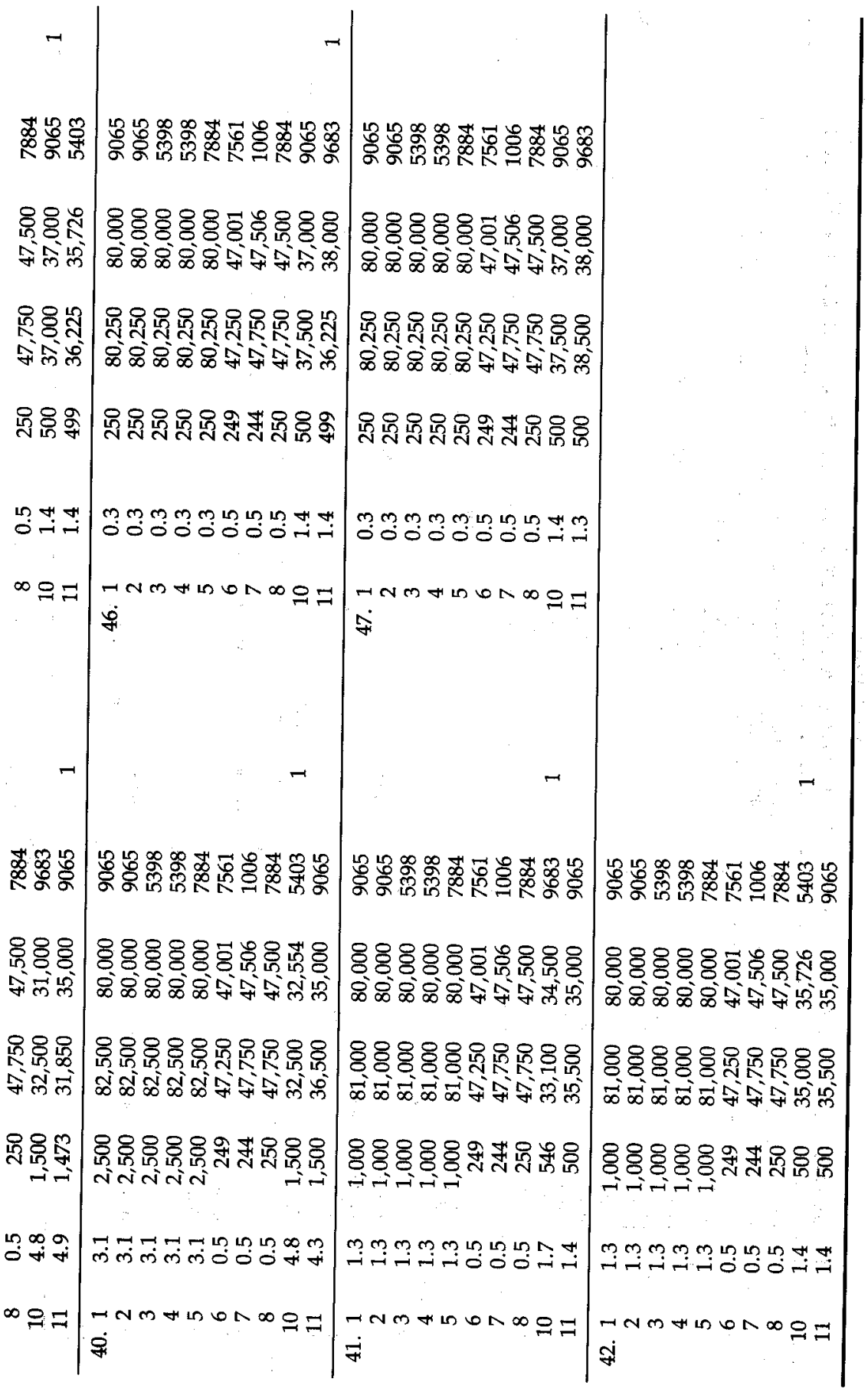




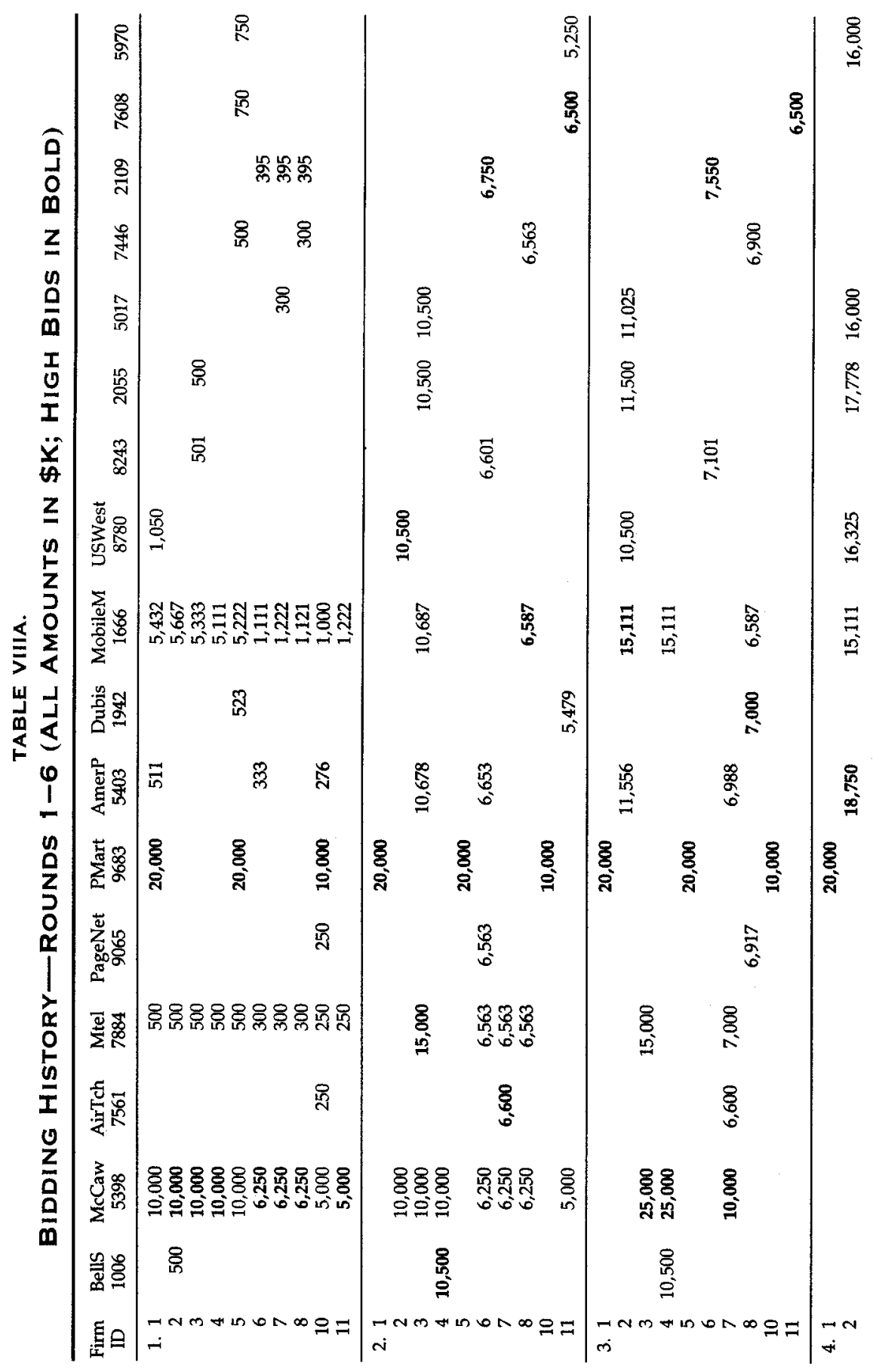




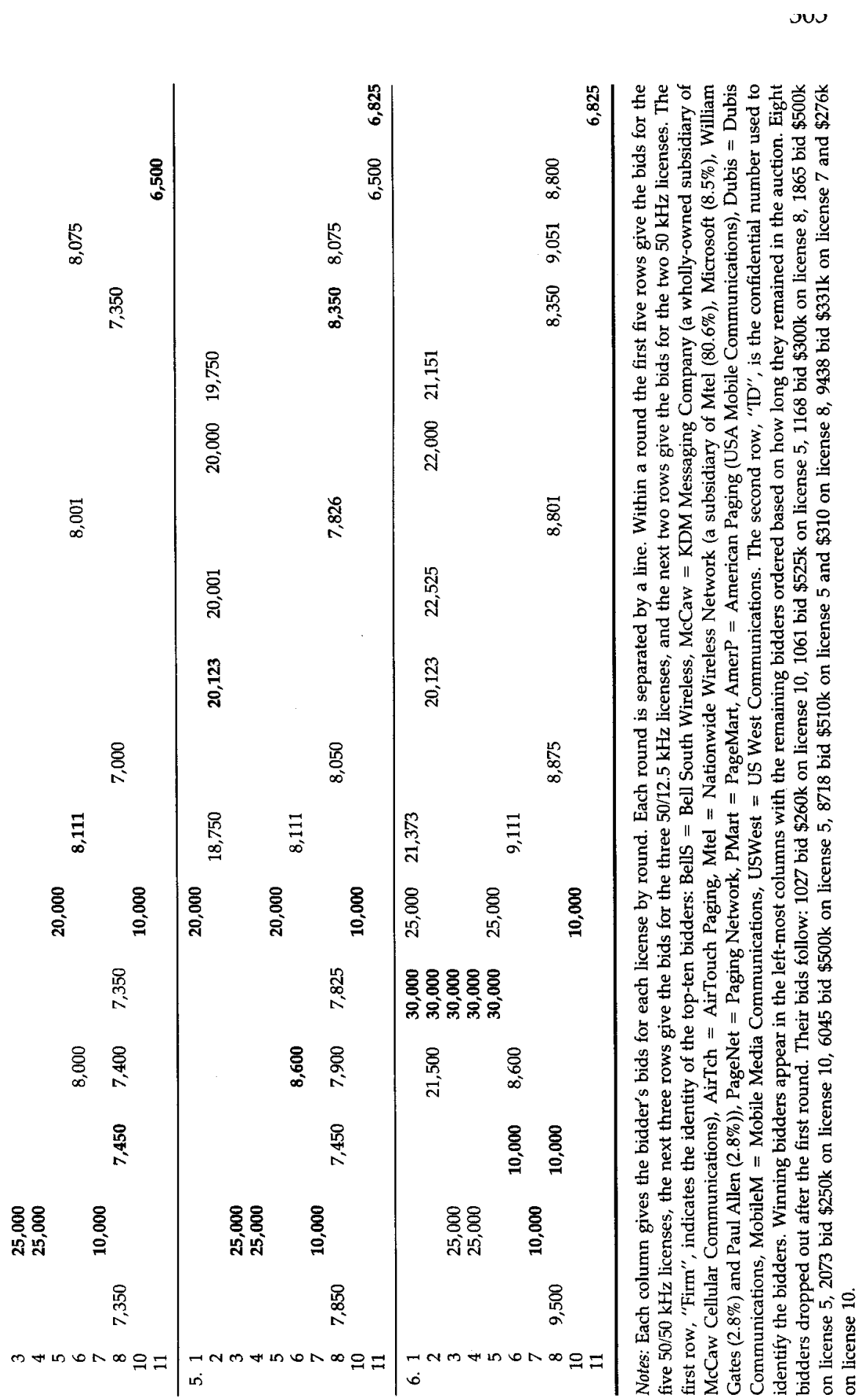




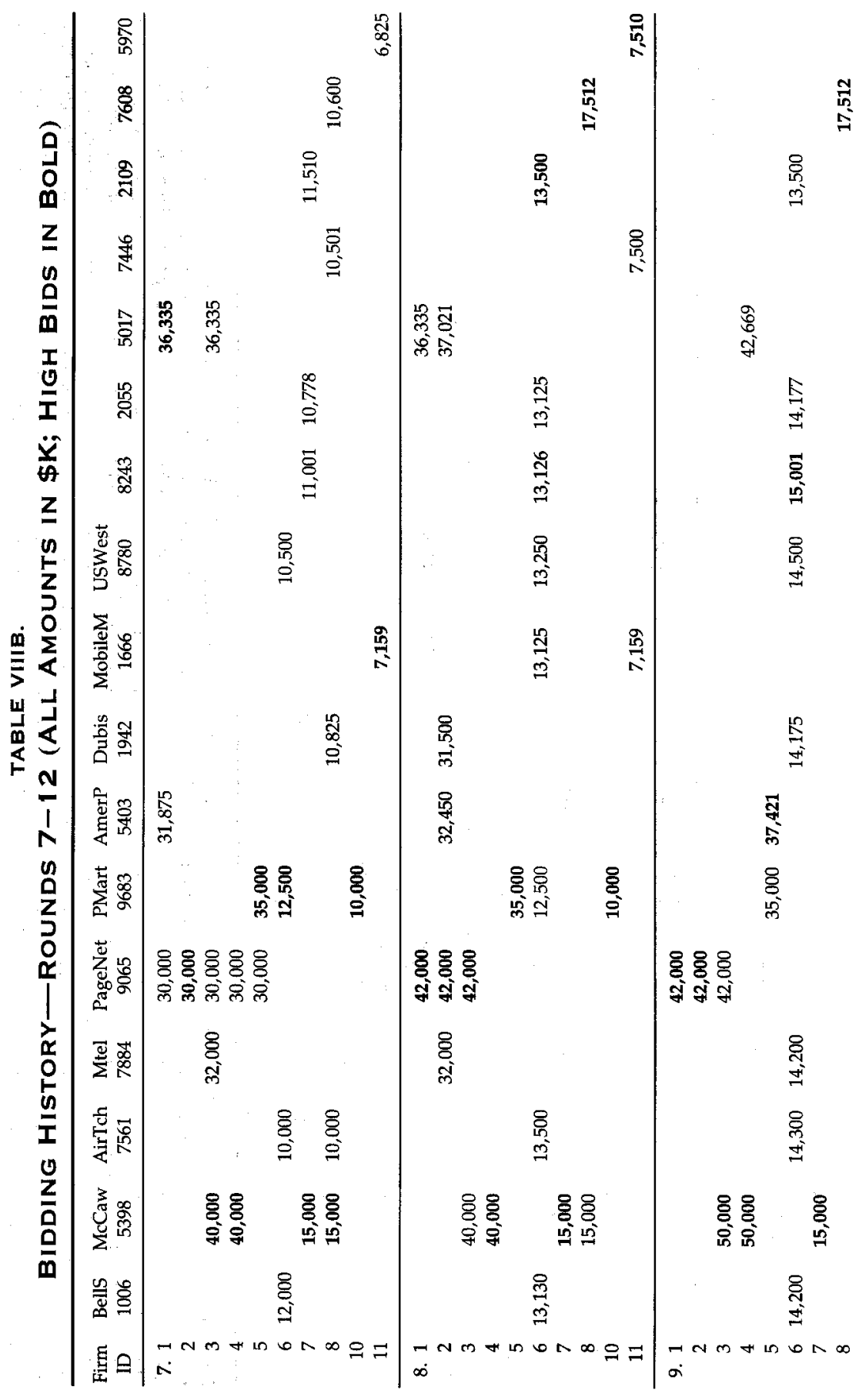




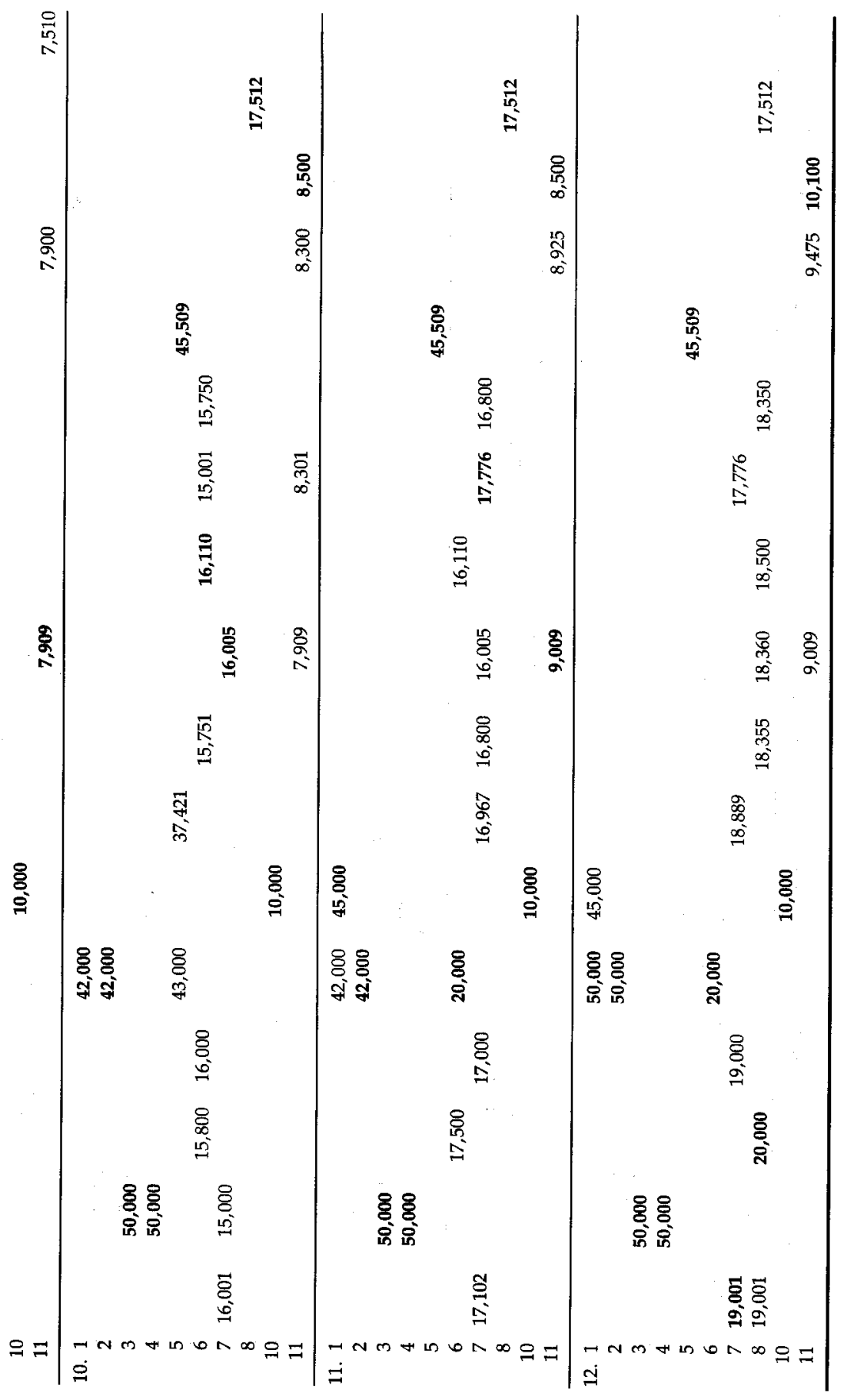




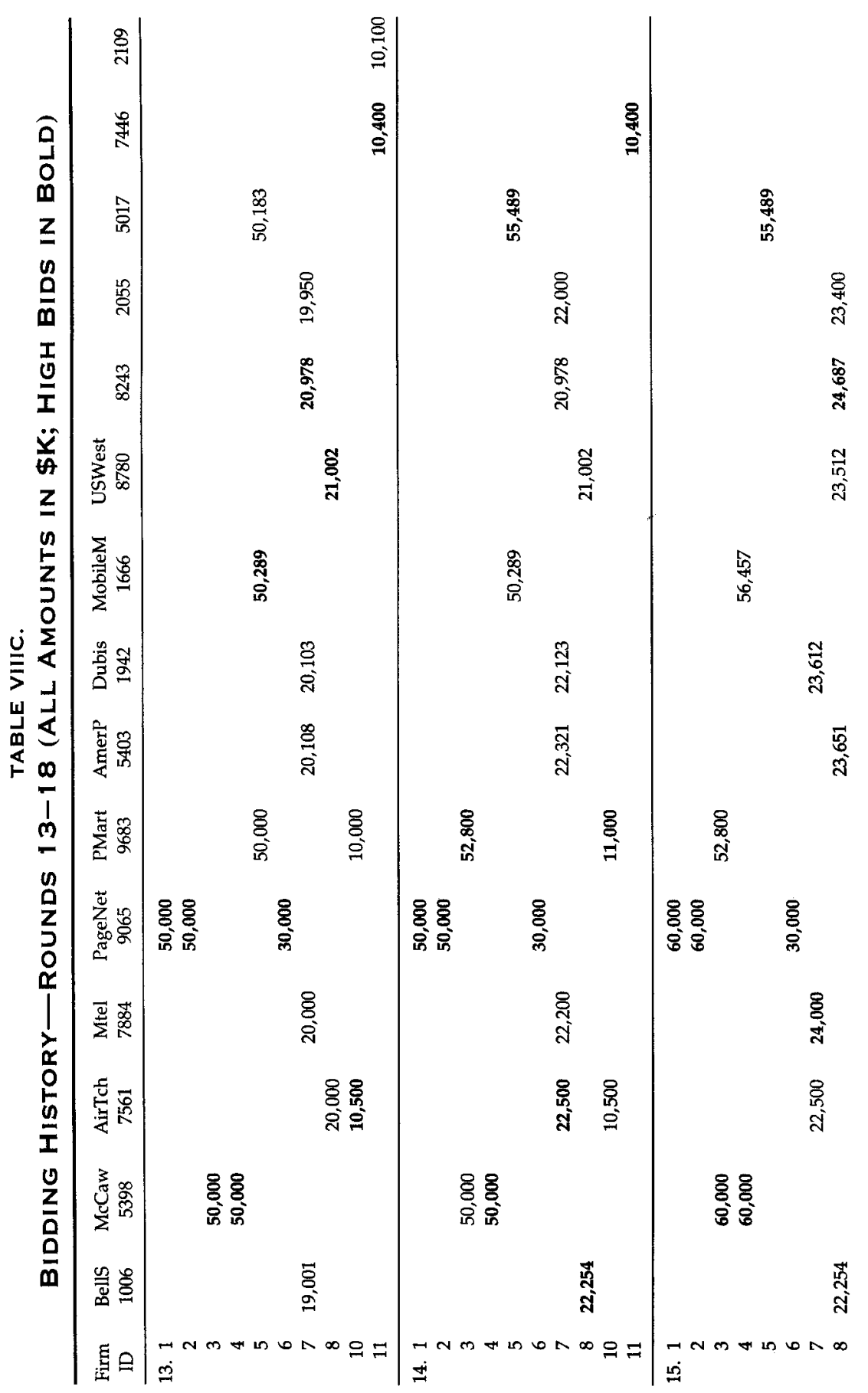




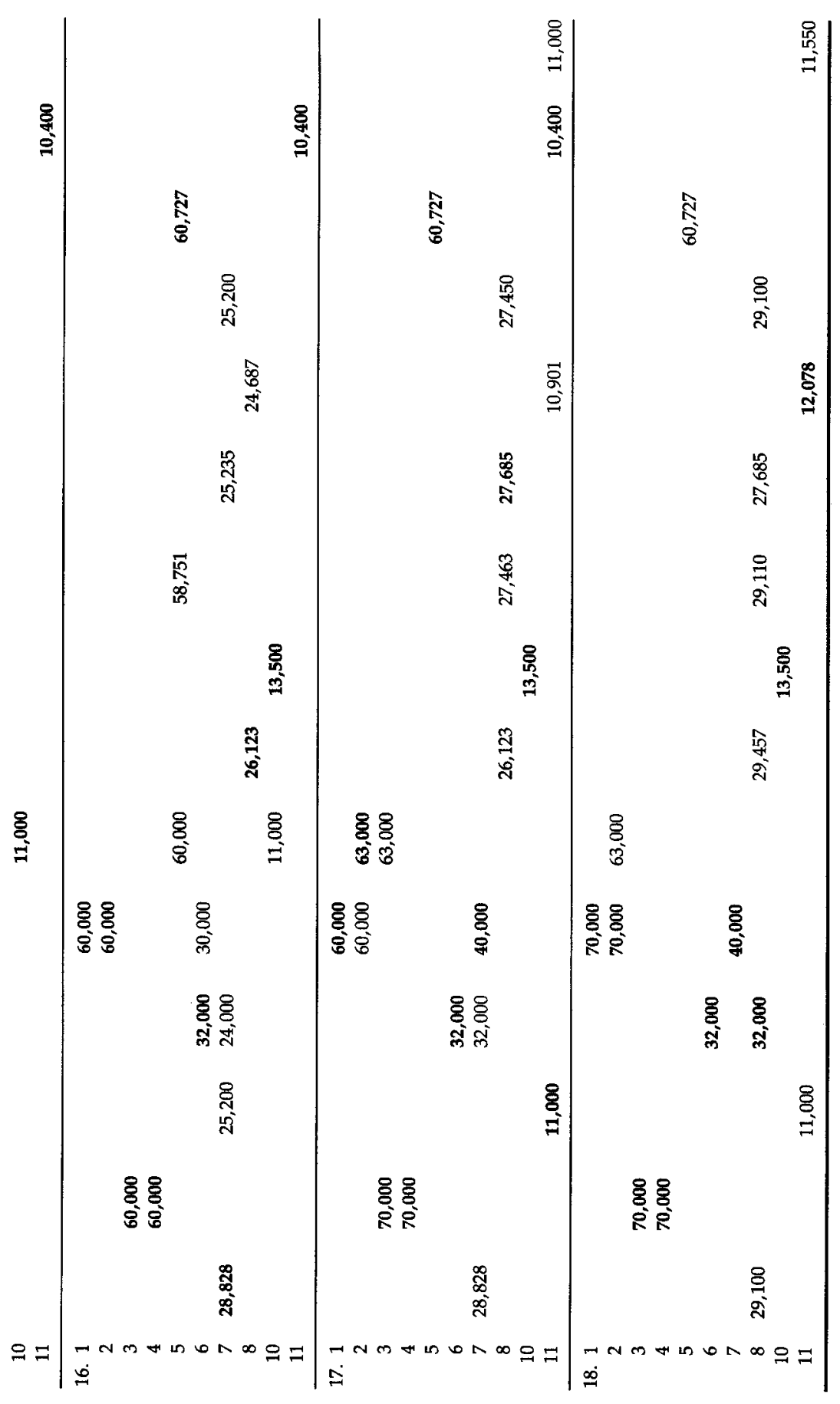




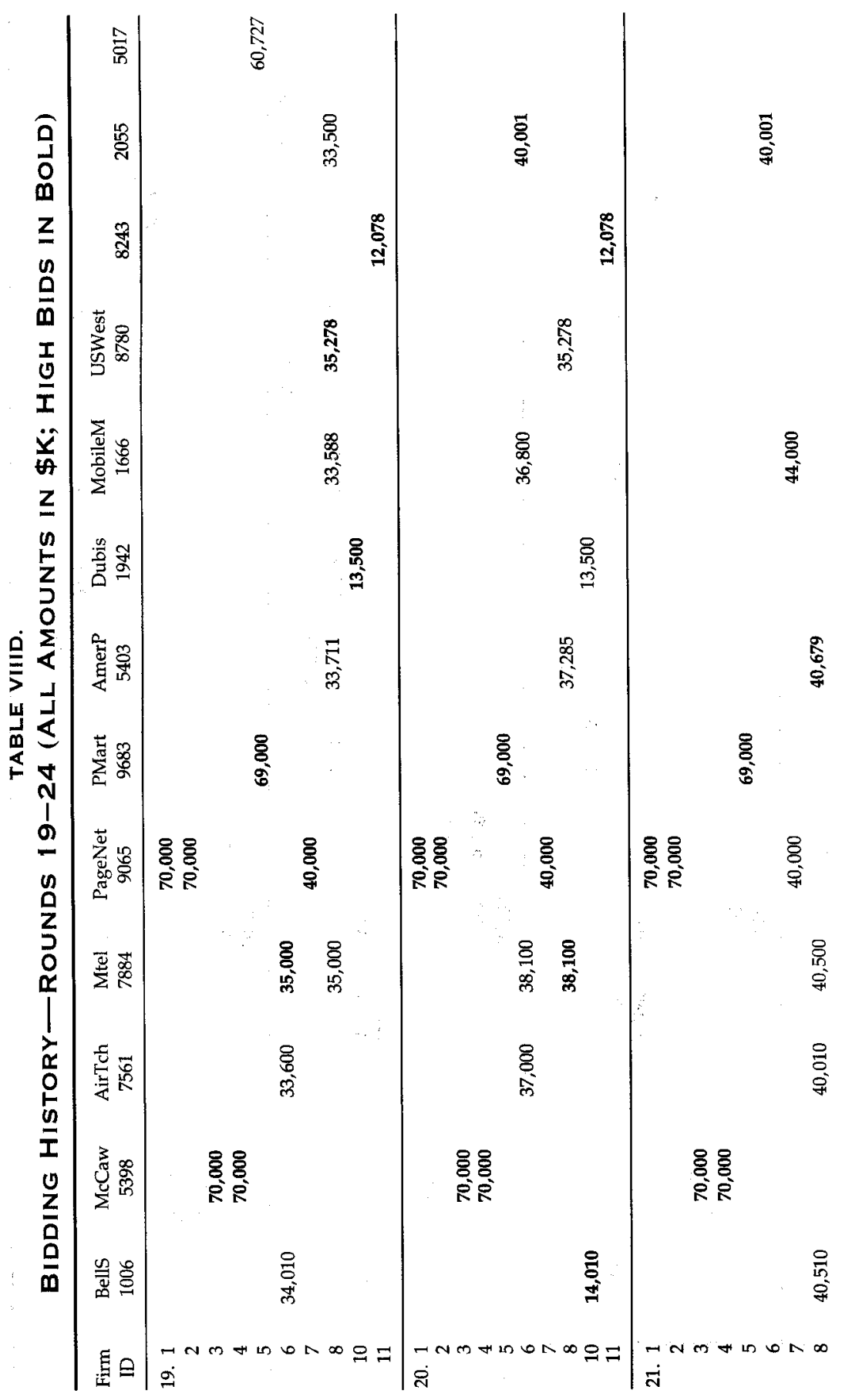




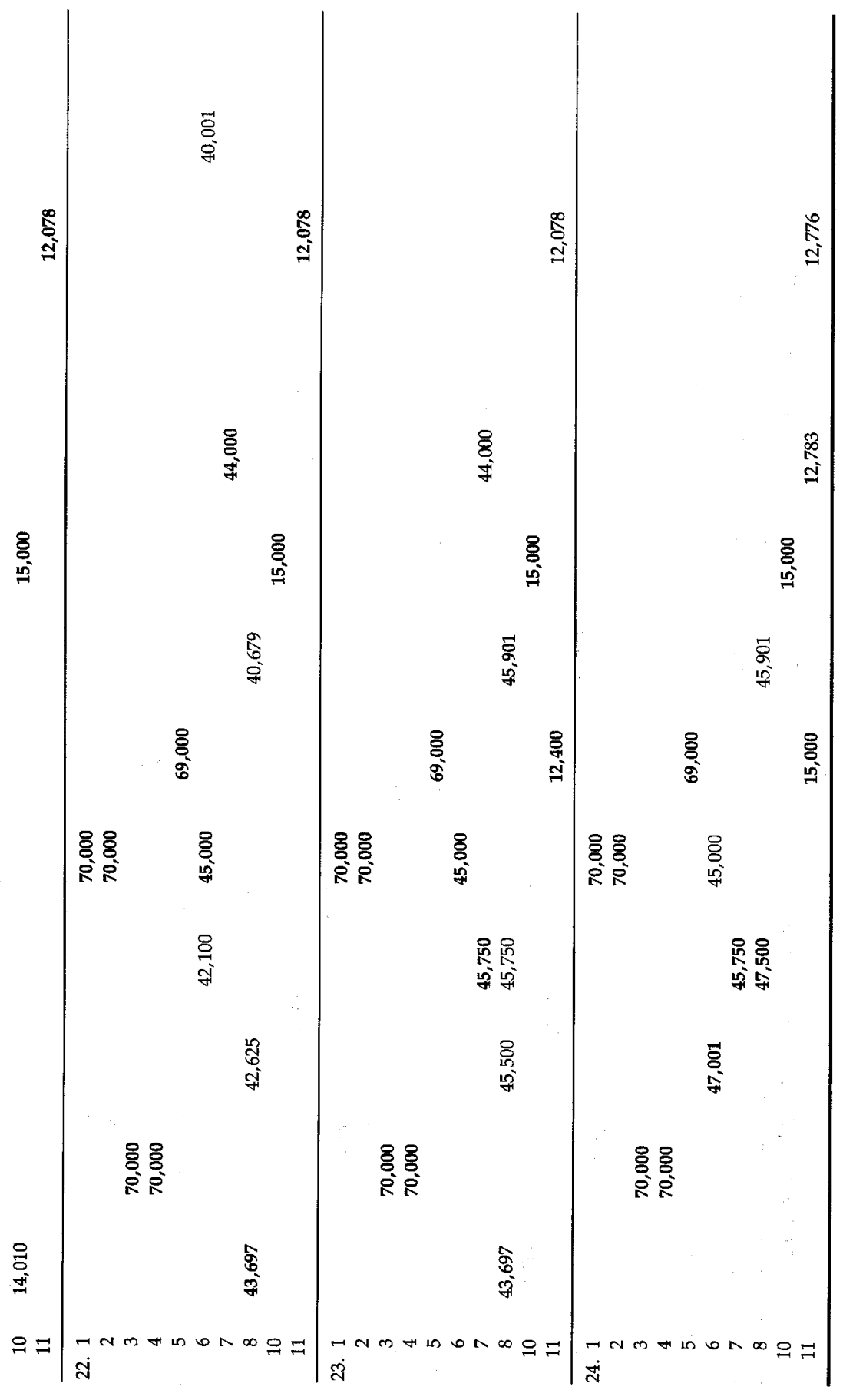




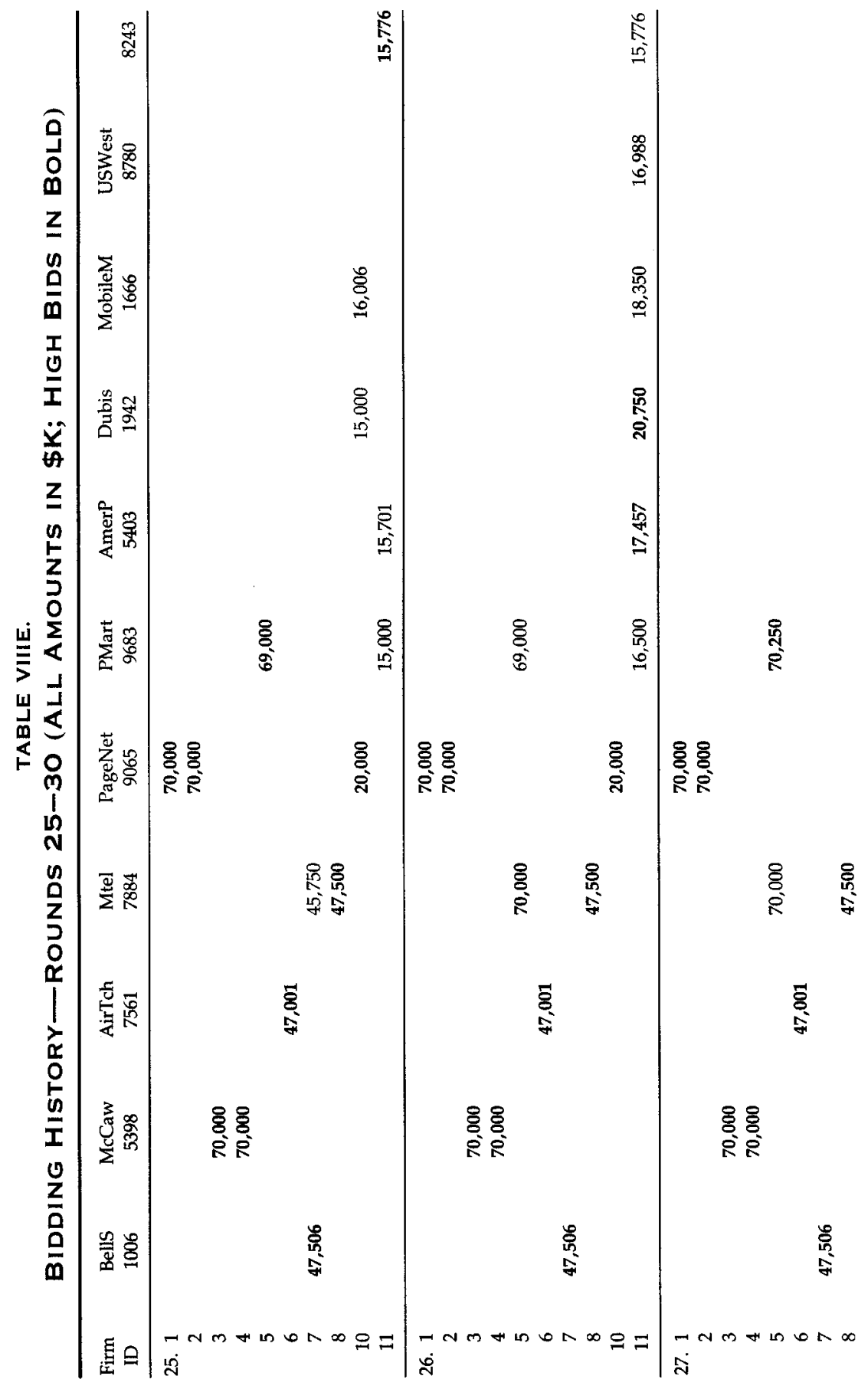




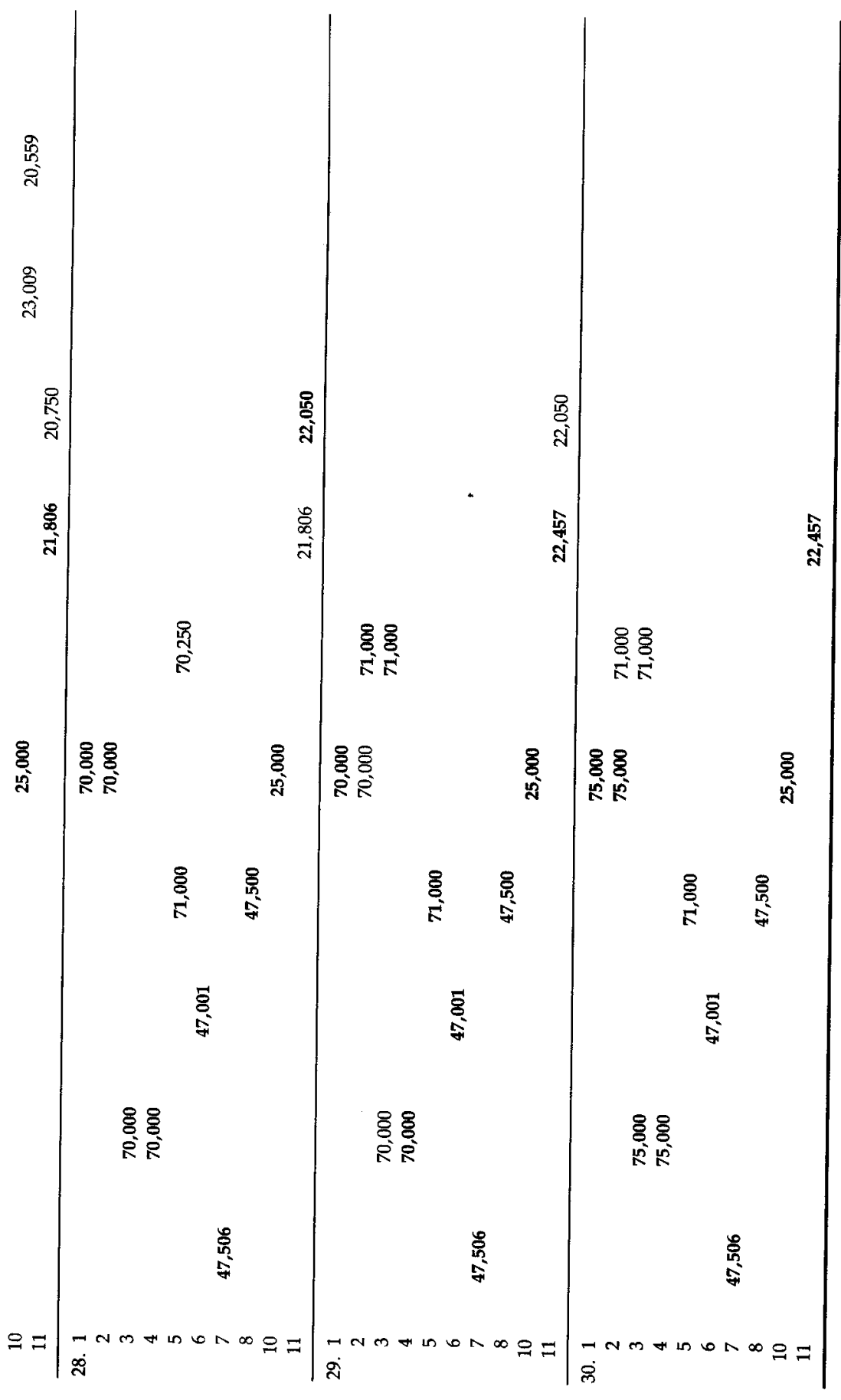


TABLE VIIIF.

BIDDING HISTORY-ROUNDS 31 - 39 (ALL AMOUNTS IN \$K; HIGH BIDS IN BOLD)

\begin{tabular}{|c|c|c|c|c|c|c|c|c|}
\hline $\begin{array}{l}\text { Firm } \\
\text { ID }\end{array}$ & $\begin{array}{l}\text { Bells } \\
1006\end{array}$ & $\begin{array}{c}\text { McCaw } \\
5398\end{array}$ & $\begin{array}{c}\text { AirTch } \\
7561\end{array}$ & $\begin{array}{l}\text { Mtel } \\
7884\end{array}$ & $\begin{array}{l}\text { PageNet } \\
9065\end{array}$ & $\begin{array}{l}\text { PMart } \\
9683\end{array}$ & $\begin{array}{c}\text { AmerP } \\
5403\end{array}$ & $\begin{array}{c}\text { Dubis } \\
1942\end{array}$ \\
\hline 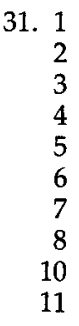 & 47,506 & $\begin{array}{l}75,000 \\
75,000\end{array}$ & 47,001 & $\begin{array}{r}75,000 \\
47,500\end{array}$ & 25,000 & 72,000 & 22,457 & 23,000 \\
\hline 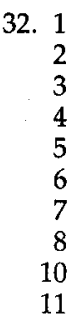 & 47,506 & $\begin{array}{l}75,000 \\
75,000\end{array}$ & 47,001 & $\begin{array}{r}77,000 \\
47,500\end{array}$ & 25,000 & 76,000 & 23,987 & 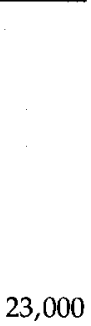 \\
\hline 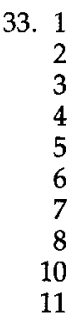 & 47,506 & $\begin{array}{l}80,000 \\
80,000\end{array}$ & 47,001 & $\begin{array}{r}77,000 \\
47,500\end{array}$ & $\begin{array}{l}78,000 \\
78,000 \\
\\
25,000\end{array}$ & 76,000 & 23,987 & \\
\hline $\begin{array}{r}34 \\
2 \\
3 \\
3 \\
4 \\
5 \\
6 \\
7 \\
8 \\
10 \\
11\end{array}$ & 47,506 & $\begin{array}{l}80,000 \\
80,000\end{array}$ & 47,001 & $\begin{array}{r}79,000 \\
47,500\end{array}$ & $\begin{array}{l}78,000 \\
78,000\end{array}$ & 25,000 & 23,987 & 25,750 \\
\hline 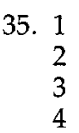 & & $\begin{array}{l}80,000 \\
80,000\end{array}$ & & & $\begin{array}{l}78,000 \\
78,000\end{array}$ & : & & \\
\hline
\end{tabular}




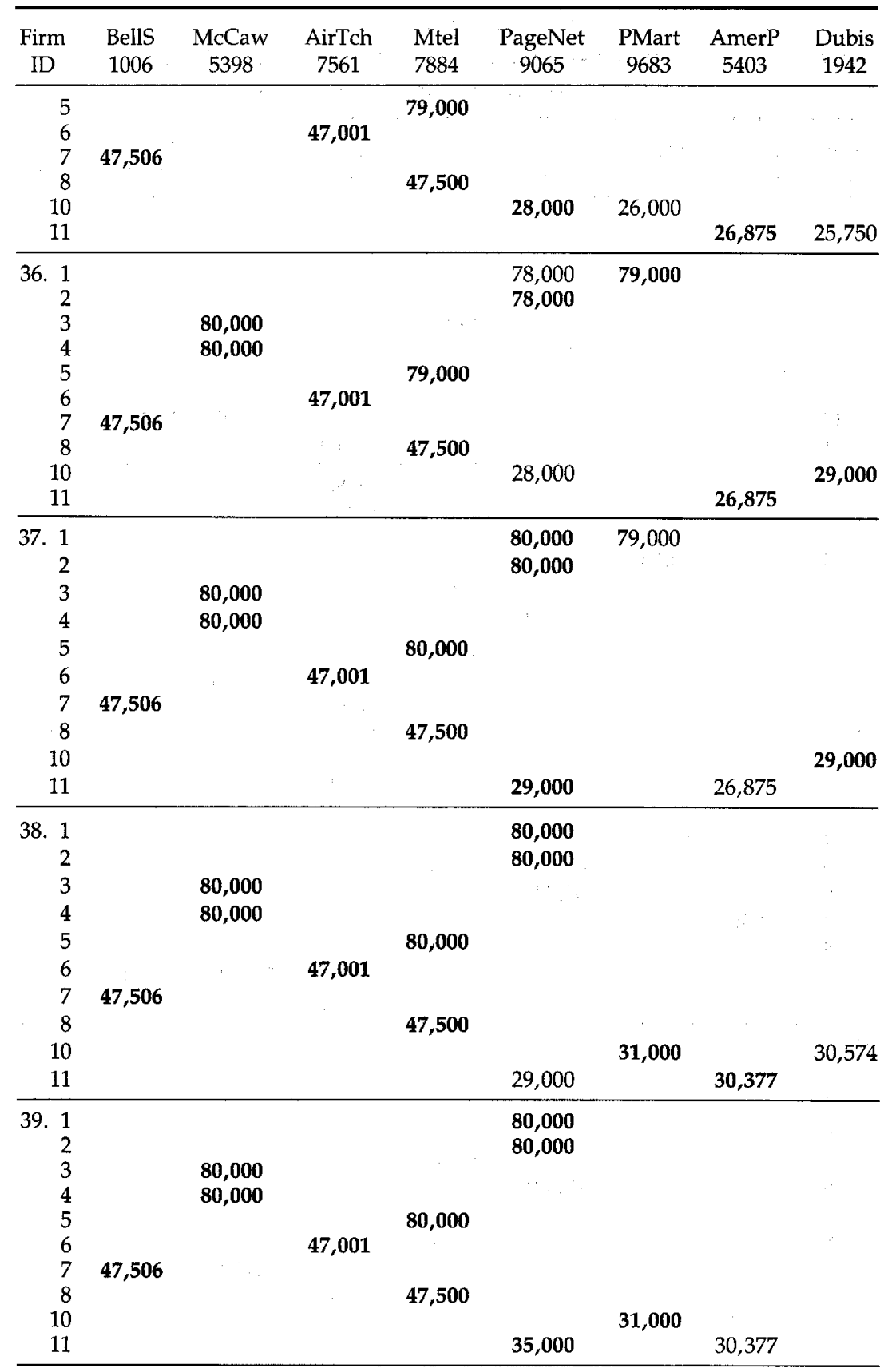


TABLE VIIIG.

BIDDING HISTORY-ROUNDS 40-47 (ALL AMOUNTS IN \$K; HIGH BIDS IN BOLD)

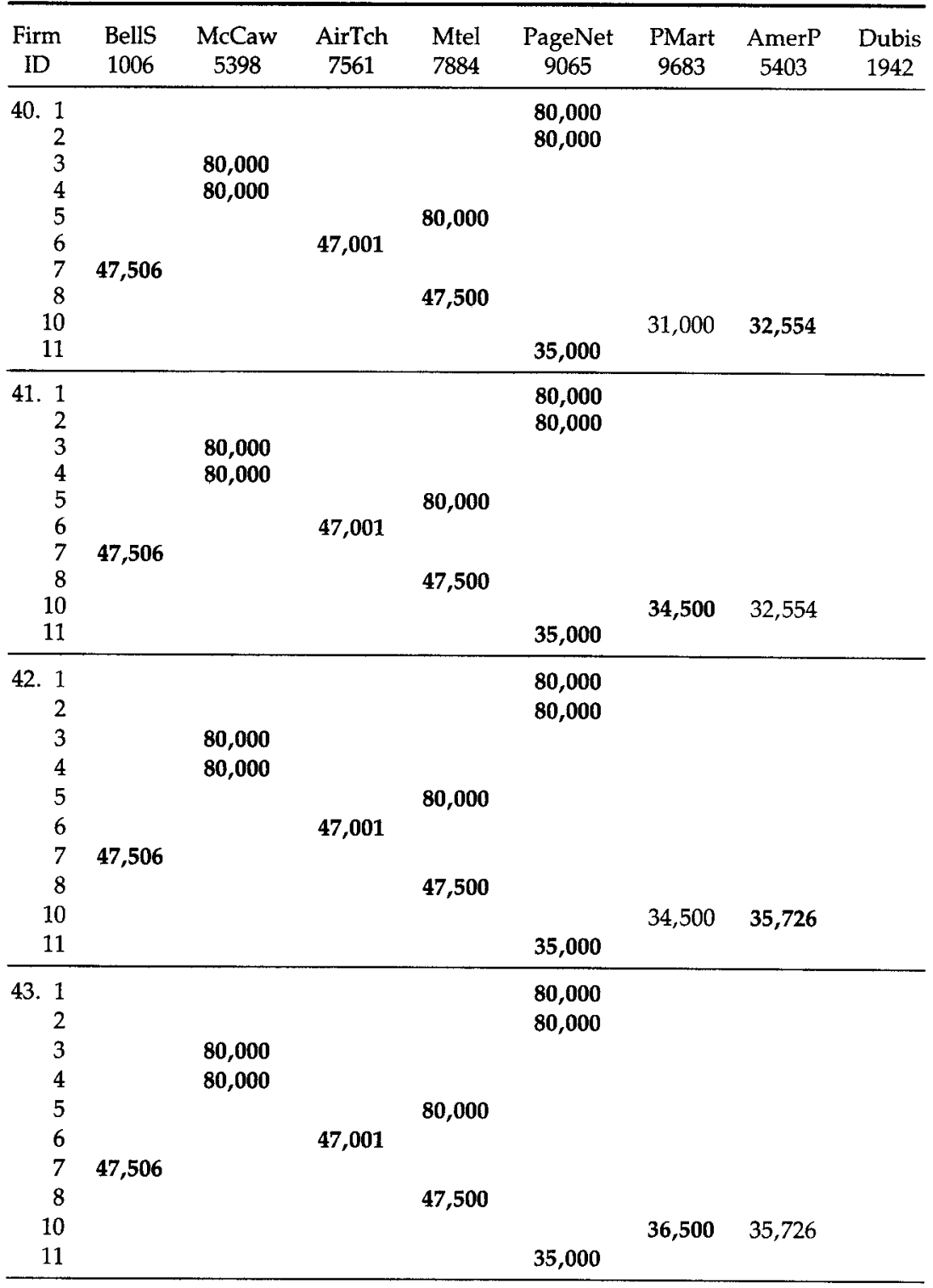




\begin{tabular}{|c|c|c|c|c|c|c|c|c|}
\hline $\begin{array}{l}\text { Firm } \\
\text { ID }\end{array}$ & $\begin{array}{l}\text { Bells } \\
1006\end{array}$ & $\begin{array}{c}\text { McCaw } \\
5398\end{array}$ & $\begin{array}{l}\text { AirTch } \\
7561\end{array}$ & $\begin{array}{l}\text { Mtel } \\
7884\end{array}$ & $\begin{array}{c}\text { PageNet } \\
9065\end{array}$ & $\begin{array}{l}\text { PMart } \\
9683\end{array}$ & $\begin{array}{c}\text { AmerP } \\
5403\end{array}$ & $\begin{array}{c}\text { Dubis } \\
1942\end{array}$ \\
\hline 44. 1 & & & & & 80,000 & & & \\
\hline 2 & & & & & 80,000 & & & \\
\hline 3 & & 80,000 & & & & & & \\
\hline 4 & & 80,000 & & & & & & \\
\hline 5 & & & & 80,000 & & & & \\
\hline 6 & & & 47,001 & & & & & \\
\hline 7 & 47,506 & & & & & & & \\
\hline 8 & & & & 47,500 & & & & \\
\hline 10 & & & & & & 36,500 & & \\
\hline 11 & & & & & 35,000 & & 35,726 & \\
\hline 45. 1 & & & & & 80,000 & & & \\
\hline 2 & & & & & 80,000 & & & \\
\hline 3 & & 80,000 & & & & & & \\
\hline 4 & & 80,000 & & & & & & \\
\hline 5 & & & & 80,000 & & & & \\
\hline 6 & & & 47,001 & & & & & \\
\hline 7 & 47,506 & & & & & & & \\
\hline 8 & & & & 47,500 & & & & \\
\hline 10 & & & & & 37,000 & 36,500 & & \\
\hline 11 & & & & & & & 35,726 & \\
\hline 46. 1 & & & & & 80,000 & & & \\
\hline 2 & & & & & 80,000 & & & \\
\hline 3 & & 80,000 & & & & & & \\
\hline 4 & & 80,000 & & & & & & \\
\hline 5 & & & & 80,000 & & & & \\
\hline 6 & & & 47,001 & & & & & \\
\hline 7 & 47,506 & & & & & & & \\
\hline 8 & & & & 47,500 & & & & \\
\hline 10 & & & & & 37,000 & & & \\
\hline 11 & & & & & & 38,000 & 35,726 & \\
\hline 47. 1 & & & & & 80,000 & & & \\
\hline 2 & & & & & 80,000 & & & \\
\hline 3 & & 80,000 & & & & & & \\
\hline 4 & & 80,000 & & & & & & \\
\hline 5 & & & & 80,000 & & & & \\
\hline 6 & & & 47,001 & & & & & \\
\hline 7 & 47,506 & & & & & & & \\
\hline 8 & & & & 47,500 & & & & \\
\hline 10 & & & & & 37,000 & & & \\
\hline 11 & & & & & & 38,000 & & \\
\hline
\end{tabular}


In what follows, I comment on the bidding on a round by round basis. These comments summarize the major strategic events in the particular round of bidding. Perhaps the most interesting strategic issue is the frequent use of jump bids to signal a strong demand for particular licenses. Out of the 196 new high bids in the auction, 96 (49\%) were jump bids that exceeded the minimum bid by more than a bid increment. Of these 96 jump bids, 22 (23\%) were jump raises of one's own high bid. The theory of jump bidding is discussed in the next section.

Monday, July 25. The bidding began at $10 \mathrm{AM}$ and ended about 6 PM. The rounds were one hour long with a ten minute withdrawal period. The FCC took about twenty minutes to display results and begin the next round; hence, there was about $1 \frac{1}{2}$ hours between rounds.

Round 1. Much information was revealed in the first round of bidding. Only four firms were eligible to bid on all ten licenses: McCaw, Mtel, PageNet, and Mobile Media. Hence, after the first round of bidding, PageNet learns that 5398, 7884, and 1666 are McCaw, Mtel, and Mobile Media (the three other bidders that were eligible to bid on all ten). Bids by McCaw and PageMart are surprisingly high. PageNet, AirTouch and others adopt a "snake in the grass" strategy: bidding the minimum bid on the cheapest license. Four bidders that were eligible to bid (i.e., that had filed short-form applications and made upfront payments), did not bid in the opening round. Apparently, these firms were unable to secure financing between the time of the upfront payment and the beginning of the auction. The number of active bidders was down from 29 to 25, even before the bidding began.

Round 2. Eight of twenty-five bidders drop out after the first round. The number of active bidders falls to 17. Mtel, who bid the minimum increment on all 10 in the initial round, jumps by $\$ 5$ million to $\$ 15$ million on license 3, and bids just over the minimum increment on all of the 50/12.5s. PageNet continues hiding in the grass.

Round 3. McCaw stakes out licenses 3 and 4 for the first time. McCaw's large jump bid, at least $\$ 10$ million above the prior high bid, signals a strong commitment to two 50/50 kHz licenses. PageNet becomes convinced that 5398 is McCaw based on its aggressive strategy for two 50/50s.

Round 4. Mtel seems more interested in the 50/12.5s.

Round 5. Despite the high prices no additional bidders drop out since the first round. Seventeen bidders remain active.

Round 6. In the last round on Monday, PageNet comes out of the grass with a large jump bid of $\$ 30$ million on all five $50 / 50 \mathrm{kHz}$ licenses. The bids reveal the fourth bidder eligible to bid on all ten licenses. It also signals a strong commitment to three $50 / 50 \mathrm{kHz}$ licenses. 9065 is a bidder to be reckoned with.

Tuesday, July 26. There was no change in the time between rounds. The bidding began at 9 AM and ended about 6 PM.

Round 7. McCaw responds to PageNet's challenge with a $\$ 10$ million dollar jump to $\$ 40$ million on licenses 3 and 4 . The battle for the 50/50s is now in full swing.

Round 8. PageNet comes back with $\$ 42$ million on licenses 1, 2, and 3, signaling a desire for three adjacent $50 / 50 \mathrm{kHz}$ licenses.

Round 9. McCaw refuses to move off licenses 3 and 4 with another $\$ 10$ million jump to $\$ 50$ million. Apparently McCaw is avoiding the designated entity license 5.

Round 10. PageNet accommodates McCaw's desire for licenses 3 and 4 by bidding on license 5 at $\$ 43$ million.:

Round 11. After round 10, the number of active bidders has fallen from 17 to 16 . This is the first drop in the number of active bidders, since round 1. PageNet responds to being bumped off license 5 by moving down to a 50/12.5 kHz license (\#6). PageMart tests PageNet's resolve for two 50/50s.

Rounded 12. PageNet responds to the PageMart challenge with an $\$ 8$ million jump bid on licenses 1 and 2, matching McCaw's bid of $\$ 50$ million. PageNet is not going to be bumped from licenses 1 and 2. ${ }^{24}$ At least one bidder used "cheap talk" to signal to competitors. Mobile Media used

24 The next morning, the New York Times reported that this aggressive bidder (PageNet) was speculated to be BellSouth. "Gamesmanship and psychological warfare have been in full evidence. BellSouth, McCaw and other big bidders planned their strategies from carefully guarded hotel rooms, each one filled with computers. One of the biggest bidderssuspected to be BellSouth—had hung back and placed almost no bids until the final round of bidding had closed on Monday. 
the bidder number of one of its rivals (PageMart, 9683) as the last four digits of its bid of $\$ 45,509,683$. Apparently Mobile Media was telling PageMart to stay out of the $50 / 12.5 \mathrm{~s}$. In prior rounds, PageMart had been bouncing among the 50/50s and 50/12.5s.

Round 13. Both McCaw and PageNet have successfully fought off challenges on licenses 1 to 4 . The battle on the 50/50s appears to be over who will get license 5 .

Round 14. The number of active bidders has fallen from 16 to 15 . McCaw is weakly challenged on license 3 by PageMart.

Wednesday, July 27. The FCC extended the hours of bidding. Bidding began at 9 AM and concluded about 8 PM.

Round 15. Both McCaw and PageNet respond with strength, jumping the price to $\$ 60$ million. PageNet correctly anticipates McCaw's response to the PageMart challenge and matches McCaw's bid. Both McCaw and PageNet signal a willingness to go much higher in jumps of $\$ 10$ million.

Round 16. PageMart responds by matching the $\$ 60$ million price on license 5. It is too little too late. 5017 anticipates PageMart's bid and tops $\$ 60$ million.

Round 17. McCaw immediately jumps to $\$ 70$ million, even though it has not been bumped off of licenses 3 and 4. PageMart tests both McCaw and PageNet with a bid of $\$ 63$ million on 2 and 3.

Round 18. PageNet responds to the challenge by matching McCaw's bid of $\$ 70$ million.

Round 19. PageMart, thinking the fight for the 50/50s might be over, places a weak jump bid of $\$ 69$ million on license 5. This will end activity on the 50/50s for the next 6 rounds. Bidding activity is shifted to the three $50 / 12.5 \mathrm{kHz}$ licenses.

Round 20. The number of active bidders has fallen to 13. Bidders are starting to drop out. Prices on the 50/12.5s and 50s are low relative to the 50/50s. At least eight bidders are competing for the three 50/ $12.5 \mathrm{~s}$. Prices on the 50/12.5s will surely go higher.

Round 21. Mobile Media lays claim to a 50/12.5 with a jump from $\$ 40$ million to $\$ 44$ million.

Round 22. In the last round on Wednesday, PageNet maintains its claim on a 50/12.5 with a jump to $\$ 45$ million on license 6 .

Thursday, July 28. Seeing the deadline approaching, the FCC extended the hours and shortened the time between rounds throughout the day. The bidding began at $9 \mathrm{AM}$ and continued until about 10 PM. The FCC announced, "Beginning in round 24, the rounds will be 45 minutes long and the withdrawal period will be 5 minutes long." In round 26, the FCC announced, "Beginning in round 27, we plan to begin 30 minute rounds and the withdrawal period will be 5 minutes long." The pace increased again in round 36, with the announcement, "From round 36 forward, we plan to begin using 20 minute rounds and the withdrawal period will be 5 minutes long."

Round 23. Bidders avoid 9065 on license 6, raising the bids on 7 and c, above $\$ 45$ million.

Round 24. AirTouch tops PageNet's bid on license 6 with a jump to $\$ 47$ million.

Round 25. PageNet acquiesces on the 50/12.5, shifting its bid to license 10 , a $50 \mathrm{kHz}$ unpaired license. The shift is strong with a jump of $\$ 5$ million from $\$ 15$ million to $\$ 20$ million. PageNet wants three licenses.

Round 26. There are now only 10 active bidders and just 5 new bids in the prior round. Bidding activity has fallen significantly. The fight for the 50/12.5s appears to be over. Indeed, round 25 will turn out to be the last activity on the 50/12.5s.

Round 27. The fight shifts to the two $50 \mathrm{kHz}$ licenses. Five firms are competing for the two licenses.

Round 28. Bidding activity drops to its lowest level with just two new bids. Only eight bidders remain active. The end appears in sight.

Round 29. PageMart challenges both McCaw and PageNet with a bid of $\$ 71$ million on licenses 2 and 3. This is the first challenge to McCaw's and PageNet's lock on the 50/50s in 11 rounds.

Round 30. Both McCaw and PageNet respond with strong jump bids to $\$ 75$ million. The jump is one-half of the prior $\$ 10$ million jumps, reflecting the reduced bid activity.

Then it abruptly bid $\$ 30$ million for each of [five] different licenses, and bumped two of those bids to \$50 million today." (New York Times, July 27, 1994, D1.) This speculation was obviously incorrect, since BellSouth was not eligible to bid on more than three licenses in any round. 
Round 31. Mtel matches the McCaw and PageNet bids, with a jump to $\$ 75$ million on license 5.

Round 32. Mtel, anticipating a challenge from PageMart, raises its own high bid on license 5 to $\$ 77$ million. PageMart, however, decides instead to challenge PageNet with a bid of $\$ 76$ million. The identity of AirTouch is confirmed when their fake bid is revealed by the FCC's "no new bid" announcement.

Round 33. PageNet responds with a jump to $\$ 78$ million on both 1 and 2. There are now four bidders on the 50/50s: PageNet, McCaw, Mtel, and PageMart. One of the four bidders must reduce its demand by one for the bidding to stop on the 50/50s.

Round 34. PageMart moves down to the 50 unpaired licenses, signaling a willingness to get out of the 50/50s. However, its bid on license 11 is topped by a bid by Dubis.

Round 35. With bids over $\$ 25$ million on license 11, PageNet feels vulnerable and so raises its own high bid from $\$ 25$ million to $\$ 28$ million on license 10. This bid blocks PageMart's attempt to get in on the 50s with a bid of $\$ 26$ million.

Round 36. PageMart responds by renewing its challenge to PageNet on the 50/50s with a bid of $\$ 79$ million on license 1.

Round 37. Both PageNet and Mtel immediately respond to this renewed activity on the 50/50s by matching McCaw's bid of $\$ 80$ million. This will prove to be the last bid activity on the 50/50s.

Round 38. There are now four firms competing for the two $50 \mathrm{kHz}$ unpaired licenses: PageNet, PageMart, American Paging, and Dubis. PageMart makes a strong jump to $\$ 31$ million, signaling an intention to come away with one license.

Round 39. PageNet responds to this jump with an even stronger jump to $\$ 35$ million, signaling that PageNet will not be content with only the two 50/50s. Dubis apparently has dropped out. The battle for the two 50s is limited to PageNet, PageMart, and American Paging.

Round 40. American Paging makes a much weaker jump on license 10 to $\$ 32.5$ million. American Paging appears to be the weakest of three firms still bidding. Amid protest from the bidders, the FCC announced that round 40 would be the last of the evening. The bidders saw the end in sight and wanted to finish tonight.

Friday, July 29. The bidding began at 9 AM. The FCC announced, "From round 41 forward, we are using 15 minute rounds and the withdrawal period will be 2 minutes long." This duration was so short that it became impossible for bidders to work from their "war rooms." Bidding teams moved down to the bidding room for the remainder of the auction. So long as the bidding activity remained only on the 50s, there was little strategizing to occur so the short time between rounds did not pose a problem to the bidders. Indeed, it was the bidders that asked for the shorter rounds. The FCC was aware that if bidding reopened on the 50/50s or 50/12.5s, then the rounds would need to be extended.

Round 41. PageMart responds with a jump to $\$ 34.5$ million, inviting a challenge from American Paging.

Round 42. American Paging tops PageMart with a bid of \$35.7 million on license 10.

Round 43. PageMart responds with a raise to $\$ 36.5$ million.

Round 44. American Paging shifts its bid of $\$ 35.7$ million to license 11, challenging PageNet.

Round 45. PageNet responds with a bid of $\$ 37$ million, besting PageMart's bid of $\$ 36.5$ million on license 10. PageNet is hoping this will leave PageMart to deliver the knockout punch to American Paging.

Round 46. PageNet's hopes are fulfilled. PageMart bids $\$ 38$ million on license 11. American Paging is unwilling to top either bid. The bidding ends.

\section{QUESTIONS FOR AUCtion TheORY}

Auction theory was of enormous value in designing the simultaneous multiple-round auction. The FCC docket on "Implementation of Section 309(j) of the Communications Act-Competitive Bidding" is filled with hundreds of pages of comments and testimony from auction theorists. The debate among auction experts influenced every aspect of this first spectrum auction. Theory: was used in a most practical way-to design a new auction form for an environment that was ill-suited to standard auction forms. Although the experiment was successful, there are several areas where the 
theorists were pushing beyond the existing theory in recommending the simultaneous multiple-round auction. Also, from a bidder's perspective, existing auction theory was less helpful than it could be with further development. In what follows, I sketch a few of the issues that are not adequately addressed in existing auction theory.

\subsection{Aggregation of Multiple Licenses}

One of the main strategic questions that the bidders faced was how best to acquire multiple licenses. The intuition is clear from basic economics. The more licenses that the bidder demands, the higher the price the bidder pays on all the licenses of that type. Hence, there is a cost associated with demanding an additional license. The cost is equal to the increase in price times the number demanded less one. The increase in price depends on the industry demand curve, which is uncertain to the bidders.

Deciding when to reduce demand or move down to less desirable licenses is an important and complex question. A good example of this came in round 11, when PageNet decided to move from three 50/50s to two 50/50s and a 50/12.5. By continuing to demand three 50/ 50s, PageNet would probably cause prices to rise on the 50/50s to a point where PageNet would want just two 50/50s. The additional inbound capacity from three 50/50s was not needed in their VoiceNow service, so PageNet assigned a much lower value to the last $37.5 \mathrm{kHz}$ of inbound capacity. Hence, it made sense to move off one of the 50/ 50s. In making this decision, it is essential for the firm to anticipate where prices are likely to go as a function of its demand. The strategic gain is lost if the firm simply reacts to current prices. Keeping a close eye on bidder activity and recognizing the possibility of "signal jamming" behavior are critical to assessing where prices are likely to go. When there is great excess demand, it is safe to predict that prices will go much higher.

It is the aggregation of multiple licenses that makes auction design so complex. The basic results from auction theory simply no longer apply. For example, in a multiple-object auction, it is no longer the case that an ascending-bid auction is efficient. Inefficiencies can occur if the bidder with the highest value for a particular combination of licenses does not bid for the aggregation gains, because it views the prospect of winning the combination unlikely. The high-valuing bidder rationally decides to stop bidding for the combination, since continuing in the bidding exposes the bidder to too much risk that it will be stuck with the "dogs"-licenses that are only valuable in combination with others.

An obvious answer to this aggregation problem is to allow combination bids, but this introduces other potential inefficiencies. With combination bids, a firm bidding for a large combination of licenses may win the combination when others value the individual licenses more. The individual bidders are unable to topple the combination bidder, because of a free-rider problem. Each individual sees that it is hopeless to outbid the combination bidder by its individual action. What is needed is for all the individual bidders to raise the bidding on the individual licenses, but each bidder has an incentive to let the others do the raising. Combination bids not only increase complexity, they introduce potentially serious inefficiencies.

An alternative is to dispense with the ascending-bid design and instead use an efficient dominant strategy mechanism, a la Vickrey (1961). Although designing such a mechanism may be straightforward theoretically, it would pose insurmountable implementation problems for the FCC. Chief among these are issues of commitment and complexity. From a political perspective, it is essential that the bidding process be public. Hence, it would be necessary to reveal all the bids, once the auction is closed. But revelation destroys the dominant strategy feature of a Vickrey auction. Even if the auctioneer does not use the winning firm's bid in determining the price, there is no guarantee that other parties will not use this information about the bidder's reservation price in subsequent transactions (Rothkopf et al. 1990). Moreover, the FCC would be ridiculed unjustly in the press for selling the licenses for less than what the bidders were willing to pay.

An important distinction to consider in auction design is the extent to which the licenses are substitutes (submodular valuations) or complements (supermodular valuations). If the licenses are substitutes, then firms' demand curves do not have large jumps and the ascending-bid auction is likely to lead to an efficient outcome. This appeared to be the case in the nationwide narrowband auction, but it may not be the case in the broadband auctions, where aggregation gains may be large. If the 
licenses are complements, then the demand curves have large jumps and convergence to an efficient outcome with the ascending-bid design may be problematic. More research is needed to determine the magnitude of the problem and the best way of dealing with it. Kelso and Crawford (1982) demonstrate the possible nonexistence of an equilibrium with complements in a closely related matching model. Roth and Sotomayor (1990) discuss the connection between matching models and auctions with multiple objects. Although there has been some theoretical work on auctions with multiple objects (see Demange et al. (1986), Engelbrecht-Wiggans (1988), Hausch (1986), Maskin and Riley (1989), and McCabe et al. (1990)), none of these issues is addressed fully.

\subsection{WAIT TILL LATER}

A second strategic decision facing every bidder is whether to wait for subsequent auctions. As is seen in Table III, only $40 \%$ of the narrowband PCS spectrum was for sale in this first auction. Would a firm be better off waiting until these later auctions to acquire needed spectrum? The answer, of course, depends on what the bidder expects prices to be in these later auctions. Empirical evidence suggests that a risk-neutral firm may be better off waiting. In both wine auctions and timber auctions, researchers have observed what is known as the "declining price anomaly"-prices of identical items sold in later auctions sell at lower prices (Ashenfelter 1989). One explanation is risk aversion (McAfee and Vincent 1993). A risk-averse bidder would prefer the sure gains from winning today, rather than the uncertain prospect of winning tomorrow. Hence, the bidder is willing to bid higher than the expected sale price in the later auction. Faced with the prospect to buy at favorable terms today, it is difficult for the bidder to wait for a similar but risky opportunity tomorrow. Black and de Meza (1993) offer an alternative explanation for declining prices in auctions in which the seller gives the initial buyer the option of buying additional units at the initial price. If bidders demand multiple objects, then this option will have value and prices should decline. Gale and Hausch (1994) show that declining prices also rise when the winner has the right to choose among the objects that have yet to be sold. If the goods are not identical, declining prices are an implication of the right-to-choose option.

There are other reasons, apart from risk aversion and buyer options, that a bidder would be willing to pay more in the first auction. First, there is a tremendous advantage to having the uncertainty about a firm's spectrum capacity resolved early. This capacity is the basis for marketing and development efforts for PCS services. The sooner the uncertainty is resolved, the sooner the goundwork for PCS services can be set in motion, and the sooner the firm can get to market. Being first to market in an industry with substantial network externalities and significant switching costs has enormous value. Second, the items sold in the later auctions are not identical, since the later licenses are not sold on a nationwide basis. A firm with a nationwide strategy would pay a premium to avoid the aggregation difficulties present in the later auctions.

Alternatively, it is possible that prices will be higher in the later auctions. If there are many firms with regional interests, rather than nationwide interests, prices in the regional and later auctions might be higher than in the nationwide auction. Another reason that prices might rise is that bidders may bid less aggressively in the first auction to make others think that the common value is less. However, this is not successful in equilibrium because it is anticipated by rivals (Hausch 1988).

\subsection{Bidding With Budget Constraints}

With perfect capital markets, bidders would simply maximize the value of the various license combinations less the cost of the licenses. Unfortunately, for investments of this size, even with large firms, capital markets are not perfect. Raising capital is both time consuming and costly. Bidders must estimate how much capital they are likely to need, and raise these funds before the auction begins. Although it may be possible to raise some money during the auction, relying on such last-minute efforts is risky. ${ }^{25}$ Hence, it is realistic to assume that all firms in this and subsequent PCS auctions face budget constraints. A bidder's objective becomes to maximize profit subject to budget

\footnotetext{
${ }^{25}$ Mtel was successful in securing additional funds from Bill Gates and Microsoft during the auction; other firms were not successful and were forced to drop out.
} 
constraints. In practice, the budget constraints are more complex than a single bound. They often are best represented by a step function: with a total cost of up to $x_{1}$, the cost of the capital is $y_{1}$, for total cost between $x_{2}$ and $x_{1}$, the cost of capital is $y_{2}$, and so on. It is likely that many bidders dropped out or reduced their demand because of binding budget constraints rather than low values.

In auctions for multiple items, budget constraints raise a new strategic issue. A bidder now cares how much its rivals pay for licenses. The bidder prefers that a rival pay a high price, so that the rival will have less money available for the purchase and development of other licenses. Because of this effect, it is possible to construct equilibria where the government raises more money when the bidders face budget constraints than when capital markets are perfect. This happens when firms engage in "predatory bidding"- bidding above one's value in an effort to raise rivals' costs. On the negative side, predatory bidding introduces another source of inefficiency. Auctions with budget constraints have been studied by Pitchik (1994), Pitchik and Schotter (1988), Che and Gale (1994a,b), and Rothkopf (1977).

\subsection{JUMP BIDDING}

Jump bidding was pervasive throughout the auction. 59\% of all new high bids were jump bids that exceeded the minimum bid by more than one bid increment. $23 \%$ of these jump bids were raises of one's own high bid. This behavior seems to fly in the face of common bidding wisdom and perhaps even common sense. ${ }^{26}$ However, there are good reasons for jump bidding, especially in an auction where the aggregation of licenses plays a role. The basic idea is that the jump bid conveys information about a bidder's valuations. It is a message of strength, conveying that the bidder has a high value for the particular license. Moreover, it conveys this message in a credible way. Jump bidding has a costit exposes the bidder to the possibility of leaving money on the table. It is precisely this cost that makes the communication credible. A bidder with a low value would not find it in its interest to make a large jump. The gain, increasing the chance of winning the license, would not exceed the cost, the risk of overbidding. It is not enough for the bidder to simply announce, "I have a high value. You had better look elsewhere." All bidders, high value and low value alike, have an interest in making such a statement. To make the statement credible, the words must be backed up by an action that a low value bidder would find too costly.

Figure 5 displays the bid increments by round, stated as a percent of the previous high bid. Although the FCC specified a minimum bid increment of 5\% or less throughout the auction, bids far exceeding this $5 \%$ minimum were common. The figure also shows bid activity by round, defined as the number of new bids in the round. Interestingly, the size of the largest jump bids follows bid activity closely. Intuitively, this is consistent with the tradeoffs involved in jump bidding. The benefit from signaling a high value is weighed against the cost of overbidding. When bidding activity is high, the cost of overbidding is negligible unless a substantial jump is made. Hence, assuming that the benefit from signaling a high value remains roughly constant, the size of the jumps should decline with bidder activity.

Equilibrium jump bidding (or preemptive bidding) has been studied in the context of corporate take-overs by Fishman (1988) and in English auctions by Avery (1994). In related work, Bikhchandani (1988) explores the role of reputations in repeated second price auctions. Rothkopf and Harstad (1994) show that jump bidding can arise, irrespective of signaling, when minimum bid increments are used.

\footnotetext{
${ }^{26}$ One memorable moment in PageNet's first mock auction was when one bidder raised her own bid. Shocked by such behavior, another participant blurted out, "Why would anyone raise their own bid?" This became the rallying cry whenever PageNet considered such behavior in the real auction.
} 


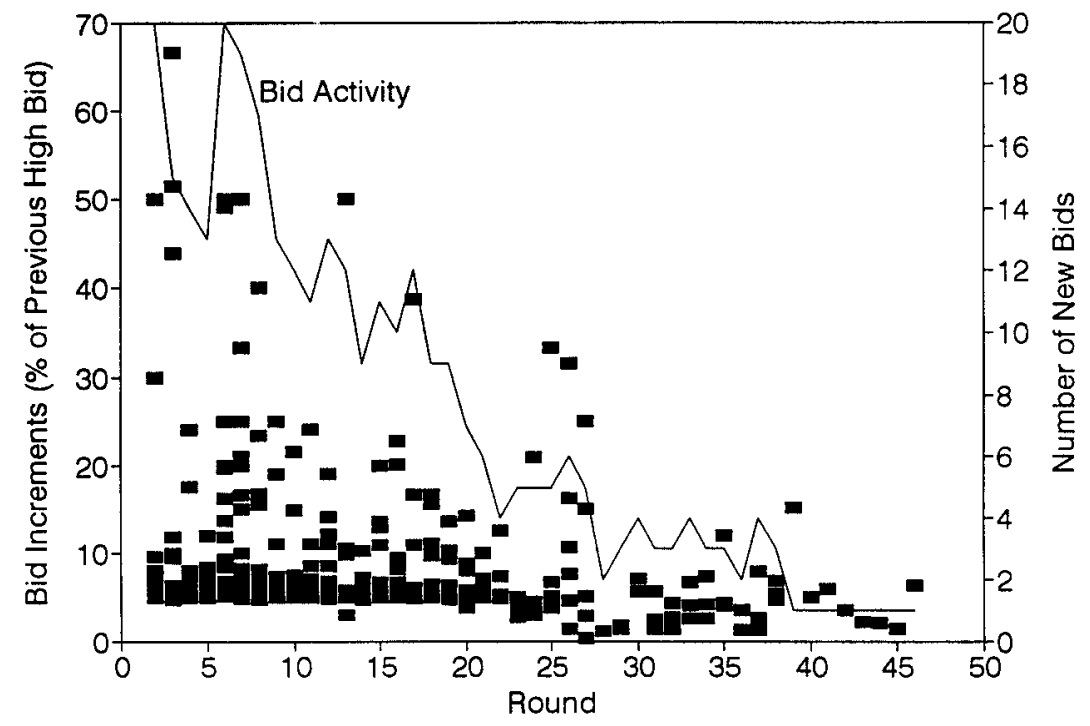

FIGURE 5. BID INCREMENTS AND ACTIVITY (excluding one bid of $138 \%$ in round 3 ).

The minimum increment introduces a discontinuity in the bidding functions, which prompts strategic jump bidding. Jump bidding also arises when there is a cost of bid submission (Daniel and Hirshleifer 1993).

One feature not captured in these models that is important in the PCS auctions is the fact that there are substantial aggregation gains. A desirable collection of licenses is worth more than the sum of the values of the individual licenses. This provides a strong incentive for jump bidding. The value of a license depends on the probability that it and related licenses can be acquired. For example, suppose that there are just two licenses, $\mathrm{A}$ and $\mathrm{B}$. Consider a firm that values the $\mathrm{AB}$ combination at $20 \%$ more than their individual values of $\$ 10$ each. Clearly the firm should be willing to bid up to $\$ 10$ each for A and B, but should it bid higher? It all depends on how confident the bidder is about the prospect of forming the aggregation. If another bidder has just made a jump bid from $\$ 5$ to $\$ 10$ on license A, the firm should be pessimistic about its chances of forming the aggregation and it should focus on $\mathrm{B}$ alone.

In bidding with aggregation gains, the bidders are effectively engaged in a war of attrition. (See Krishna and Morgan (1994) for an analysis of the war of attrition and its relation to auctions.) One way to think of jump biding is that a jump bid effectively "selects" the asymmetric equilibrium favoring the jump bidder in this war of attrition. At first glance, many may view jump bidding as introducing inefficiencies not present in a "Japanese"-style auction. However, jump bidding actually may be a more efficient means of signaling a high value than the screening in the symmetric equilibrium.

\subsection{ASYMmetric BIDders}

Nearly all of auction theory focuses on the case of bidders that are symmetric ex ante. ${ }^{27}$ This allows the researcher to focus on symmetric equilibrium bidding strategies, which greatly simplifies the analysis. This focus on symmetric bidders limits the application of auction theory and can be misleading. In most practical situations, there are significant differences in the bidders ex ante. The nationwide narrowband auction is a good example. Of the 25 bidders, a few bidders were known to have high values because of their large market share, prior product development, or other advantages. PageNet, for example, had by far the largest market share in paging going into the auction. It also had a well developed product, VoiceNow, that required a substantial slice of narrowband spectrum for nationwide distribution. McCaw was known to have deep pockets, as were some of the other large

${ }^{27}$ Exceptions are Myerson (1981), Maskin and Riley (1983), and Marshall et al. 
firms (AirTouch and BellSouth). These differences were known by all. The relevant auction model to analyze was clearly one with asymmetric bidders. However, such models have yet to be developed in any detail.

One area where an asymmetric bidding model would be helpful is in determining the appropriate bidding discount. Intuitively, it is clear that the optimal bidding discount will depend on any ex ante asymmetries, but without more theoretical work it is difficult to say more.

\subsection{JOINT BIDDING AND COLLUSION}

A political issue that has been troubling the FCC throughout the auction design process is how to encourage broad participation in the spectrum auctions. Congress had mandated that the FCC design the auction to encourage participation in PCS auctions by women, minorities, and small businesses. This represents a significant challenge given that the offering of PCS services requires extensive technical knowledge and has large economies of scale. In short, it is difficult for parties outside of the telecommunications industry to participate in an efficient way. Recognizing these problems the FCC has developed a menu of rules that favor women, minorities, and small businesses on a subset of the licenses. Paradoxically, favoring these groups may increase government revenues. By favoring a disadvantaged group of bidders, these bidders become more effective competitors with the large telecommunication incumbents. This leveling of the playing field stimulates competition and raises seller revenues (Myerson 1981).

To encourage small firms to participate, the FCC allows the formation of bidding alliances for joint bidding. By banding together small firms may be able to reap economies of scale that would not be available to them if they bid alone. In future auctions, the FCC allows bidders to form an alliance during the bidding, so long as the firms have applied for disjoint sets of licenses. Debrock and Smith (1983) show that allowing joint bidding in a common value auction does not necessarily lead to lower revenues. Although the number of bidders is reduced, so too is the winner's curse, which allows the bidders to bid more aggressively. Indeed, in the PCS auctions, joint bidding is apt to increase revenues, since it helps the smaller bidders become more effective competitors to the incumbent firms.

Joint bidding could be a problem if it became so extensive that there would be only a few bidders for each license. However, given the large number of firms involved and the enormous gains from deviating from such a collusive posture, it is almost inconceivable that collusion could persist in such a public process. Collusion has been a problem in some auctions in the past ${ }^{28}$ however, it should not be difficult for the FCC to discourage collusion among large public firms.

One of the rules in the initial auction intended in part to limit collusion was keeping bidder identities secret. Based on the nationwide auction experience, the FCC has since decided to reveal bidder identities in subsequent auctions. It was felt that the bidders were able to figure out who was who, despite the confidential bidder numbers, so that little was gained by the attempt at secrecy. This change will enable firms to focus more on bidding strategy and less on public surveillance. It should have no effect on collusion, since under the old rules colluding firms could exchange bidder numbers. Really the only advantage of concealing identifies is that it might reduce predatory bidding. However, predatory bidding is most likely in situations where there are large ex ante asymmetries among the firms, but this is the case where firms are most able to uncover identifies, regardless of the FCC's efforts to conceal them. On balance, the benefits of revealing identities would seem to outweigh the costs.

\subsection{Controlling the Pace of the Auction}

A main concern of bidders in the nationwide auction was whether the auction would come to a natural end, according to the simultaneous stopping rule. Many bidders feared that the FCC would be forced to declare a final round of bidding if the FCC did not take steps to control the pace of the auction. This fear was based on the fact that the FCC originally only budgeted enough time to allow at most 26

\footnotetext{
${ }^{28}$ See Baldwin et al. (1994), Feinstein et al. (1985), Graham and Marshall (1987), Hendricks and Porter (1992), McAfee and McMillan (1992), Moody and Kruvant (1988), and Porter and Zona (1993).
} 
rounds. Bidders believed that the FCC had grossly underestimated the number of rounds needed to reach closure in a simultaneous multiple-round auction. This fear was confirmed by the auction simulations, which suggested that the time to closure was more apt to occur after between 40 and 80 rounds, depending on the auction rules and bidder values.

Bidders and the FCC wished to avoid a declared final round because of the inefficiencies it would introduce. Much of the benefits of the simultaneous multiple-round auction is lost if a final round of bidding is declared. There are two main problems. First, equivalent licenses may go for substantially different prices. If several bidders with high values happen to bid on the same license, that license will sell for a premium, while other equivalent licenses may go for substantially less if only bidders with low values happened to bid on them. Second, a bidder's values will typically depend on the combination of licenses it is able to obtain. In a final round, a bidder is unable to express its valuations for license combinations in an effective way. See Engelbrecht-Wiggans and Weber (1979) and Lang and Rosenthal (1991). For example, the second $50 / 50 \mathrm{kHz}$ license may be worth substantially less than the first to a bidder. Should the bidder bid high on one $50 / 50 \mathrm{kHz}$ license and bid low on a second? Such a strategy is risky - the bidder may lose on both if it happens that another bidder happened to place its high and low bids on the same licenses. The alternative of bidding high on both (in the hopes of winning one) is equally risky. The bidder may win two at high prices, even though only the first $50 / 50 \mathrm{kHz}$ license is highly valued. Exposing the bidders to these strategic risks creates inefficiencies, discourages bidding, and reduces auction revenues. Faced with these potential inefficiencies, it is not surprising that there was an industry consensus against declaring a final round of bidding.

In assessing how long the auction may last, it is important to make conservative assumptions about bidding behavior and bidder values. Only in this way can the FCC be confident that the auction will conclude in the available time. A conservative bidding strategy is for a bidder to look at the current high bids and to bid the minimum bid on the licenses that represent the best value, given the bidder's preferences. Bidding at or near the minimum bid avoids the risk of leaving money on the table. Given the great uncertainty about when bidders are likely to drop out, this is a prudent strategy.

This assumption is insufficient to predict the number of rounds needed to reach closure. There remain two large uncertainties. First, no one knows what the market-clearing price of the licenses will be. The higher these prices, the longer it will take to reach closure. Second, it is difficult to predict how quickly prices will rise, since it is likely that bidding activity will shift to different groups of licenses from round to round. It is likely that a license will increase in price in only a minority of the rounds. Toward the end of the auction it is especially likely that the pace will slow as bidders drop out.

\section{Industry Recommendations}

In order to avoid a declared final round of bidding, the industry recommended that the FCC modify the auction procedures as follows: ${ }^{29}$

- Adopt contingencies for extending the auction. Given the large uncertainties about bidder values, bidder behavior, and auction implementation, the FCC should have viable contingency plans for extending the auction beyond Friday, July 29. Even if it is unlikely an extension will be necessary, it would be unfortunate if a final round was forced in this first auction, because of a lack of viable options.

- Increase the minimum bid increment in the early rounds. Increasing the minimum bid increment in the early rounds can make a substantial difference in the time to reach closure. Moreover, this is the most desirable way to increase the pace of the auction. It increases the pace precisely when it is most valuable and the cost of doing so is smallest.

\footnotetext{
29 These comments were filed with the FCC on 14 June 1994 by the industry's two trade associations, National Association of Business and Educational Radio (NABER) and Personal Communications Industry Association (PCIA). Most of these recommendations were adopted by the FCC before the auction began.
} 
- Extend the hours of the auction. The FCC's proposal allowed for only about 30 rounds. By extending the hours, about 60 rounds could be conducted over the five days.

- Reduce the duration of a round. The FCC proposed one hour between rounds. This could be shortened to 45 minutes or less. This change is self-correcting. If logistical problems prevent the auctioneer from processing all bids within the shorter time frame, the round would simply be extended.

- Close a round after all bids are in. Since the auctioneer knows who the eligible bidders are in any round, the auctioneer can close the round and immediately post the high bids as soon as every eligible bidder has bid.

\section{Adjusting the Bid Increment in Response to Bidding Activity}

A critical element of the simultaneous multiple-round auction is the minimum bid increment. With proper adjustment of the bid increment, the auction will come to a timely closure and yet allow bidders to express small differences in valuations. Without proper adjustment, the auction will not close in a reasonable amount of time or it will share the undesirable properties of a single sealed bid auction. In what follows, I present a method for adjusting the bid increment in the nationwide narrowband PCS auction. The method was designed and tested using the simulation described earlier.

The simultaneous multiple-round auction is most similar to an English auction. In an English auction, the auctioneer plays a key role in adjusting the bid increment throughout the auction. With a simultaneous multiple-round auction, adjustment of the bid increment is even more important for two reasons. First, there is a significant amount of time between rounds (say, an hour) rather than a few seconds as in an English auction. Adopting a pace that is too slow would add days to the auction, rather than minutes. Second, because there are many items for sale in the simultaneous multiple-round auction, many more rounds are needed to reach closure than in an English auction for a single item. As bid activity falls, it becomes more likely that it will take several rounds for the price of a particular type of license to increase by a single bid increment.

The importance of the bid increment stems from the fact that bidders may bid near the minimum bids in any round. As in an English auction, aside from signaling issues, there is little reason to raise a bid by more than the bid increment. Doing so exposes the bidder to the risk of leaving money on the table. A bidder knows that if its bid is not the highest in this round, it will have an opportunity to bid again in subsequent rounds.

Of course, a bidder could bid well above the minimum bids in an effort to hasten the auction. But this individual action is unlikely to be effective. Other bidders will simply shift to the other licenses and continue with the minimum increments. The bidder could place a high bid on all licenses, thereby forcing a rapid pace. But this strategy involves enormous risk (the possibility of substantial withdrawal penalties) for little gain (a more timely closure and a reduced risk of a declared final round). Moreover, there is a free-rider problem. Every bidder has the incentive to let the other bidders take the risk of overbidding. Timely closure is unlikely to be assured by the aggressive behavior of an individual bidder.

\section{Principles of Bid Increment Adjustment}

There are five basic principles for an effective method of adjusting the bid increment:

1. Start large. It is best to have a large bid increment early, when there are many bidders. A large increment quickly brings the price level to a point where bidders start to drop out. In the early rounds, bidding activity is great and there is no cost to a large increment. The large increment simply saves valuable rounds-rounds that are better used at the end of the auction.

2. End small. Toward the end of the auction, the bid increment should be small, allowing the bidders to express small differences in valuations. A small increment increases efficiency and government revenues. It reduces the importance of gaming and strategy.

3. Reduce the increment as bidding activity falls. As bidding activity drops the bid increment should fall. The best way to measure bidding activity is the number of new bids in the prior round across all licenses. This is a better measure than the number of new high bids, since it is possible for 
there to be great activity with all the activity concentrated on a single license. This would happen if a particular license was relatively underpriced. Since the licenses are substitutes, it is important to use the same bid increment (adjusting for the size of the license) across all licenses. Waivers should not be counted as new bids, since a waiver does not indicate a willingness to raise prices. Indeed, waivers may be used by bidders who are unwilling to bid under the current bid increment, but who are hopeful that the increment will fall in subsequent rounds.

4. Avoid large drops in the bid increment. The bid increment should decline gradually with bidding activity. Large drops (say, dropping from $10 \%$ to $5 \%$ when activity falls below a particular level) introduce more complex strategies. For example, bidders may use waivers strategically, anticipating a large drop in the increment. Faced with a large drop in the increment, bidders are more apt to regret a prior bid.

5. Adopt and announce a plan for bid increment adjustment. The FCC should adopt and announce a plan for adjusting the bid increment before the auction begins. By adopting a sensible plan up front, the FCC can focus on other things during the auction. Some modifications may be needed as the auction proceeds, but these changes would be minor relative to the changes needed under the current plan. With the current plan, the FCC's behavior is more apt to be viewed as arbitrary. The prior announcement of the plan allows the bidders to develop bidding strategies in light of specific rules. Bidding is more apt to be orderly and rational. As a result, efficiency improves.

\section{A Simple Method for Bid Increment Adjustment}

The following method for adjusting the bid increment is consistent with the principles above. The increment in any round depends on the number of new bids in the prior round. If there are more than 25 new bids in the prior round, the bid increment is the greater of $\$ .10$ per MHz-pop or $25 \%$ of the prior high bid. If there are fewer than 5 new bids in the prior round, the bid increment is the greater of $\$ .02$ per MHz-pop or 5\% of the prior high bid. As the number of new bids falls from 25 to 5 , the bid increment falls linearly from $25 \%$ to $5 \%$ (\$.10 to \$.02 per MHz-pop), dropping 1\% (\$.004 per MHz-pop) with each fewer bid made.

This bid increment approach accomplishes the five goals above, The bid increment is large initially and declines gradually as bid activity lessens. It is simple and responsive. If bidding activity is slight in the initial round, the increment immediately drops to an appropriate level in the next round. For example, if no firms are willing to bid the minimum bids in the initial round (every firm submitted a waiver), then the bid increment and the minimum bid drop to $\$ .02$ per MHz-pop. 


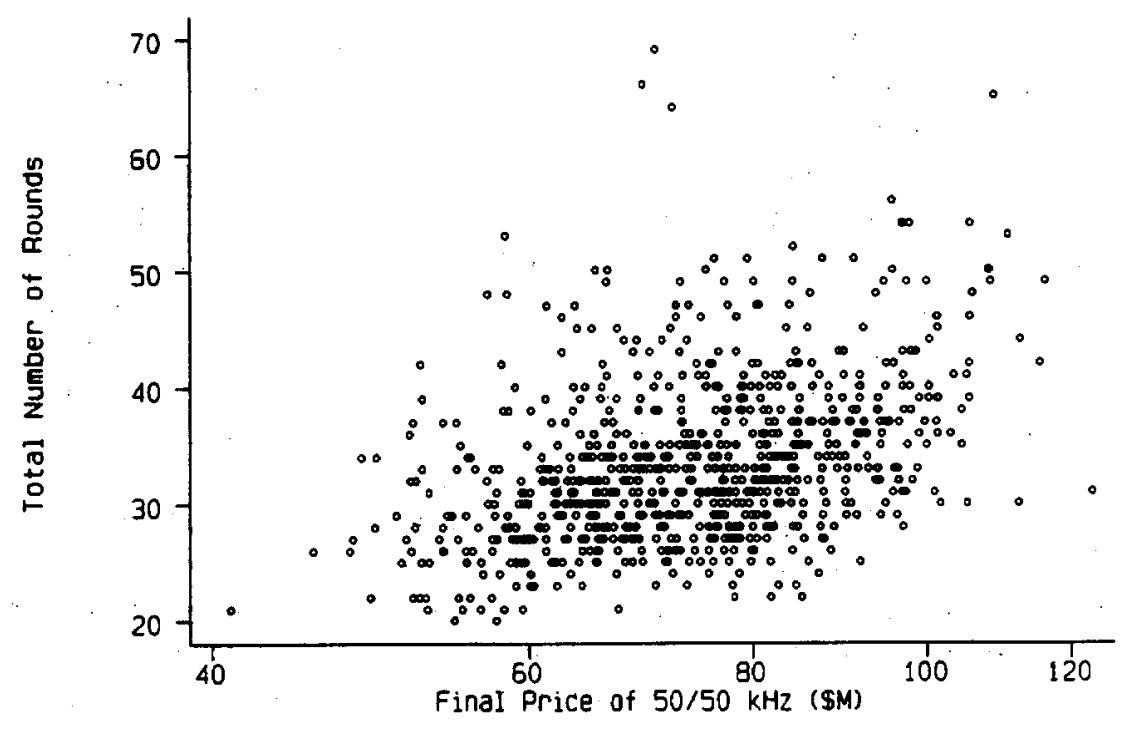

FIGURE 6. NUMBER OF ROUNDS; INCREMENT FROM 25\% TO 5\%: Based on 777 auction simulations; bid increment falls from $25 \%$ to $5 \%$ as new bids fall from 25 to 5 .

To evaluate this method, I conducted 777 auction simulations. The simulation parameters are given in Table VI. Figure 6 shows the number of rounds to close as a function of the final sale price of a $50 / 50 \mathrm{kHz}$ license. Several conclusions can be drawn from the simulations:

- The number of rounds is not too sensitive to the final prices. About eight additional rounds are needed with each doubling of prices.

- The total number of rounds is likely to be under 60 rounds even if the final prices are high. In only 4 cases out of $777(0.5 \%)$ were more than 60 rounds needed.

A further advantage of this method is that the FCC can make minor adjustments to the plan in response to unforeseen difficulties. Although adjustments are unlikely to be necessary, the FCC may find that after 40 rounds bidding activity is still high. In this case, the FCC can announce that the bid increment will not fall below $8 \%$; that is, it will reach its minimum when the number of new bids in the prior round has fallen to 8 , rather than 5. Likewise, the FCC might find that bidding activity is slight after only 15 rounds. In this case, the FCC can announce that the bid increment will continue to fall to $3 \%$ when there are three new bids in the prior round. In this way, bidders will be able to express smaller differences in value, if there is sufficient time.

This method depends on just two parameters: an activity level upper bound (25), that defines the maximum bid increment, and an activity level lower bound (5), that defines the minimum bid increment. For all activity levels between these upper and lower bounds, the percentage bid increment is $n$ and the absolute increment is $\$ .004 \cdot n$, where $n$ is the number of new bids in the prior round. I have chosen the upper and lower bounds so that it is extremely likely that closure is reached within 60 rounds.

This method can be extended to auctions for regional, MTA, or BTA licenses. In doing so, there are two issues that need attention. First, different licenses may have substantially different values in terms of MHz-pops because of different population densities, or some other factor. Hence, it does not make sense to start the bidding on all licenses at the same level per MHz-pop. The solution is not to have a minimum bid until after the license has been bid on. Second, the best measure of bidding activity needs to be determined. One reasonable measure would be counting the number of bids in terms of MHz-pops relative to the total MHz-pops being auctioned. Such a method would work regardless of the size of the licenses, either geographically or in bandwidth. The parameters for setting 
the bid increment and for determining the transition between auction stages should be set using a detailed simulation of the particular auction.

There was a consensus among auction experts that tying the bid increment to bid activity was a good idea. Moreover, the consensus view was that this particular procedure would result in a pace that was about right. The FCC concurred, but decided not to announce a particular bid increment procedure, since actual bidding behavior was still uncertain and the FCC wanted to maintain maximum flexibility to respond to the unforeseen. It was at this point, two weeks before the auction, that the FCC decided to use a panel of auction experts to control the pace of the auction.

\section{Activity Rules}

A second instrument for controlling the pace of the auction is the activity rule. A properly designed activity rule will encourage sincere bidding without limiting a bidder's strategic options in an important way. In the nationwide narrowband auction, the activity rule is simple. In stage 1, a bidder must be active on at least one license in every round; in stage 2, a bidder's eligibility is reduced to the number of licenses the bidder is active on in the prior round. A bidder is active on a license if it places a valid bid on the license or it was the high bidder in the prior round. Hence, in stage 2, a bidder desiring three licenses at the current prices must be active on three licenses. As it turned out, the FCC was so pleased with the way that things were going throughout the nationwide narrowband auction that it never moved to stage 2. Said one FCC staffer, "Why mess with the rules when things are going so well?" By Wednesday, the FCC became convinced that no one was "hiding in the grass" and that stage 2 was unnecessary.

Had the FCC declared a stage 2 some time on Wednesday or later, it would have had little effect on the outcome. Declaring stage 2 would have prevented the insincere bid of $\$ 71$ million each on licenses 2 and 3 by PageMart in round 29. However, PageMart would have been able to accomplish the same thing by bidding $\$ 71$ million in two consecutive rounds. Declaring stage 2 would also have prevented Mtel's insincere bids on only a single 50/12.5 license in rounds 20 and $21 .^{30}$

In the broadband auctions and the subsequent narrowband auctions, the activity rules will play a much more important role. There are two reasons for this prediction: (1) there will be a much larger and more diverse set of licenses, and (2) aggregation issues will be much more complex and important. In these auctions, the FCC has decided to use the Milgrom-Wilson activity rule. There are three stages, which require increasing levels of activity to maintain eligibility. In stage 1, a bidder's maximum eligibility is three times its activity in the prior round. In stage 2, maximum eligibility is 1.5 times its activity in the prior round. In stage 3, maximum eligibility is 1 times its activity in the prior round. Activity is measured as the number of MHz-pops on which the bidder placed a new bid or was the high bidder from the prior round.

This activity rule does a good job of encouraging sincere bidding, especially in stage 2 and stage 3. However, I am concerned that stage 3 is too harsh. It limits flexibility too much. This is especially a problem with large licenses (regional or MTA auctions). For example, suppose a firm's first choice is the Miami MTA (population 5.4 million) and its second choice is Tampa (population 5.7 million). In stage 3, the firm is prevented from switching from Miami to Tampa, should Tampa become a better value. Once stage 3 is declared, the bidder for Miami is forced to bid on Tampa to keep both options open. Such strategic bidding can lead to inefficiencies.

The FCC recognized this problem in the regional narrowband auction and modified stage 3. In stage 3, a bidder must be active on $90 \%$ of its eligibility; otherwise, eligibility is reduced to $1 / .9$ of its prior activity. This $90 \%$ rule probably strikes a better balance between encouraging sincere bidding and maintaining bidder flexibility. A further enhancement would reduce the large discontinuities created by a three-stage activity rule. Instead, the activity requirement could move continuously with a measure of bid activity (measured either as the number of megahertz-pops of activity or the percentage increase in total spending). Much work remains to be done in analyzing the ramifications of various activity rules. However, one thing seems clear. Activity rules should be used in conjunction with bid increment rules that tie the bid increment to bidding activity. In some sense, the activity rule

${ }^{30}$ In these rounds, Mtel might have been waiting for a commitment from William Gates and Microsoft for more funds. 
is a more draconian instrument than the bid increment rule, and therefore it can lead to greater distortions. In the example above, the activity rule prevents the firm from ever bidding again on Tampa (unless the bidder bids strategically), whereas the bid increment rule is self-correcting. If the bid increments are so high as to choke off the bidding, then in the next round the increments are reduced. However, activity rules are needed to assure a timely closure of the auction-relying on bid increments alone is insufficient.

\section{Conclusion}

The FCC's first spectrum auction was a welcome event for economists. After decades of lobbying for auctions, economists finally got their way and witnessed the wisdom of their recommendations. Nearly every constituent benefits from auctioning the airwaves. Taxpayers, consumers, and firms are all better off with auctions The only, losers are inefficient firms, which are unsuccessful in the auctions, but have a chance in lotteries or comparative hearings.

The success of this first "experiment" with simultaneous multiple-round auctions means that the FCC can move with confidence into the regional narrowband auction (October 1994) and the MTA broadband auction (December 1994). These two auctions will use essentially the same auction rules as in the nationwide auction. The only significant changes are: (1) allowing firms to form alliances during the auction as long as the firms are bidding for disjoint sets of licenses, and (2) revealing bidder identities.

The success of the spectrum auctions should encourage the government to use auctions of this form in other applications, such as airport landing rights (Rassenti et al. 1982), pollution rights (Cason and Plott 1994), mineral rights, and hazardous waste (Kunreuther and Kleindorfer 1986). It is easy to think of other applications, such as the allocation of university resources (Boyes and Happel 1989).

The good news is that auctions for spectrum are here to stay. The auction outcome is compelling to taxpayers. So long as budget deficits remain a problem, it is hard to imagine that Congress would be able to reverse the auction decision without setting off a grassroots rebellion among taxpayers. Indeed, the auction outcome is so compelling that the FCC had to reverse its decision on the Pioneer's Preference awards. On December 24, 1993, following through on a policy adopted before the FCC was granted auction authority, the FCC gave away four premium licenses, worth well over one billion dollars, to firms as a "reward" for the firms' development of "pioneering technology." These awards, intended to inspire research and development in communications, were really nothing more than a holdover from the days of comparative hearings. On August 9, 1994, under pressure from Congress, the FCC announced that the Pioneer winners would be required to pay $90 \%$ of the winning bids of similar licenses. ${ }^{31}$

The sentiment of the auction winners was summed up by Terry L. Scott, President of Paging Network, Inc., "Through these newly acquired narrowband PCS frequencies, wireless messaging companies will offer advanced communications services to businesses and consumers that may fundamentally change when, where, and how people communicate. For a company such as PageNet, the largest wireless messaging company in the country, frequency is our lifeblood and the frequency we acquired provides us the raw material we need for significant future growth." FCC Chairman Reed Hundt also was delighted with the outcome, "We're happy the [federal budget] deficit issue is being

\footnotetext{
${ }^{31}$ The pressure came in the form of legislation introduced by John Dingell that would withhold the FCC's appropriations unless it made the Pioneer winners pay $90 \%$ of the auction price. The four Pioneer winners are: Mtel (which won a nationwide $50 \mathrm{kHz}$ unpaired), American Personal Communications (which won a Washington $30 \mathrm{MHz}$ MTA), Omnipoint Corp. (which won a $30 \mathrm{MHz}$ New York MTA), and Cox Enterprises (which won a $30 \mathrm{MHz}$ Los Angeles MTA). The FCC's reversal on August 9 was challenged in court by the Pioneer winners. Since then, Congress introduced legislation tied to GATT (General Agreement on Trade and Tariffs) requiring that the broadband Pioneer winners pay 85\% of the average auction price per pop in the top twenty markets, excluding New York, Los Angeles, and Washington. (Washington Post, October 5, 1994, p. A1.) This strange pricing rule, which excludes the most relevant markets, was negotiated for political reasons. Since New York, Los Angeles, and Washington will sell for a premium on a per pop basis, this rule enables the Pioneer winners to pay less than $85 \%$ of the other license in the relevant market, but have the appearance of getting only a $15 \%$ discount.
} 
addressed so successfully." (Washington Post, July 30, 1994, p. A1.) "All budget targets for this fiscal year have been substantially exceeded." (Wall Street Journal, August 1, 1994.)

Gone are the days of comparative hearings and lotteries. From consumers and firms can be heard a collective cheer: Good riddance!

\section{REFERENCES}

Ashenfelter, Orley, 1989, "How Auctions Work for Wine and Art," Journal of Economic Perspectives, 3, 23-26.

Avery, Christopher, 1994, "Strategic Jump Bidding in an English Auction," Working Paper, Kennedy School of Government, Harvard University.

Baldwin, Laura H., Robert C. Marshall, and Jean-Francois Richard, 1994, "Bidder Collusion at Forest Service Timber Sales," Working Paper, Duke University.

Bazerman, Max H. and William F. Samuelson, 1983, "I Won the Auction But Don't Want the Prize," Journal of Conflict Resolution, 27, 618-634.

Bikhchandani, Sushil, 1988, "Reputation in Repeated Second-Price Auctions," Journal of Economic Theory, 45, 97-119.

Black, Jane M. and David de Meza, 1993, "Systematic Price Differences Between Sucessive Auctions are No Anomaly," Journal of Economics and Management Strategy, 1, 607-628.

Boyes, William J. and Stephen K. Happel, 1989, "Auctions as an Allocation Mechanism in Academia: The Case of Faculty Offices," Journal of Economic Perspectives, 3, 37-40.

Capen, E. C., R. V. Clapp, and W. M. Campbell, 1971, "Competitive Bidding in High-Risk Situations," Journal of Petroleum Technology, 23, 641-653.

Cason, Timothy N. and Charles R. Plott, 1994, "EPA's New Emissions Trading Mechanism: A Laboratory Evaluation," Working Paper, CalTech.

Chakravorti, Bhaskar, Robert E. Dansby, William W. Sharkey, Yossef Spiegel, and Simon Wilkie, 1995, "Auctioning the Airwaves: The Contest for Broadband PCS Spectrum," Journal of Economics \& \& \& Management Strategy, 4, $345-373$.

Che, Yeon-Koo and Ian Gale, 1994a, "Auctions with Financially-Constrained Bidders," Working Paper, University of Wisconsin.

Che, Yeon-Koo and Ian Gale, 1994b, "Sales to Budget-Constrained Buyers: The Gains from Using Multiple-Player Mechanisms," Working Paper, University of Wisconsin.

Coase, Ronald H., 1959, “The Federal Communications Commission,” Journal of Law and Economics, 2, 1-40.

Cramton, Peter, Robert Gibbons, and Paul Klemperer, 1987, "Dissolving a Partnership Efficiently," Econometrica, 55, 615-632.

Daniel, Kent and David Hirshleifer, 1993, “A Theory of Costly Sequential Bidding,” Working Paper, University of Chicago.

Debrock, Larry M. and James L. Smith, 1983, "Joint Bidding, Information Pooling, and the Performance of Petroleum Lease Auctions," Bell Journal of Economics, 14, 395-404.

Demange, Gabrielle, David Gale, and Marilda Sotomayor, 1986, "Multi-item Auctions," Journal of Political Economy, 94, 863-872.

Dyer, Douglas, John H. Kagel, and Dan Levin, 1989, “A Comparison of Naive and Experienced Bidders in Common Value Offer Auctions: A Laboratory Analysis,” Economic Journal, 99, 108-115.

Engelbrecht-Wiggans, Richard, 1988, "Revenue Equivalence in Multi-object Auctions,” Economic Letters, 26, 15-19.

Engelbrecht-Wiggans, Richard and Robert J. Weber, 1979, “An Example of a Multi-Object Auction Game," Management Science, 25, 1272-1277.

Federal Communications Commission, 1994, Third Report and Order, FCC 94-98.

Feinstein, Jonathan S., Michael K. Block, and Frederick D. Nold, 1985, “Asymmetric Information and Collusive Behavior in Auction Markets," American Economic Review, 75, 441-460.

Fishman, Michael J., 1988, “A Theory of Preemptive Takeover Bidding,” Rand Journal of Economics, 19, 88-101.

Gale, Ian L. and Donald B. Hausch, 1994, "Bottom-Fishing and Declining Prices in Sequential Auctions," Games and Economic Behavior, 6, forthcoming.

Giliberto, S. Michael and Nikhil P. Varaiya, 1989, "The Winner's Curse and Bidder Competition in Acquisitions: Evidence from Failed Bank Auctions," Journal of Finance, 44, 59-65.

Graham, Daniel A. and Robert C. Marshall, 1987, "Collusive Bidder Behavior at Single-Object Second-Price and English Auctions," Journal of Political Economy, 95, 1217-1239.

Hausch, Donald, 1986, "Multiobject Auctions: Sequential vs. Simultaneous Sales," Management Science, 32, $1599-1610$.

Hausch, Donald, 1988, “A Model of Sequential Auctions," Economic Letters, 26, 227-233.

Hendricks, Kenneth and Robert H. Porter, 1992, "Joint Bidding in Federal OCS Auctions," American Economic Review: Papers and Proceedings, 82, 506-511.

Hendricks, Kenneth, Robert H. Porter, and Bryan Boudreau, 1987, "Information, Returns, and Bidding Behavior in OCS Auctions: 1954-1969," Journal of Industrial Economics, 35, 517-542.

Kagel, John H., Ronald M. Harstad, and Dan Levin, 1987, "Information Impact and Allocation Rules in Auctions with Affiliated Private Values: A Laboratory Study,” Econometrica, 55, 1275-1304.

Kagel, John H. and Dan Levin, 1986, "The Winner's Curse and Public Information in Common Value Auctions," American Economic Review, 76, 894-920. 
Kagel, John H., Dan Levin, Raymond C. Battalio, and Donald J. Meyer, 1989, "First-Price Common Value Auctions: Bidder Behavior and the Winner's Curse," Economic Inquiry, 27, 241-258.

Kelso, Alexander S. and Vincent P. Crawford, 1982, "Job Matching, Coalition Formation, and Gross Substitutes," Econometrica, 50, 1483-1504.

Krishna, Vijay and John Morgan, 1994, “An Analysis of the War of Attrition and the All-Pay Auction,” Working Paper, Penn State University.

Kunreuther, Howard and Paul R. Kleindorfer, 1986, “A Sealed-Bid Auction Mechanism for Siting Noxious Facilities," American Economic Review, 76, 295-299.

Kwerel, Evan R. and Alex Felker, 1985, "Using Auctions to Select FCC Licenses," Working Paper, Office of Plans and Policy, FCC.

Kwerel, Evan R. and John R. Williams, 1993, "Moving Toward a Market for Spectrum," CATO Review of Business and Government Regulation, 1993:2, 53-62.

Lang, Kevin and Robert W. Rosenthal, 1991, "The Contractors' Game," Rand Journal of Economics, 22, 329-338.

Levin, Dan, John H. Kagel, and Jean-Francois Richard, 1994, "Revenue Effects and Information Processing in English Common Value Auctions," Working Paper.

Marshall, Robert C., Michael J. Meurer, Jean-Francois Richard, and Walter Stromquist, 1994, "Numerical Analysis of Asymmetric First Price Auctions," Games and Economic Behavior, 7, 193-220.

Maskin, Eric S. and John G. Riley, 1983, “Auctions with Asymmetric Beliefs,” Working Paper, UCLA.

Maskin, Eric S. and John G. Riley, 1989, "Optimal Multi-unit Auctions,” in Frank Hahn (ed.) The Economics of Missing Markets, Information, and Games, Oxford: Oxford University Press, 312-35.

McAfee, R. Preston and John McMillan, 1987, “Auctions and Bidding,” Journal of Economic Literature, 25, 699-738.

McAfee, R. Preston and John McMillan, 1992, "Bidding Rings," American Economic Review, 82, 579-599.

McAfee, R. Preston and Daniel Vincent, 1993, “The Declining Price Anomaly,” Journal of Economic Theory, 60, $191-212$.

McCabe, Kevin A., Stephen J. Rassenti, and Vernon L. Smith, 1990, “Auction Institutional Design: Theory and Behavior of Simultaneous Multiple-Unit Generalizations of the Dutch and English Auctions," American Economic Review, 80, 1276-1283.

McMillan, John, 1994a, “Selling Spectrum Rights,” Journal of Economic Perspectives, 8, 145-162.

McMillan, John, 1994b, "Why Auction the Spectrum?” Working Paper, University of California, San Diego.

Milgrom, Paul R., 1987, "Auction Theory," in Truman Bewley (ed.), Advances in Economic Theory-Fifth World Congress, Cambridge, England: Cambridge University Press.

Milgrom, Paul R., 1989, “Auctions and Bidding: A Primer," Journal of Economic Perspectives, 3, 3-22.

Milgrom, Paul R. and Robert J. Weber, 1982, "A Theory of Auctions and Competitive Bidding," Econometrica, 50, 1089-1122.

Moody, Carlisle E., William J. Kruvant, 1988, "Joint Bidding, Entry, and the Price of OCS Leases," Rand Journal of Economics, 19, 276-284.

Myerson, Roger B., 1981, “Optimal Auction Design,” Mathematics of Operations Research, 6, 58-73.

Ortega-Reichert, Armando, 1968, Models for Competitive Bidding under Uncertainty, Ph.D. dissertation, Stanford University.

Pitchik, Carolyn, 1994, "Budget-Constrained Sequential Auctions with Incomplete Information,” Working Paper, University of Toronto.

Pitchik, Carolyn and Andrew Schotter, 1988, "Perfect Equilibria in Budget-Constrained Sequential Auctions: An Experimental Study," Rand Journal of Economics, 19, 363-388.

Porter, Robert H. and J. Douglas Zona, 1993, "Detection of Bid Rigging in Procurement Auctions," Journal of Political Economy, 101, 518-538.

Rassenti, Stephen J., Vernon L. Smith and R. L. Bulfin, 1982, “A Combinatorial Auction Mechanism for Airport Time Slot Allocation," Bell Journal of Economics, 13, 402-417.

Roth, Alvin E. and Marilda Sotomayor, 1990, Two-Sided Matching: A Study in Game-Theoretic Modeling and Analysis, Cambridge, England: Cambridge University Press.

Rothkopf, Michael H., 1969, “A Model of Rational Competitive Bidding,” Management Science, 15, 362-373.

Rothkopf, Michael H., 1977, "Bidding in Simultaneous Auctions with a Constraint on Exposure," Operations Research, 25, 620-629.

Rothkopf, Michael H. and Ronald M. Harstad, 1994, "Modeling Competitive Bidding: A Critical Essay," Management Science, 40, 364-384.

Rothkopf, Michael H. and Ronald M. Harstad, 1994, "On the Role of Discrete Bid Levels in Oral Auctions," European Journal of Operational Research, 74, 572-581.

Rothkopf, Michael H., Thomas J. Teisberg, and Edward P. Kahn, 1990, “Why Are Vickrey Auctions Rare?” Journal of Political Economy, 98, 94-109.

Thaler, Richard H., 1988, “Anomalies: The Winner's Curse,” Journal of Economic Perspectives, 2, 191-202.

Thiel, Stuart E., 1988, "Some Evidence on the Winner's Curse," American Economic Review, 78, 884-895.

Vickrey, William, 1961, “Counterspeculation, Auctions, and Competitive Sealed Tenders," Journal of Finance, $16,8-37$.

Wilson, Robert, 1969, “Competitive Bidding with Disparate Information,” Management Science, 15, 446-448.

Wilson, Robert, 1981, "The Basic Model of Competitive Bidding," Office of Policy Analysis, U.S. Department of the Interior.

Wilson, Robert, 1992a, “Market Trading,” Teaching Note, Stanford Graduate School of Business. 
Wilson, Robert, 1992b, "Strategic Analysis of Auctions," in R.J. Aumann and S. Hart, (eds.), Handbook of Game Theory with Economic Applications, Vol. 1, Amsterdam: North Holland, 227-280. 